\title{
Fruit and vegetable consumption : measurement, determinants and intervention effects
}

Citation for published version (APA):

Bogers, R. P. (2005). Fruit and vegetable consumption : measurement, determinants and intervention effects. [Doctoral Thesis, Maastricht University]. Universitaire Pers Maastricht. https://doi.org/10.26481/dis.20050225rb

Document status and date:

Published: 01/01/2005

DOI:

10.26481/dis.20050225rb

Document Version:

Publisher's PDF, also known as Version of record

\section{Please check the document version of this publication:}

- A submitted manuscript is the version of the article upon submission and before peer-review. There can be important differences between the submitted version and the official published version of record.

People interested in the research are advised to contact the author for the final version of the publication, or visit the DOI to the publisher's website.

- The final author version and the galley proof are versions of the publication after peer review.

- The final published version features the final layout of the paper including the volume, issue and page numbers.

Link to publication

\footnotetext{
General rights rights.

- You may freely distribute the URL identifying the publication in the public portal. please follow below link for the End User Agreement:

www.umlib.nl/taverne-license

Take down policy

If you believe that this document breaches copyright please contact us at:

repository@maastrichtuniversity.nl

providing details and we will investigate your claim.
}

Copyright and moral rights for the publications made accessible in the public portal are retained by the authors and/or other copyright owners and it is a condition of accessing publications that users recognise and abide by the legal requirements associated with these

- Users may download and print one copy of any publication from the public portal for the purpose of private study or research.

- You may not further distribute the material or use it for any profit-making activity or commercial gain

If the publication is distributed under the terms of Article $25 \mathrm{fa}$ of the Dutch Copyright Act, indicated by the "Taverne" license above, 


\section{ISBN}

Cover

Printing
$90-6464-816-6$

Bernard Bos

Grafisch bedrijf Ponsen en Looijen BV, Wageningen

\section{(92005, RP Bogers}

All rights roserved. No part of this thesis may be reproduced or transmitted in any form or by any means, electronic or mechanical, including photocopying, reconding or any information storage or retrieval system, without permission in writing from the author, or, when appropriate, from the publistier of the publications. 


\section{Fruit and vegetable consumption}

measurement, determinants and intervention effects

\section{Proefschrift}

ter verkrijging van de graad van doctor

aan de Universiteit Maastricht.

op gezag van de Rector Magnificus,

Prof mir GPMF Mols,

volgens het besluit van het College van Decanen,

in het openbaar te verdedigen op

vrijdag 25 februari 2005 om 12.00 uur

door

Roderik Pieter Bogers 


\section{Promotores}

Prof dr ir PA van den Brandt

Prof dr KR Westerterp

\section{Copromotores}

Dr P van Assema

Dr ir PC Dagnelie

\section{Beoordelingsicommissie}

Prof dr NK de Vries (voorzitter)

Prof dr RA Knibbe

Prof dr ir RP Mensink

Dr ir MC Ocké (RIVM)

Prof dr WA van Staveren (Wageningen Universiteit)
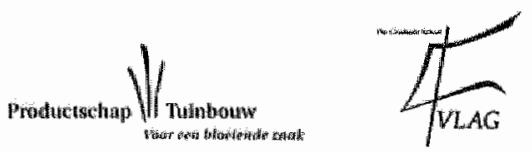

\section{nitutim}

This project was performed at the departments of Epidemiology. Health Education \& Promotion and Human Biology (Maastricht University), Nutrition and Toxicology Research Institute Maastricht (NUTRlM), which participates in the Graduate School VLAG-2 (Food Technology, Agrobiatechnology, Nutrition and Haalth Sciences) accredited by the Royal Netherlands Academy of Arts and Sciences.

The research described in this thesis was financially supported by the Dutch Product Board for Horticulture. 


\section{Contents}

1. Introduction

2. Using a correction factor to correct for overreporting in a food-frequency questionnaire does not improve biomarker-assessed validity of estimates for fruit and vegetable consumption

3. Repraducibility, validity and responsiveness to change of a short questionnaire for measuring intake of fruits and vegetables

4. Explaining fruit and vegetable consumption: the Theory of Planned Behaviour and misconception of personal intake levels

5. Psychosocial predictors of increases in fruit and vegetable consumption

6. Family-related influences on fruit and vegetable consumption in seven to ten-year-old chilldren

7. Effect of four weeks of increased fruăt and vegetable consumption on plasma folate and homocysteine concentrations

8. General discussion

Summary

Samenvatting

Dankwoard en Curriculum Vitae 



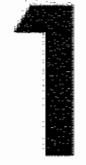

Introduction 
Fruit and vegetables are rich sources of a variety of nutrients, including vitamins, trace minerals, and dietary fibre, and many other classes of biologically active compounds that could slow or prevent the onset of chronic diseases (1). A relatively high consumption of fruits and vegetables is associated with a decreased risk of chronic diseases, including cardiovascular disease (2) and cancer (3). It is estimated that in the Netherlands a mean increase in the consumption of fruit and wegetable from $250 \mathrm{~g} / \mathrm{day} 10400 \mathrm{~g} / \mathrm{day}$ could reduce cardiovascular deaths by $16 \%$ ( 8000 deaths annually), ranging from a conservative estimate of $6 \%$ to an optimistic $22 \%$ (4). Cancer incidence could be reduced by $19 \%(12,000$ cases annually) ranging from $6 \%$ to $28 \%(4)$, although recent insights suggest a smaller preventive effect of fruit and vegetables for cancer than was previously thought $(5,6)$. Consumption of fruit and vegetables may also play an important role in weight management $(7)$. These potential beneficial effects have led to recommendations on the amounts of fruit and vegetables that individuals should consume in order to decrease their risk of chronic diseases. In the Netherlands it is recommended to eat $200 \mathrm{~g}$ of vegetables and two pieces of fruit per day $(8,9)$. A similar recommendation to consume at least $400 \mathrm{~g} /$ day of firuits and vegetables has also been specified by the WHO/FAO (10). However, in spite of these recommendations, mean fruit and vegetable consumption in many countries is still too low $(11-13)$, and in the Netherlands the consumption even has decreased from 1987 to 1998. According to the Dutch Food Consumption Surveys $s$ consumption of fruit/vegetables was $125 / 141 \mathrm{~g} /$ day in $1987-1988,114 / 128 \mathrm{~g} /$ day in 1992 , and $105 / 123 \mathrm{~g} /$ day in $1997-1998(14)$. Thus, the challenge is to develop interventions that are effective in increasing the consumption of fruits and vegetables. To maximise the chance of success of these interventions, a systematic approach based on knowledge about determinants of the (low) consumption of fruit and vegetables is essential (15).

In studies on determinants of fruit and vegetable consumption and effects of interventions, and in etiological studies that look into health effects of fruit and vegetables, dietary assessment instruments that provide valid estimates of fruit and vegetable consumption are a prerequisite. Invalid assessment of fruit and vegetable consumption could lead to biased associations between fruit and vegetable consumption and determinants and health-related outcomes, and to wrong estimates of the effectiveness of interventions that aim to increase fruit and vegetable intake.

This thesis deals with three topics with respect to fruit and vegetables: measurement and determinants of consumption, and effects on plasma concentrations of carotenoids, vitamin $\mathrm{C}_{\mathrm{s}}$ folate, and homocysteine.

\section{Measurement of fruit and vegetable consumption}

\section{Avallable methods}

Food intake can be measured by using various methods, which can be divided into accounting, recording, and interview methods (16). The first are indirect techniques that express availability of foods at nationall or household level. An example is a household budget survey performed in ten European countries (13). However, such methods measure food availability on a group aggregation level instead of individual food intake. To assess individual food intake, recording techniques ((precise) weighed records, estimated records, observed weighed (estimated) records, or menu records) or interview techniques (list-recall method, 24hour recall method, dietary history method, food frequency method) exist. A detailed description of these methods is given by Bingham et al. (17).

Validity is a concept that indicates whether a dietary assessment instrument measures what it intends to measure, and as such validity depends on the purpose for which the instrument is intended (18). Van Staveren et al. (19) discriminate between the measurement 
of habitual vs. actual diet, and between four levels of information that can be obtained "being 1) mean daily intakes of food components in certain groups, 2) mean and distribution of daily intakes of food components in groups, 3) the relative magnitude of food consumption of an individual as belonging to a certain third or fifth of the distribution, and 4) the absolute magnitude of the average food consumption of an individual.

The information that is required in a study guides the choice of the dietary assessment method (19). However, other (practical) factors also direct this choice, as some methods require a high investment in terms of effort (by the researcher and study participants), trained personnel, and money. Food-frequency questionnaires (FFQ) are relatively cheap, convenient for participants and researchers, and are designed to measure habitual food intake over an extended period of time. Therefore, FFQs have become the primary method for measuring dietary intake in epidemiological studies (20). FFQs collect information on the frequency of consumption of a number of items of interest, and some also collect data on serving size (20).

Unfortunately, estimates of food intake obtained with FFQs and other dietary assessment instruments are not without error. Sources of error and variation include systematic defects in information (due to the discrepancy between what the investigator wants to estimate and what the technique actually estimates), systematic and random response error, biological within-person variation, and between-person variation (21). As a result, variations in the design of FFQs can lead to different estimates of food intake (22). Examples are the collection of information on portion size (23-26) and the use of visual aids to help respondents make estimates on portion size $(27,28)$. Another important issue concerns the number of items in an FFQ, which is positively associated with the reported frequency of firuit and vegetable consumption (29). Therefore, summary questions and/or adjustment factors are often used $(30)$. It is however unknown if this will lead to better estimates of fruit and vegetable consumption.

FFQs with an extensive list of specific food items are mostly used in etiological studies on health effects of total fruit and vegetable consumption as well as specific fruits and vegetables and micronutrients that are present in fruit and vegetables. However, in some studies it is not necessary to obtain detailed information about consumption of specific fruits and vegetables, but it is sufficient to have an estimate of the total fruit and vegetable consumption. Moreover, reducing the length and complexity of an FFQ minimises the participants' efforts and time to complete it, and thereby maximises participation rates. Another reason for using brief FFQs is to minimise potential influence on participants' awareness of their personal fruit and vegetable consumption, which may be introduced by the use of intensive research methods for assessing dietary intake. Enhanced awareness might result in altered consumption and might have an effect on the reporting of psychosocial determinants of fruit and vegetable consumption. Therefore a number of brief FFQs have been developed to measure fruit and vegetable intake (for an overview see (31)).

For some studies, e.g. evaluations of the effectiveness of (health promotion) interventions ( $32 \%$ it is necessary that an FFQ can determime changes in fruit and vegettable consumption. Although this is an important aspect of an FFQ, only one study is known to the authors that validated an FFQ for its ability to measure changes in fruit and vegetable intake (over a six-year period) (33).

\section{Validation of food-frequency questionnaires.}

Relative validity indicates the validity of one instrument relative to another (reference) instrument (21). Unfortunately there is no so-called "gold standard" that can determine the diet of individuals without error, so the validity of FFQs must be determined by comparing the FFQ with a different method like diet records or dietary recalls, which is why we speak of relative validity. Depending on the purpose for which the FFQ will be used, validity can be presented as the absolute mean difference between estimates obtained with the FFQ and the reference 
method, the agreement between these two methods when individuals are divided into categories of absolute intake, correlation coefficients, and regression coefficients (18).

A limitation of validating an FFQ against another method based on self-report is that errors in both methods are not independent of each other (34), and thus a high agreement between the two methods can be partially caused by a high correlation between the errors of both estimates. A better option in this respect is to validate the FFQ against a reference method that is not based on seif-report. This is the rationale for using biochemical markers of food intake in validation studies (34). Some biomarkers reflect absolute nutrient intake for example, protein intake can be calculated from the daily urinary nitrogen excretion (35). Biomarkers of fruit and vegetable intake will be discussed below.

\section{Validation with carotencid and vitamin C concentrations in blood}

To date no marker has been identified that reflects absolute fruit and vegetable consumption. However, plasma and serum concentrations of carotenoids and vitamin $\mathrm{C}$ are suitable to rank individuals according to their fruit and vegetable intake (the third type of information mentioned above). Carotenoids are micronutrients that are predominantly present in fruits and vegetables, and some carotenoids are concentrated in relatively few fruits and vegetables (36). The major carotenoids in human plasma are lycopene, lutein+zeaxanthin and $\beta$-carotene $(37,38)$. Some carotenoids such as $\alpha$ - and $\beta$-carotenes and cryptoxanthins

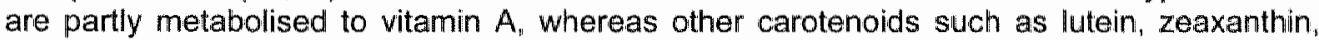
and lycopene are not (39). The efficiency of conversion to vitamin A decreases when vitamin A status is adequate and/or when dietary carotenes are high (40). After ingestion of carotenoids, several processes are necessary for optimal absorption to occur: sufficient digestion of the food matrix to release carotenoids; formation of lipid micelles in the small intestine; uptake of carotenoids by intestinal mucosal cells; and transport of carotenoids or their metabolic products to the lymphatic and/or portal circulation (40). In blood, carotenoids are transported via lipoproteins. Each of the above processes is influenced by a variety of dietary and non-dietary factors. (40). Therefore the magnitude of the correlations between plasma carotenoid concentrations and dietary intake is generally modest $(<0.5)(36)$. Nevertheless, previous studies have shown significant associations between fruit and vegetable consumption and blood concentrations of carotenoids, e.g. $(41,42)$. Furthermore, plasma carotenoid concentrations are responsive to change in fruit and vegetable intake $(43,44)_{1}$ and have been reported to change within two weeks when daily fruit and vegetable intake is increased, after which they remained stable $(45,46)$. In addition, carotenoids are chemically relatively stable in blood (47) and the number of separate days necessary to rank subjects according to their long-term blood concentrations is limited (48).

Vitamin $\mathrm{C}$ (ascorbic acid) is a water-soluble nutrient found primarily in fruits and vegetables (36). However, several of its properties limit the use of plasma vitamin $C$ concentrations as a biomarker for fruit and vegetable consumption. First, plasma vitamin $\mathrm{C}$ concentrations fluctuate more than carotenoids in response to current intake (36). Second, special care should be taken to the preservation of ascorbate in blood samples at the time of blood collection (49). Third, the relationship between dietary intake of vitamin $\mathrm{C}$ and plasma concentrations is anly linear at doses between 30 and $100 \mathrm{mg} /$ day; as a result of increased renal clearance at higher intake levels, blood vitamin $\mathrm{C}$ concentrations reach a plateau of about $70 \mu \mathrm{mol} / \mathrm{L}$ at an intake of about $200 \mathrm{mg} /$ day (50). However, this may only be a problem in persons consuming five portions of fruit and vegetables daily "i.e. in a small part of the population. Finally, vitamin $C$ in food may be lost during cooking (36). Despite its limitations, blood vitamin $C$ concentrations have been shown to be responsive to changes in frulit and vegetable intake (44), and to correlate with dietary intake of fruit and vegetables $(42,51)$. 


\section{Determinants of fruit and vegetable consumption}

When studying determinants of fruit and vegetable intake, various models can be used as a theoretical framework (52). The theory of planned behaviour is one such madel that can be used to study psychosocial determinants. The theory of planned behaviour originated from the earlier theory of reasoned action, which states that the likelihood of someone engaging in a particular behaviour can be predicted by their intention to perform that behaviour, which in turn is predicted by attifudes and subjective norms. Altitude refers to the degree to which a person thas a favourable or unfavourable evaluation or appraisal of the behaviour in question. Subjective norm refers to the perceived social pressure to perform or not perform a behaviour. In order to extend the scope of the theory of reasoned action to behaviours that may not be under complete volitional control, the perceived behavioural control construct was introduced as a third predictor of behavioural intention. Perceived behavioural contral reflects the perceived ease or difficulty of performing a particular behaviour, and is thought also to have a direct effect on behaviour, which is not mediated by intentions (53). Environmental and demographic influences on behaviour are thought to be mediated by the above constructs.

Demographic factors positively associated with higher fruit and vegetable consumption include being female (54-58), having a higher age (54-57,59-61), being married $(54,59,61)$, having a higher educational level $(54,55,57,58,61,62)$, and belonging to a higher social cllass or income group $(55,57,59)$.

Although knowledge about demographic determinants of fruit and vegetable intake is useful to identify groups of low fruit and vegietables consumers, health promotion campaigns cannot change any of these determinants. Therefore studies have been performed to identify psychosocial characteristics associated with fruit and vegetable intake, which are thought to be more modifiable by health promotion programmes. Attitudinal psychosocial factors positively associated with fruit and/or vegetable consumption include favourable attitudes $(56,62,63)$, taste preferences for fruit and vegetables $(55,60,63-65)$, and perceived (health) benefits of eating fruit and vegetables $(54,61,64)$. A factor related to perceived behavioural control that is positively related with fruit and vegetable intake is self-efficacy with respect to eating fruit and vegetables $(62,63,65)$, whereas perceived barriers are neglatively associated with fruit and vegetable intake $(54,61,62)$. Regarding social influences, people eat more fruit and vegetables when they perceive more social support or stronger norms to eat fruits and vegetables $(62,63,65)$. Intention is also positivelly related to fruit and vegetable consumption. In addition to the constructs from the theory of planned behaviour, a positive association has been shown between fruit and vegetable consumption and correct knowledge of the recommended intake levels for fruit and vegetables $(55,62,65)$. Further, people eat less fruit and vegetables if they are not aware of the fact that their consumption is insufficient (66).

A limitation of studies on psychosocial determinants of fruit and vegetable consumption is that all but one (67) had a cross-sectional design. Since information about psychosocial factors and fruit and vegetable consumption in these studies is obtained at the same point of time, factors that predict a change in fruit and vegetable intake cannot be identified. For this purpose studies with a longitudinal design are needed. Another limitation of studies on psychosocial determinants of fruit and vegetable intake is that for complex behaviour, such as dietary behaviour, the predictive value of the theory of planned behaviour and other models may be limited. One cause of the low explannatory value of those models may lie in the fact that psychosocial determinants are stronger correlates of self-rated food intake than of FFQ-measured intake, which has been shown for intake of fat $(68,69)$ and fruit and vegetables (66), and the fact that many persons are unrealistically optimistic about their own diets, i.e., they overestimate their own consumption of fruit and vegetables (66).

Inadequate consumption of fruit and vegetables is prevallent in various demographic groups including children $(14,70)$. Two main reasons can be mentioned why especially children should be encouraged to eat more fruits and vegetables. The first reason is that the importance of fruit and vegetable consumption in the prevention of chronic diseases starts 
from an early age onwards. The second reason is that encouraging children to eat sufficient amounts of fruits and vegetables can help to establish heatthy food thabits and preferences (71). Previous studies have identified several factors associated with children's fruit and vegetable consumption, of which the most important are preferences for fruits and vegetables (72) (73), and availlability and accessibility of fruits and vegetables (74-78). Furthermore, selfefficacy (76), outcome expectations (73) (76), children"s nutritional knowledge (76), and sex and ethnicity (79) have been found to be associated with children's fruit and vegetable consumption. Various authors have also indicated the importance of the family and parents in the composition of children's diets (80-83). In a review, Nicklas et al discriminate between at least five ways in which parents can influence their children's fruit and vegetable consumption: controlling the availability and accessibility; meal structure; food modelling; food socialisation practices; and parenting style and food-related parenting practices (83) However, the relative influence of each of these family-related factors on children"s fruit and vegetable intake remains to be established, and like in adults, longitudinal studies are needed to study predictors of changes in fruit and vegetable intake among children.

\section{Intervention effects on plasma carotenoids, vitamin C, folate, and homocysteine}

Among the micronutrients present in fruit and vegetables, folate is thought to play an important role in disease prevention. A high folate intake by women of child-bearing age is associated with a reduced risk of neural tube defects in their new-born children (84). Moreover, increasing the intake of folate has the potential of lowering elevated blood concentrations of homocysteine, which are considered as an independent risk factor for cardiovascular disease (85-87). As an alternative to the use of synthetic folate in dietary supplements, prior studies suggest that increasing intake of fruits and vegetables can also raise blood folate levels. However, these studies either compared the folate status of subjects consuming controlled diets high or low in fruits and wegetables (88-91), or provided them with a list of foods rich in folate from which they could choose in order to enhance their folate intake (92-94). Little is known about the effects of consuming the recommended amounts of fruits and vegetables irrespective of their follate content, which is closer to the real-life situation and to current dietary recommendations, which do not specifically recommend the consumption of folate-rich fruits and vegetables. With respect to carotenoids and vitamin $\mathrm{C}_{\text {, }}$ an effect of increased fruit and vegetable consumption on plasma concentrations of these vitamins would further support their usefulness as biomarkers of fruit and vegetable intake.

\section{Study objectives and overview}

The first objective of the project described in this thesis was to validate two FFQs against plasma concentrations of carotenoids and vitamin C. One FFQ was an extensive questionnaire which was originally designed to estimate nitrate intake from foods of vegetable origin (95). Since this FFQ had not been validated, a validation study was performed (chapter 2). Because of the large number of specific fruit and vegetable items in this FFQ, and the presence of additional items for total fruit and total vegetable intake, it was decided to also study the validity of using adjustment factors to correct for overreporting as a result of the long list of items. The second FFQ was a concise questionnaire consisting of eight fruit and vegetable items. In the Netherlands, a brief validated FFQ for measuring fruit and vegetable consumption was available (31), but after a validation study of this FFQ relative to seven-day diet records it was concluded that this FFQ needed further revision, especially for valid 
measurement of vegetable intake as well as total fruit and vegetable intake among adults (31). Therefore a concise FFQ was developed from this existing FFQ. The validation study of this concise FFQ is described in chapter 3 . The concise FFQ was also validated for the ability to measure changes in frutt and vegetable intake.

The second objective was to identify determinants of fruit and vegetable intake in adults and children. The effect of overestimation of fruit and vegetable consumption on the explanatory value of the theory of planned behaviour model is reported in chapter 4 . A longtudinal study aimed at finding psychosocial predictors of (intervention induced) changes in fruit and vegetable consumption is presented in chapter 5. Family-related factors associated with children's fruit and wegetable consumption were studied in chapter 6 .

The third objective was to assess the effects of an increased fruit and vegetable consumption on plasma concentrations of carotenoids, vitamin $C_{\text {, }}$ folate and homocysteine (chapter 7). A general discussion of all results is presented in chapter 8.

\section{Study design}

The design of the overall research project described in this thesis is shown in figure 1. This design allowed the combined study of the validity of the two FFQs, determinants of fruit and vegetable consumption and intervention effects on plasma folate and homocysteine concentrations. At baseline $\left(t_{0}\right)$, study participants completed a written questionnaire which included the concise FFQ and a questionnaire about potential determinants of fruit and vegetable intake (demographic variables, parenting styles, mealtime practices). Other potential determinants (constructs from the theory of planned behaviour and other beliefs, availability of fruit and vegetables, parenting food-related practices) were assessed at a second baseline measurement $\left(t_{1}\right)_{1}$ after a one-month dietary intervention $\left(t_{2}\right)$, and one year later $\left(t_{3}\right)$. On these three occasions both the concise and the extensive FFQ were also completed, and a blood sample was drawn for the analysis of carotenoids, vitamin $\mathrm{C}$, folate and homocysteine. Between $t_{1}$ and $t_{2}$ was an intervention period of one month. During the intervention half of the participants were asked to consume the recommended amounts of fruit and vegetables. To help participants to increase their fruit and vegetable consumption, packets containing recommended amounts of fruits and vegetables for each family member were delivered each week at the participants' homes free of charge, together with a weekly newsletter and recipes. In addition, participants in the intervention group were asked to use self-monitoring as a means to encourage ample consumption of fruits and vegletables. Persons in the control group neither received packets of fruits and vegetables, nor further information on fruits and vegetables. Allocation to either the control or the intervention group was at random, after prestratification for prior level of fruit and vegetable consumption as determined with the concise FFQ at to. Since changes in fruit and vegetablle consumption and in biomarkers (43) are dependent on baseline values, prestratification was necessary to ensure that mean fruit and vegetable consumption and mean biomarker concentrations were similar in the control and intervention group at baseline.

Since fruit and vegetable consumption varies between different seasons (96) and correlations between intake and plasma levells of carotenoids differ according to seasons (97), all measurements were done in spring in order to minimise seasonal influences in the reproducibility study. As plasma carotenoids have been reported to change within two weeks when daily fruit and vegetable intake is increased, after which they remained stable $(45,46)$, an intervention period of one month was chosen so that biomarker concentrations could have reached a new stable level by the time the intervention had finished. 


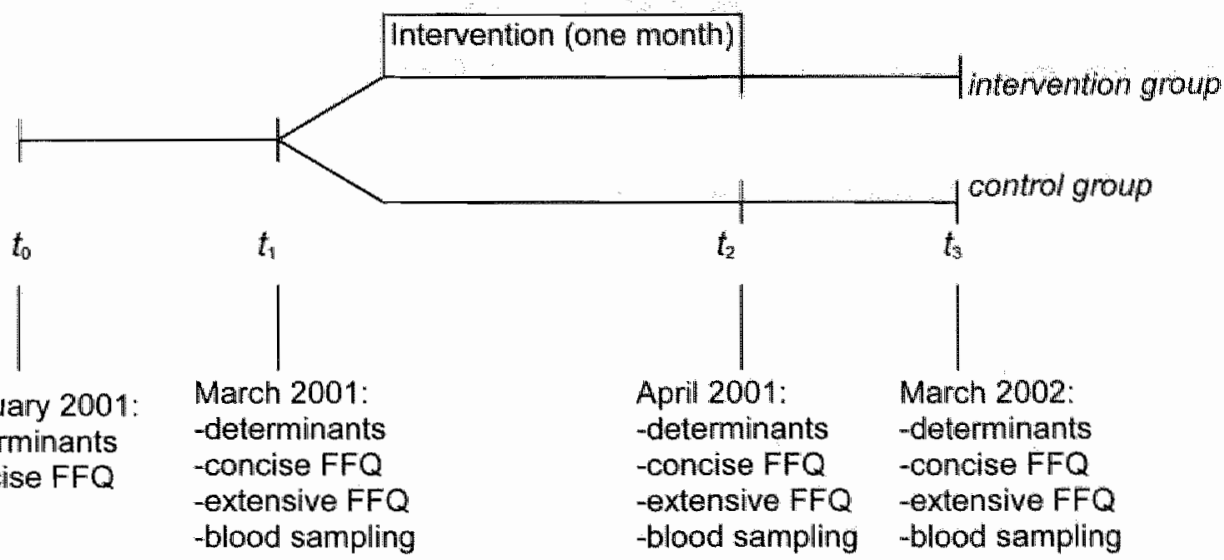

Figure I. Study design

The choice for the study population was guided by the fact that we wanted to study determinants of fruit and vegetable intake in both adults and children. It was decided to study elementary school children because, in contrast to younger children or adolescents, it was supposed they have a relatively stable diet which is less subject to rapid developments. Since in most families with elementary school children the mother is responsible for the buying and preparing of food (98), and since we expected a lower response rate if both mothers and fathers from the same family would have to complete questionnaires and give blood samples, only mothers were included in the study.

\section{References}

1. Lampe JW (1999): Health effects of vegetables and fruit: assessing mechanisms of action in human experimental studies. Am J Clin Nutr 70, 475S-490S.

2. Ness AR and Powles JW (1997): Fruit and vegetables, and cardiovascular disease: a review. Int $J$ Epidemiol 26, 1-13.

3. Steinmetz KA and Potter JD (1996): Vegetables, fruit, and cancer prevention: a review. $J$ Am Diet Assoc 96, 1027-39.

4. van't Veer $P$, Jansen MC, Klerk M and Kok FJ (2000): Fruits and vegetables in the prevention of cancer and cardiovascular disease. Public Health Nutr 3, 103-7.

5. International Agency for Research on Cancer (2003). Fruit and vegotables (eds. Vaiano $H$ \& Bianchini F). Lyon: IARC Press.

6. Signaleringscommissie Kanker van KWF Kankerbestrijding (2004): De rol van voeding bij het ontstaan van kanker (in Dutch). Amsterdam: KWF Kankerbestrijding.

7. Rolls BJ, Ello-Martin JA and Tohill BC (2004): What can intervention studies tell us about the relationship between fruit and vegetable consumption and weight management? Nutr Rev 62, 1-17.

8. Netherlands Bureau for Food and Nutrition (1992): Practical food stuff guide (in Dutch). The Hague: Voeding scentrum.

9. Commissie Richtlijnen Goede Voeding (1986): Guidelines for a healthy diet: recommendations drawn up by the Committee on Guidelines for a Healthy Diet. The Hague: Nutrition Council. 
10. WHO/FAO (2003): Joint WHO/FAO Expert Consultation on Diet Nutrition and the Prevention of Chronic Diseases. Geneva: WHO/FAO.

11. Li R, Serdula $M$. Bland $S$, Mokdad A, Bowman $B$ and Nelson D (2000): Trends in fruit and vegetable consumption among adults in 16 US states: Behavioral Risk Factor Surveillance System, 1990-1996. Am I Public Health 90, 777-81.

12. Agudo $A$, Slinani $N$, Ocke $M C$, Naska $A$, Miller $A B$, Kroke $A$, Bamia $C$, Karalis $D$, Vineis P, Palli D, Bueno-de-Mesquita HB, Peeters PH, Engeset D. Hiartaker A. Navarro $C_{0}$ Martinez Garcia $\mathbb{C}_{i}$ Wallstrom $P$, Zhang $J X_{*}$ Welch $\mathrm{AA}_{\mathrm{i}}$ Spencer $\mathrm{E}_{\mathrm{s}}$ Stripp $C$. Overvad K, Clavel-Chapelon $F$, Casagrande $C$ and Riboli $E$ (2002): Consumption of vegetables, fruit and other plant foods in the European Prospective Investigation into Cancer and Nutrition (EPIC) cohorts from 10 European countries. Public Health Nutr 5 , $1179-96$.

13. Naska $A$, Vasdekis VG, Trichopoulou A, Friel $S$, Leonhauser lU "Moreiras $O$, Nelson $\mathbb{M}$, Remaut AM, Schmitt $A$, Sekula W, Trygg KU and Zajkas $G(2000)$ : Fruit and vegletable availability among ten European countries: how does it compare with the "ffive-a-day" recommendation? DAFNE I and II projects of the European Commission. $\mathrm{Br}$ J Nutr 84, 549-56.

14. Hulshof KFAM, Kistemaker $C$ and Bouman M (1998): The consumption of food groups by Dutch population groups: food consumption survey 1997-1998 (in Dutch). Zeist: TNO Nutrition and Food Research.

15. Brug J, Schaalma H, Kok G, Meertens RM and Van der Molen HT (2000). Gezondheidsvoorlichting en gedragsverandering: een planmatige aanpak. Assen: Van Gorcium.

16. Klaver W, Burema J, van Staveren WA and Knuiman JT (1988). Definition of terms. in Manual on methodology for food consumption studies (eds. Cameron ME \& van Staveren WA). New York: Oxford University Press.

17. Bingham $S A$, Nelson $M$, Paul $A A$, Haraldsdottir J, Loken $A B$ and van Staveren WA (1988). Methods for data collection at an individuall level. in Manual on methodology for food consumption studies (eds. Cameron ME \& van Staveren WA). New York: Oxford University Press.

18. Willett $W$ and Lenart $E$ (1998). Reproducibility and validity of food-frequency questionnaires. in Nutritional Epidemiology (ed. Willett W). New York: Oxford University Press.

19. van Staveren WA, Feunekes $G$ I, Elburg $L$ and Erdelmann $F$ (1992): Validity of dietary questionnaires in studies on nutrition and heart disease. Bibl Nutr Dieta 49, 47-58.

20. Willett W (1998), Food-frequency methods. in Nutritional Epidemiology (ed. Willett W) New York: Oxford University Press.

21. Burema J, van Staveren WA and van den Brandt PA (1988). Validity and reproducibility. in Marnual on methodology for food consumption studies (eds. Cameron ME \& van Staveren WA) New York: Oxford University Press.

22. Kuskowska Wolk $A_{x}$ Holte $S$, Ohlander EM, Bruce A, Holmberg L, Adami HO and Bergstrom R (1992): Effects of different designs and extension of a food frequency questionnaire on response rate, completeness of data and food frequency responses. Int $J$ Epidemiol 21, 1144-50.

23. Haraldsdottir J, Tjonneland $A$ and Overvad K (1994): Validity of individuall portion size estimates in a food frequency questionnaire. Int J Epidemio/ 23, 786-96.

24. Tjonneland A, Haraldsdottir J. Overvad $K$, Stripp $C$, Ewertz $M$ and Jensen $O M(1992)$ : Influence of individually estimated portion size data on the validity of a semiquantitative food frequency questionnaire. Int $J$ Epidemiol 21, 770-7.

25. Clapp JA, McPherson RS, Reed DB and Hsi BP (1991): Comparison of a food frequency questionnaire using reported vs standard portion sizes for classifying individuals according to nutrient intake. J Am Diet Assoc 91, 316-20. 
26. Cotugna $N$ and Fleming $E$ (1998): Comparison of standard and portion-assisted responses to a brief fruit and vegetable food frequency questionnaire in a Hispanic WIC population. I Am Diet Assoc 98, 1462-4.

27. Cypel YS, Guenther PM and Petot GJ (1997): Validity of portion-size measurement aids: a review. J Am Diet Assoc 97, 289-92.

28. Ocke MC, Bueno de Mesquita HB, Goddijn HE, Jansen A, Pols MA, wan Staveren WA and Kromhout D (1997): The Dutch EPIC food frequency questionnaire. I. Description of the questionnaire, and relative validity and reproducibility for food groups. Int $I$ Epidemiol 26(suppl 1), $\$ 37-48$.

29. Krabs Smith $S M$, Heimendinger J, Subar AF, Patterson BH and Pivonka E (1995): Using food frequency questionnaires to estimate fruit and wegetable intake: association between the number of questions and total intakes. J Nutr Educ 27, 80-85.

30. Haraldsdottir $J$ (1993): Minimizing error in the field: quality control in dietary surveys. Eur J Clin Nutr 47 (suppl), S19-S24.

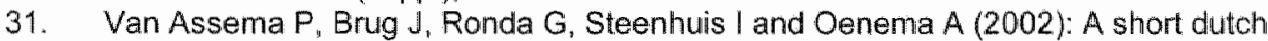
questionnaire to measure fruit and vegetable intake: relative validity among adults and adolescents. Nutr Health 16,85-106.

32. Kristal AR, Beresford SA and Lazovich D (1994): Assessing change in diet-intervention research. Am J Clin Nutr 59, 185s-189s.

33. Osler $\mathrm{M}$ and Heitmann $\mathrm{BL}$ (1996): The validity of a short food frequency questionnaire and its ability to measure changes in food intake: a longitudinal study. Int $J$ Epidemiol $25,1023-9$.

34. van 't Veer P, Kardinaal AF, Bausch Goldbohm RA and Kok. FJ (1993): Biomarkers for validation. Eur J Clin Nutr 47(suppl 2), S58-S63.

35. Bingham SA (1987): The dietary assessment of individuals; methods, accuracy, new techniques and recommendations. Nutrition abstracts and reviews (series A) 57,70542 .

36. Mayne ST (2003): Antioxidant nutrients and chronic disease: use of biomarkersi of exposure and oxidative stress status in epidemiologic research. J Nutr 133(Suppl 3), 933S-940s.

37. Yong LC, Forman MR, Beecher GR, Graubard BI, Campbell WS, Reichman ME, Taylor PR, Lanza E, Holden JM and Judld JT (1994): Relationship between dietary intake and plasma concentrations of carotenoids in premenopausal women: application of the USDA-NC $\mid$ carotenoid food-composition database. Am J Clin Nutr $60,223-30$.

38. Ascherio A, Stampfer MJ, Colditz GA, Rimm EB, Litin L. and Willett WC (1992): Correlations of vitamin $A$ and $E$ intakes with the plasma concentrations of carotenolds and tocopherols among American men and women. J Nutr 122, 1792-801.

39. Yeum KJ and Russell RM (2002): Carotenoid bioavailability and bioconversion. Annu Rev Nutr 22, 483-504.

40. Erdman JW, Jr., Bierer TL and Gugger ET (1993): Absorption and transport of carotenoids. Ann N Y Acad Sci 691, 76-85.

41. Campbell DR, Gross MD, Martini MC, Grandits GA, Slavin JL and Potter JD (1994): Plasma carotenoids as biomarkers of vegetable and fruit intake. Cancer Epidemiol Biomarkers Prev 3, 493-500.

42. Drewnowski $A$, Rock $C L$, Henderson $S A$, Shore $A B$, Fischler $C$, Galan P, Preziosi $P$ and Hercberg $S$ (1997): Serum beta-carotene and vitamin $C$ as biomarkers of vegetable and fruit intakes in a community-based sample of French adults. Am $J$ Cin Nutr 65, 1796-802.

43. Rock CL, Flatt SW. Wright FA, Faerber S, Newman V, Kealey S and Pierce JP (1997): Responsiveness of carotenoids to a high vegetable diet intervention designed to prevent breast cancer recurrence. Cancer Epidemiol Biomarkers Prev 6, 617-23. 
44. Le Marchand L, Hankin $J H$, Carter FS, Essling $C$, Luffey D, Franke AA, Wilkens LR, Cooney RV and Kolonel LN (1994): A pilot study on the use of plasma carotenoids and ascorbic acid as markers of compliance to a high fruit and vegetable dietary intervention. Cancer Epidemiol Biomarkers Prev 3, $245-51$.

45. Zino S, Skeaff M. Williams $S$ and Mann J (1997): Randomised controlled trial of effect of fruit and vegetable consumption on plasma concentrations of lipids and antioxidants. BMJ 314, 1787-91.

46. Yeum KJ, Booth SL, Sadowski JA, Liu C, Tang G, Krinsky NI and Russell RM (1996): Human plasma carotenoid response to the ingestion of controlled diets high in fruits and vegetables. Am $J$ Clin Nutr 64, 594-602.

47. Craft NE, Brown ED and Smith JC, Jr. (1988): Effects of storage and handling conditions on concentrations of individual carotenoids, retinol, and tocopherol in plasma. Cin Chem 34, 44-8.

48. van Kappel AL, Steghens JP, Zeleniuch Jacquotte $A$, Chajes $V$, Toniolo $P$ and Riboli $E$ (2001): Serum carotenoids as biomarkers of fruit and vegetable consumption in the New York Women's Health Study. Public Health Nutr 4, 829-35.

49. Margolis SA and Duewer DL (1996): Measurement of ascorbic acid in human plasma and serum: stability, intralaboratory repeatability, and interlaboratory reproducibility. Clin Chem 42, 1257-62.

50. Levine $M$, Conry-Cantilena $C$, Wang $Y$, Welch RW, Washko PW, Dhariwal KR, Park

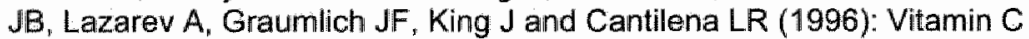
pharmacokinetics in healthy volunteers: evidence for a recommended dietary allowance. Proc Natl Acad Sci U S A 93, 3704-9.

51. Block $G$, Norkus E, Hudes $M_{1}$ Mandel S and Helzlsouer K (2001): Which plasma antioxidants are most related to fruit and vegetable consumption? Am J Epidemiol 154, 1113-8.

52. Baranowski T, Cullen KW and Baranowski J (1999): Psychosocial correlates of dietary intake: advancing dietary intervention. Annu Rev Nutr 19, 17-40.

53. Ajzen I (1991): The theory of planned behavior. Organ Behav Hum Decis Process 50, 179-211.

54. Hagdrup NA, Simoes EJ and Brownson RC (1998): Fruit and vegetable consumption in Missouri: Knowledge, barriers and benefits. Am J Health Behav 22, 90-100.

55. Krebs Smith SM, Heimendinger $\downarrow$, Patterson $B H_{1}$, Subar AF, Kessler $R$ and Pivonka $E$ (1995): Psychosocial factors associated with fruit and vegetable consumption. Am J Health Promot 10, 98-104.

56. Thompson RL, Margetts BM, Speller VM and McVey D (1999): The health education authority's health and lifestyle survey 1993: Who are the low fruit and vegetable consumers? I Epidemiol Community Health 53, 294-9.

57. Wardle $\mathrm{J}$, Parmenter $\mathrm{K}$ and Waller $\mathrm{J}$ (2000): Nutrition knowledge and food intake. Appetite 34, $269-75$.

58. Laforge RG, Greene GW and Prochaska JO (1994): Psychosocial factors influencing low fruit and vegetable consumption. J Behav Med 17, 361-74.

59. Billson H, Pryer JA and Nichols R (1999): Variation in fruit and vegetable consumption among adults in Britain. An analysis from the dietary and nutritional survey of British adults. Eur J Clin Nutr 53, 946-52.

60. Glanz K, Basil M, Maibach E, Goldberg J and Snyder D (1998): Why Americans eat what they do: taste, nutrition, cost, convenience, and weight control concerns as influences on food consumption. J Am Diet Assoc 98, 1118-26.

61. Trudeau E, Kristal AR, Li S and Patterson RE (1998): Demographic and psychosocial predictors of fruit and vegetable intakes differ: implications for dietary interventions. $J$ Am Diet Assoc 98, 1412-7. 
62. Havas $S$, Treiman $K$, Langenberg $P$. Ballesteros $M$, Anliker $d$, Danron $D$ and Feldman $R$ (1998): Factors associated with fruit and vegetable consumption among women participating in WIC. J Am Diet Assoc 98, 1141-8.

63. Brug J, Lechner $L$ and De Vries H (1995): Psychosocial determinants of fruit and vegetable consumption. Appetite 25, 285-96.

64. Satia JA, Kristal AR, Patterson RE, Neuhouser ML and Trudeau E (2002): Psychosocial factors and dietary habits associated with vegetable consumption. Nutrition 18, 247-54.

65. Van Duyn MA, Kristal AR, Dodd K, Campbell MK, Subar AF, Stables G, Nebeling L and Glanz K (2001): Association of awareness, intrapersonal and interpersonal factors, and stage of dietary change with fruit and vegetable consumption: a national survey. Am J Health Promot 16, 69-78.

66. Lechner L, Brug $\mathrm{J}$ and De Vries $H$ (1997): Misconceptions of fruit and vegetable consumption: differences between objective and subjective estimation of intake. J Nutr Educ 29, 313-20.

67. Langenberg $P$, Ballesteros $M$, Feldman $R$, Damron D, Anliker J and Havas S (2000): Psychosocial factors and intervention-associated changes in those factors as correlates of change in fruit and vegetable consumption in the Maryland WIC 5 a day promotion program. Amn Behav Med 22, 307-15.

68. Brug $\mathrm{J}$ and Van Assema P (2001). Beliefs about fat: Why do we hold beliefs about fat and why and how do we study these beliefs? in Food, People and Society: A European perspective of consumers" food choices (eds. Frewer $\mathbb{L}$, Risvik $E$ \& Schifferstein H). Heidellberg: Springer-Verlag.

69. Brug J, Assema PV, Kok G, Lenderink T and Glanz K (1994): Self-ratled dietary fat intake: association with objective assessment of fat, psychosocial factors, and intention to change. J Nutr Educ 26, 218-23.

70. Krebs-Smith SM, Cook A, Subar AF, Cleveland L, Friday $』$ and Kahle LL (1996): Fruit and vegetable intakes of children and adolescents in the United States. Arch Pediatr Adolesc Med 150, 81-6.

71. Kelder SH, Perry CL, Klepp KI and Lytle LL (1994): Longitudinal tracking of adolescent simoking, physical activity, and food choice behaviors. Am J Public Health 84, 1121-6.

72. Domel SB, Thompson WO, Davis HC, Baranowski T, Leonard SB and Baranowski J (1996): Psychosocial predictors of fruit and vegetable consumption among elementary school children. Health Educ Res 11, 299-308.

73. Resnicow K, Davis Hearn M, Smith M. Baranowski T and et al. (1997): Soclal-cognitive predictors of fruit and vegetable intake in children. Health Psychology 16, 272-6.

74. Hearn M (1998): Environmental influences on dietary behavior among children: availability and accessability of fruits and vegetables enable consumption. J Health Educ 29, 26-32.

75. Reynolds KD, Hinton AW, Shewchuk RM and Hickey CA (1999): Social cognitive model of fruit and vegetable consumption in elementary school children. J Nutr Educ $31,23-30$.

76. Kratt $P$, Reynolds $K$ and Shewchuk $R(2000)$ : The role of availability as a moderator of family fruit and vegetable consumption. Health Educ Behav 27, 471-82.

77. Edmonds J, Baranowski T, Baranowski J, Cullen KW and Myres D (2001): Ecological and socioeconomic correlates of fruit, juice, and vegetable consumption among African-American boys. Prev Med 32, 476-81.

78. Cullen KW. Baranowski T, Owens E, Marsh T, Rittenberry L and de Moor C (2003): Availability, accessibility, and preferences for fruit, $100 \%$ fruit juice, and vegetables influence children's dietary behavior. Health Educ Behav 30, 615-26.

79. Reynolds KD, Baranowski T, Bishop DB, Farris RP, Binkley D, Nicklas TA and Elmer PJ (1999): Patterns in child and adolescent consumption of fruit and vegetables: effects of gender and ethnicity across four sites. I Am Coll Nutr 18, 248-54. 
80. Wardle J (1995): Parental influences on children's diets. Proc Nutr Soc 54, 747-58.

B1. Contento $I R$ and Michela $J L$ (1997). Nutrition and food choice behavior among children and adolescents. in Handbook of pediatric and adolescent health psychology. Boston: Allyn \& Bacon.

82. Koivisto Hursti UK (1999): Factors influencing children's food choice. Ann Med 31(Suppi 1). 26-32.

83. Nicklas TA, Baranowski T, Baranowski JC, Cullen K, Rittenberry L and Olvera $N$ (2001): Family and child-care provider influences on preschool children's fruit, juice. and vegelable consumption. Nutr Rev 59, 224-35.

84. Geisel J (2003) Folic acid and neural tube defects in pregnancy: a review. J Perinat Neonatal Nurs 17, 268-79.

85. The homocysteine studies collaboration (2002): Homocysteine and risk of ischemic heart disease and stroke: a meta-analysis. JAMA 28i8, 2015-22.

86. Klerk M, Verhoef $P$, Clarke $R$, Blom HJ, Kok FJ and Schouten EG (2002): MTHFR $677 \mathrm{C}-\rightarrow \mathrm{T}$ polymorphism and risk of coronary heart disease: a meta-analysis. JAMA $288,2023-31$.

87. Mangoni AA and Jackson SH (2002): Homocysteine and cardiovascular disease: current evidence and future prospects. Am J Med 112, 556-65.

88. Appel LJ, Miller ER, 3rd, Jee SH, Stolzenberg Solomon $R$, Lin $P H$, Erlinger $T_{\text {, }}$ Nadeau MR and Selhub J (2000): Effect of dietary patterns on serum homocysteine: results of a randomized, controlled feeding study. Circulation 102, 852-7.

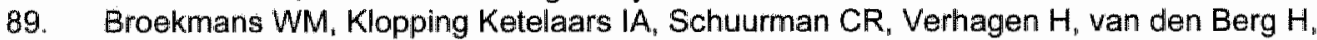
Kok FJ and van Poppell G (2000): Fruits and vegetables increase plasma carotenoids and vitamins and decrease homocysteine in humans, J Nutr 130, 1578-83.

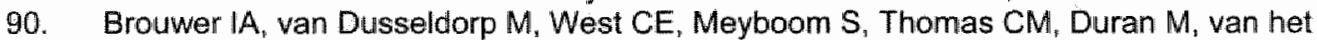
Hof $\mathbb{K H}$, Eskes TKK, Hautvast JG and Steegers Theunissen RP (1999): Dietary folate from vegetables and citrus fruit decreases plasma homocysteine concentrations in humans in a dietary controlled trial. J Nutr 129, 1135-9.

91. Silaste ML, Rantala M, Alfthan $G$, Aro A and Kesaniemi YA (2003): Plasma homocysteine concentration is decreased by dietary intervention. Br J Nutr 89, 295301.

92. Ashfield Watt PA, Whiting JM, Clark ZE, Moat SJ, Newcombe RG, Burr ML and McDowell IF (2003): A comparison of the effect of advice to eat either '5-a-day' fruit and vegetables or folic acid-fortified foods on plasma folate and homocysteine. Eur $d$ Cilin Nutr 57, 316-23.

93. Riddell LJ, Chisholm A, Williams S and Mann Jl (2000): Dietary strategies for lowering homocysteine concentrations. Am J Clin Nutr 71. 1448-54.

94. Venn BJ, Mann JI, Williams SM, Riddell LJ, Chisholm A, Harper MJ and Aitken W (2002) Dietary counseling to increase natural folate intake: a randomized, placebocontrolled trial in free-living subjects to assess effects on serum folate and plasma total homocysteine. Am J Clin Nutr 76, 758-65.

95. van Dooren-Flipsen MMH and van Klaveren JD (1998): VEG-

Voedselfrequentievragenlijst: Ontwikkeling vragenlijst naar de inname van stoffen gerelateerd aan plantaardige voedingsmiddelen (in Dutch). Wageningen: RIKILT-DLO.

96. Ziegler RG, Wilcox HBd, Mason TJ, Bill JS and Virgo PW (1987): Seasonal variation in intake of carotenoids and vegetables and fruits among white men in New Jersey. Am $J$ Clin Nutr 45, 107-14.

97. Scott KJ, Thumham DI, Hart DJ, Bingham SA and Day K (1996): The correlation between the intake of lutein. "ycopene and beta-carotene from vegetables and fruits, and blood plasma concentrations in a group of women aged 50-65 years in the UK. $\mathrm{Br}$ J Nutr 75, 409-18. 
98. Harnack L, Story M, Martinson B, Neumark-Sztainer D and Stang J (1998): Guess who's cooking? The role of men in meal planning, shopping, and preparation in US families. J Am Diet Assoc 98, 995-1000. 



\section{2}

Using a correction factor to correct for overreporting in a food-frequency questionnaire does not improve biomarker-assessed validity of estimates for fruit and vegetable consumption

Rik P Bogers

Pieter C Dognelie

Klaas R Westerterp

Arnold DM Kester

Jacob D van Klaveren

Aalt Bast

Piet A van den Brandt

Published in J Nufr 133, 1213-9, 2003 


\section{Abstract}

To correct for overreporting of fruit and vegetable consumption in a food-frequency questionnaire, summary questions about consumption of main fruit and vegetable groups are often used to calculate correction factors. This study compared the ability to rank people according to their fruit and vegetable intake of those summary questions and the sum of questions on individual fruit and vegetable items within categories, and of corrected or uncorrected estimates of specific sorts of fruit and vegetables. Healthy middle-aged women ( $n=161)$ completed a food-frequency questionnaire about fruit and vegetable consumption during the previous month and gave a single fasting blood sample. Correction factors were calculated as the reported frequency on a summary question divided by summed frequencies of all items in a category. Plasma carotenoids and vitamin $\mathrm{C}$ served as biomarkers of fruit and vegetable consumption. Significant correlations between fruit and vegetable consumption and biomarkers were observed (e.g. Spearman's $r$ with total carotenoids/vitamin $C: 0.32 / 0.34$ for vegetables, 0.3010 .25 for fruits). Summary estimates of cooked, raw and total vegetable consumption correlated higher with biomarkers than did sum estimates. For fruits no differences in correlations between sum and summary estimates were observed. Applying a correction factor on the consumption of carrots and total cabbage resulted in lower correlations with relevant biomarkers. For broccoli/cauliflower, Brussels sprouls and citrus fruits, correlations with biomarkers did not change after correction. We conclude that summary questions may suffice to rank individuals according to their intake of main fruit and vegetable categories, and that correction for overreporting of individual fruit and vegetable items is probably not advisable when ranking individuals according to intake of these items. 


\section{Introduction}

Many human observational studies suggest that consumption of fuit and vegetables or associated micronutrients is beneficial in the prevention of cancer (1-4), and cardiovascular disease (5-7).

For epidemiolagical studies aimed at further establishing associations between fruil and vegetable consumption and disease, a food-frequency questionnaire ( $F F Q$ ) that adequately classifies persons according to their usual fruit and vegetable intake is a useful tool. Such a questionnaire not only must be suitable for estimating total fruit and vegetable consumption, but also will have to cover consumption of all relevant sorts of fruit and vegetables in order to calculate intake of specific (groups of) fruit and vegetablies and of essential nutrients and other bioactive compounds.

However, estimates of consumption derived from an FFQ are never free of errors, and result in biased estimates of reported consumption frequency and portion size. Most subjects have difficulties in estimating the frequency of consumption of specific food items (in this case specific fruits or vegetables). The sum of all items within a certain food category usually results in an estimate that is higher than the true overall frequency of consumption $(8,9)$. On the other hand, estimates derived from the sum of items might better represent true intake, because in that case a more appropriate weight belonging to each specific item instead of a mean weight for all the items can be used in the calculations (e.g. an apple weighing more than a tangerine).

In studies where the intake of specific items or nutrients is of interest, a common practice to correct for this overreporting is to include a summary question (how often do you eat vegetables?) preceding or following questions on intake of specific items within a food category. In data analysis, frequencies of intake of specific items are then calibrated so that the sum of all items equals the overall frequency (10). However, the question arises whether in the case of vegetables this is a valid method, because more than one type of vegetable may be served at the same meal. Also for fruits, different sorts may be eaten during a single day. Amanatidis et al. (9) found that applying a correction factor did not substantially affect the ranking of subjects according to intake of various micronutrients. However, they did not have an independent reference method against which validity of corrected and uncorrected estimates could be determined.

The concept of validity consists of several aspects, each of which can be addressed depending on the purpose and context of the method used $(11,12)$. The type of validity we refer to in the present study concerns the relative ranking of subjects by two different methods. A correlation coefficient is the typical measure used to evaluate this aspect of validity (12).

One way of validating FFQ is by using biochemical markers of dietary intake. Although there are several drawbacks in the use of biomarkers (13), they provide an objective measure of intake of which the errors are largely independent of the errors associated with FFQ (14). Frequently used biomarkers for fruit and vegetable intake are plasma carotenoids and vitamin $\mathrm{C}$, which have been shown to be responsive to intake of fruit and vegetables (15-18). Significant (although moderate) correlations between plasma or serum concentrations of carotenoids and carotenoid intake (19-24) or fruit and vegetable consumption (24-28) have been observed, and plasma/serum vitamin $\mathrm{C}$ was found to be significantly correlated with fruit and vegetable intake $(26,28$ ) or vitamin $C$ intake (29). The present study focuses on two questions: first, are summary questions on fruit and vegetable consumption better able to rank subjects according to their usual fruit and vegetable consumption than the sum of specific items within each category? This question was studied for the categories total vegetables (excluding potatoes), cooked vegetables (excluding potatoes), raw vegetables, fruits and fruit juice. Second, do calibrated estimates of three (groups of) fruit and vegetables 
(cabbage, carrots and citrus fruits) lead to a better ranking of subjects than uncalibrated estimates? Plasma carotenoids ( $\alpha$-carotene, $\beta$-carotene, lutein, lycopene, $\beta$-cryptoxanthin) and vitamin $C$ were used to serve as independent estimates of fruit and vegetable consumption as criterion variables against which validity was assessed. At the same time, this study can be regarded as a validation study of the FFQ we developed for estimating fruit and vegetable consumption.

\section{Methods}

\section{Study design}

The study was part of a larger project aimed at increasing fruit and vegetable consumption in children aged $7-10$ years and their mothers, for which we received approval by the medical ethical committee of the University Hospital in Maastricht. Participants completed an FFQ about fruit and vegetable consumption in the previous month, after which blood was taken from the mothers for the analysis of biomarkers. fruit and vegetable consumption was calculated both with summary questions about fruit and vegetable categories (cooked vegetables, raw vegetables, fruits, fruit juice) and with extensive lists of single items within each category. Consumption of specific fruits and vegetables was calculated with and without correction for overreporting. All data presented in this publication were collected in March 2001.

\section{Participants}

From the population registry of the municipality of Maastricht, a random sample was obtained containing 2,000 addresses of mothers with children aged $7-10$ years. A letter was sent inviting the mother and the selected child in each family to participate. An additional 1,100 letters were distributed in elementary schools in Maastricht. The women had to be apparently healthy nonsmokers who agreed not to use vitamin supplements from one month before the first blood collection to the end of the study period. We explained to the participants that the purposes of the study were to develop questionnaires to assess both fruit and vegetable intake and determinants of fruit and vegetable consumption (the latter, in another part of the project, are not described here). A total of 207 volunteers were recruited $(6.7 \%$ response rate), of whom 163 women (79\%) fully completed the study, making an overall response rate of $5.3 \%$. Two subjects having FFQ with more than $20 \%$ missing values were excluded from further analyses, leaving a total number of 161 subjects.

\section{Food-frequency questionnaire}

The FFQ was designed to measure fruit and vegetable intake during the past month and was completed in March 2001. We distributed the questionnaires by mail and asked the participants to fill out the FFQ on the day before blood collection.

"The FFQ we used was a modified version of the VEG-FFQ (from 'vegetable') developed at the Dutch State Institute for Quality Control of Agricultural Products (30). This VEG-FFQ was a 172-item semi-quantitative food-frequency questionnaire that was developed and first used as a part of the Third Dutch National Food Consumption Survey in 1998 (31). Questions were asked separately for summer and winter. In the design of the VEG-FFQ existing Dutch FFQs (32-37) served as guidelines. Specific features of the VEG-FFQ were as follows: the use of household measures and natural units in questions on amounts eaten; ordering of the questions according to the Dutch meal pattern; questions at the level of meals; addition of overall questions on each product category (e.g., fruits) for correction for overreporting; grouping products within the same food category and ordering foods within a 
category according to frequency of consumption of products; taking into account seasonal differences in fruit and vegetable consumption. The food categonies included in the VEG-FFQ were soup, warm meals, potatoes, mashed vegetables, salads, cooked vegetables, fruits (including apple sauce), drinks and snacks. Questions on foods were noted as consumption frequency and portion size, except for sweet peppers, mushrooms, tomatoes and onions, which were estimated by asking the amount eaten per month or week. The seven frequency categories used were: never or less than one day/month, one day/month, 2-3 days/month, and one, 2-3, 4-5 and 6-7 days/week.

Before the present study the VEG-FFQ had been used in 1592 out of 5958 participants of the third Dutch National Food Consumption Survey in which subjects recorded their 48-h food intake on two consecutive days. These 1592 participants completed the VEG-FFQ 4-8 weeks after the 48-h records. It was found that mean fruit and vegetable intake calculated using the VEG-FFQ corresponded well with mean intake calculated from the 48-h records. After correction for overreporting using summary questions on food categories, mean vegetable intake was $105 \mathrm{~g} /$ day according to the VEG-FFQ and 123 (95) g/day according to the records; for fruit intake this was 114 and 105 (114) g/day, respectively (30). Further validation was not performed.

For the present study, we slightly madified the VEG-FFQ to fit into the study design. Separate questions on consumption of fruit and vegetables in summer and winter were combined into questions on fruit and vegetable consumption during the past month. Openended questions on average portion size were changed to multiple-choice questions so that the questionnaires could be read by an optical scanner. The result was a 106-item semiquantitative FFQ. Calculated fruit and vegetable categories were fruits (including fresh orange and grapefruit juice), cooked vegetables (not including potatoes), raw vegetables, total vegetables (the sum of cooked and raw vegetables), and fruit juice (from a cartion or bottle). For each of these categories, a summary question was asked, followed by a list of items belonging to a category that we used for calculating the sum estimates. The numbers of items were 17 (fruits), 21 (cooked vegetables), 14 (raw vegetables) and 5 (fruit juice).

\section{Assessment of biomarkers in blood}

Blood was taken shortly after the participants completed the FFQs. After an overnight fast, $14 \mathrm{~mL}$ venous blood was collected between 0700 and $1100 \mathrm{~h}$ in two $\mathrm{K}_{2}$ EDTA-coated plastic tubes (Becton Dickinson Vacutainer Systems "Plymouth, UK). Both tubes were immediately placed on ice in the dark.

Total ascorbic acid was determined according to the method of Speek et all. (38). Briefly, blood was collected in a $4-\mathrm{mL}$ tube in which $0.08 \mathrm{~mL}$. EGTA-glutathione solution had been injected before blood sampling. A $250-\mu \mathrm{L}$ aliquot of blood was stabilised in $1 \mathrm{~mL}$ trichloroacetic acid and centrifuged after 20 to $60 \mathrm{~min}\left(15,000 \times \mathrm{g}, 10 \mathrm{~min}, 4^{\circ} \mathrm{C}\right)$. A pilot study showed that ascorbic acid in trichloroacetic acid placed on ice is stable for at least 60 min of incubation. Of the supernatant, $350 \mu \mathrm{L}$ was transferred in amber Eppendorf vials (EppendorfNetherler-Hinz-GmbH, Hamburg, Germany) and stored at $-80^{\circ} \mathrm{C}$. The samples were analysed within 2 weeks with high performance liquid chromatography with fluorometric detection. For this purpose, 1 -ascorbic acid was enzymatically oxidised to dehydro-tascorbic acid and the latter was condensed with o-phenylenediamine to its fluorescent quinoxaline derivative. The high performance liquid chromatography mobile phase consisted of 0.08 mollL potassium dihydrogen phosphate and methanol $(4: 1 \mathrm{w} / \mathrm{v})$.

Plasma carotenoids were analysed according to Hess el al. (39), with modifications described by Oostenbrug et al. (40). Briefly, after blood was drawn in a 10-ml tube it was centrifuged (1000 $\left.\times \mathrm{g}, 10 \mathrm{~min}, 4^{\circ} \mathrm{C}\right)$, and the plasma was transferred into amber Eppendorf vials and stored at $-80^{\circ} \mathrm{C}$. The plasma was analysed within 5 months using high performance liquid chromatography with UV detection. First, $500 \mu \mathrm{L}$ double-distilled water was added to $500 \mu \mathrm{L}$ plasma and this mixture was denatured with $1 \mathrm{~mL}$ of a mixture of absolute ethanol and 
methanol (1:1 vol:wol). Carotenoids were twice extracted into $3 \mathrm{~mL}$ hexane. The pooled supernatant was evaporated to dryness under nitrogen at $37^{\circ} \mathrm{C}$ and resuspended in $200 \mu \mathrm{L}$ ethanol-dioxan $(1: 1 \mathrm{w} / \mathrm{v})$, after which $300 \mu \mathrm{L}$ acetonitrile was added. The high performance liquid chromatography mobile phase consisted of acetonitrile, tetrahydrofuran, methanol and double-distilled water $(684: 220: 68: 28 \mathrm{v} / \mathrm{w} / \mathrm{v} / \mathrm{v})$. Ethyl- $\beta$-apo-8'-carotenoate was used as an internal standard.

\section{Calculations of fruit and vegetable intake and statistical analysis}

Statistical analyses were performed using the SPSS program (version 10.0; SPSS, Chicago, IL). Standard amounts as indicated in a Dutch table for measures and weights $(41,42)$ were used for converting household measures to portion sizes. Missing values for portion sizes on a particular item were substituted with mean portion sizes for the item concerned. Fruit and vegetable intake (in g/day) was calculated as the product of frequency of intake and portion size. Mean values were used to substitute missing values for fruit and vegetable intake.

Besides under the heading 'raw vegetables', consumption of sweet peppers and tomatoes was asked as the absolute amount eaten both raw and cooked per week or month. After subtraction of raw sweet peppers and tomatoes we added these amounts to cooked vegetables. We supposed that onions and mushrooms, which were also asked as raw and cooked amount eaten per month, were eaten predominantly cooked and added these two items to cooked vegetables. The correction facior for calibrating items was calculated as the reported frequency on the summary question divided by the sum of frequencies of all items belonging to a category. Corrected intake of items was callculated by multiplying intake of an item by the correction factor. Corrected intake of a category was the sum of all corrected items in a category. The relative validity of corrected and uncorrected intakes was determined for carrots, citrus fruits and cabbage (total cabbage, Brussels sprouts and broccoli/cauliflower), because of their known high contents of $\alpha$-carotene, $\beta$-cryptoxanthin and lutein, respectively.

Agreement between the summary question and the sum of individual items within a category was determined by cross-classifying quartiles of fruit and vegetable intake according to the sum of items in a category with quartiles according to the summary question. Validity was calculated as correlation coefficients between fruit and vegetable intake and biomarkers. We used Spearman's correlation coefficients because of the skewed distribution of most food consumption data. To compare the validity of two estimates of fruit and vegetable consumption, equality of correlations was tested using a formula stated by Olkin and Siotani $(43,44)$. 
Table 1

Characteristics of the study population $\mid n=161$ women|

\begin{tabular}{ll}
\hline Characteristic & \\
\hline Age (years), mean (SD) & $41(4.0)$ \\
Body Mass Index $\left(\mathrm{kg} / \mathrm{m}^{2}\right)$, mean (SD) & $24.1(3.5)$ \\
Educational level & \\
Low, \% & 6 \\
Intermediate, \% & 52 \\
High, \% & 42 \\
\hline
\end{tabular}

\section{Results}

Table 1 provides a summary of the participants" characteristics. Table 2 presents a comparison between mean fruit and vegetable consumption derived from one summary question or from summing all items in a category. The greatest difference in intake between these two methods was for cooked vegetables: $110 \mathrm{~g} /$ day using the summary question (summary amount) vs. $204 \mathrm{~g} /$ day using the sum of items (sum amount). For cooked vegetables the correlation between frequencies $(r=0.35)$ and intake $(r=0.49)$ measured with either method was lowest; however, the mean correction factor of 0.89 was closer to 1.00 , and the mean difference between sum and summary frequencies was lower than for raw vegetables and fruit. For fruit juice the sum amount approached the summary amount most closely ( 67 vs. $79 \mathrm{~g} /$ day), and for fruits this was $156 \mathrm{vs} .195 \mathrm{~g} /$ day. The mean correction factor for fruit juice was almost 1.00 because most people drank onlly orange juice, so that the sum frequency consisted of only one item.

Table 3 illustrates the agreement in results when the summary question or the sum of items in a category was used to calculate fruit and vegetable intake. The best agreement was. found for fruits and fruit juice, where $95 \%$ and $93 \%$ of the subjects were classified in the same or adjacent quartile, respectively. Again, the lowest agreement was observed for cooked vegetables ( $83 \%$ in the same or adjacent quartile).

Table 4 details the descriptive statistics for the biomarkers. The carotenoid most abundant in plasma was $\beta$-cryptoxanthin, and the least abundant was $\alpha$-carotene. The median values corresponded well with mean values.

Table 5 presents the results of the validation of the two methods for calculating fruit and vegetable consumption against plasma carotenoids and vitamin C. Values of correlations with biomarkers were consistently higher for summary amounts than for sum amounts. Some of these differences were statistically significant, especially for total vegetable consumption. In contrast, for fruit consumption the correlations of biomarkers were comparable for the summary and the sum amounts. For cooked vegetables, the highest correlation was with vitamin $C$ (Spearman's $r=0.35$ ). Consumption of raw vegetables correlated highest with $\alpha_{-}$ carotene and total carotenoids ( $r=0.31$ for both), and firuit consumption with $\beta$-cryptoxanthin $(r=0.43)$. Consumption of fruit juice was not significantly correlated with any of the biomarkers, regardless of whether it was expressed as summary or sum amount. 


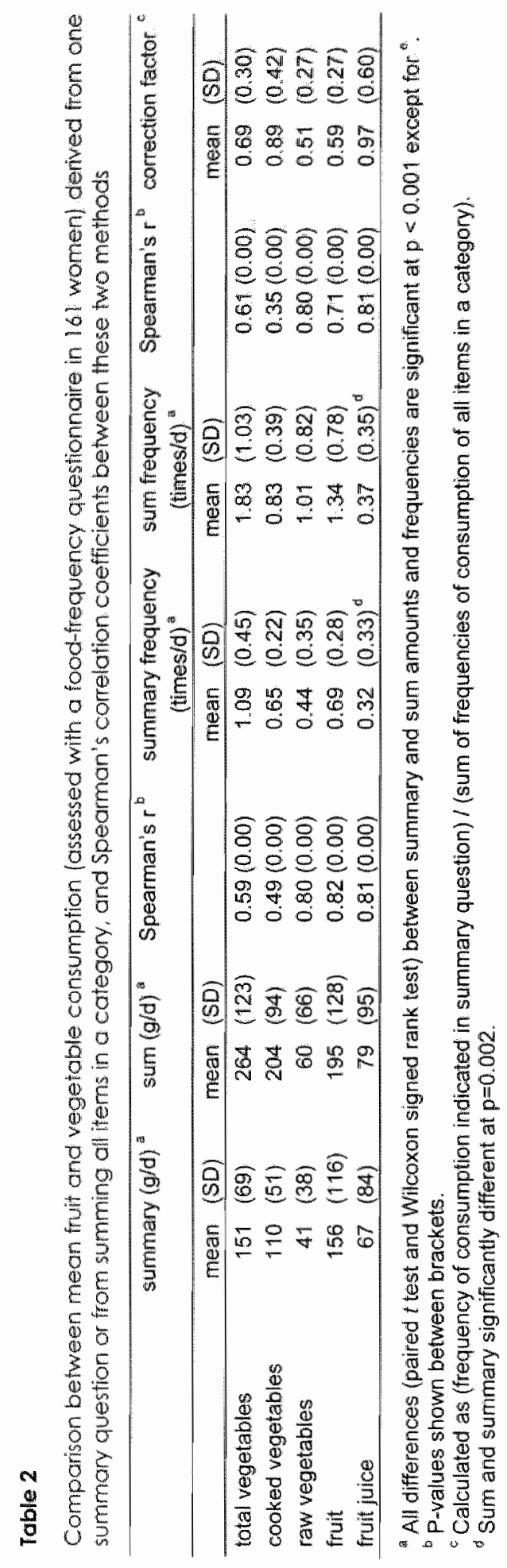




\section{Table 3}

Cross-classification of quartiles derived from colculating fruit and vegetable inteke as the sum of all items in a category by quartiles of intake using a summary questiona

\begin{tabular}{lcccc}
\hline & $\begin{array}{c}\text { Same quartile } \\
\text { using summary }\end{array}$ & $\begin{array}{c}\text { Adjacent } \\
\text { quartile using } \\
\text { summary }\end{array}$ & $\begin{array}{c}\text { 2 Quartiles } \\
\text { difference using } \\
\text { summary }\end{array}$ & $\begin{array}{c}\text { Extreme } \\
\text { opposites using } \\
\text { summary }\end{array}$ \\
\hline Total vegetables $(\%)$ & 47.2 & 39.2 & 10.6 & 3.1 \\
Cooked vegetables $(\%)$ & 42.2 & 41.0 & 17.9 & 3.1 \\
Raw vegetables $(\%)$ & 56.5 & 36.6 & 6.7 & 0.0 \\
Fruits $(\%)$ & 59.7 & 35.5 & 4.9 & 0.0 \\
Fruit juice $(\%)$ & 67.1 & 25.9 & 4.9 & 1.8 \\
\hline
\end{tabular}

Assessed with a food-frequency questionnaire in 1611 women.

\section{Table 4}

Percentiles of plasma concentrations of vitamin $C$ and carotenoids ( $\mu$ mol/L) in 161 women

\begin{tabular}{lccccc}
\hline & P10 & P25 & P50 & P75 & P90 \\
\hline Vitamin C & 39.93 & 47.89 & 56.24 & 65.64 & 72.65 \\
Total carotenoids & 1.24 & 1.49 & 1.90 & 2.20 & 2.94 \\
Lutein & 0.24 & 0.29 & 0.38 & 0.48 & 0.61 \\
B-cryptoxanthin & 0.30 & 0.39 & 0.51 & 0.71 & 1.04 \\
Lycopene & 0.14 & 0.22 & 0.26 & 0.36 & 0.43 \\
d-carotene & 0.06 & 0.09 & 0.13 & 0.19 & 0.24 \\
B-carotene & 0.21 & 0.29 & 0.45 & 0.65 & 1.02 \\
\hline
\end{tabular}

" P10 to P90 are the $10^{\text {th }}$ to the $90^{\text {th }}$ percentiles.

Table 6 shows the relative validity of the estimated consumption of cabbage, carrots and citrus fruits when a correction factor was used or not. For carrots, correlations with $\alpha$ - and $\beta$-carotene were significantly higher when consumption was not corrected for overreporting; this was also the case for a-carotene and consumption of total cabbage. However, there were no differences in correlations with biomarkers between corrected and uncorrected consumption of broccoli/cauliflower and Brussels sprouts, two specific sorts of cabbage. The correlation between consumption of citrus fruits and its most important marker, $\beta$ cryptoxanthin, did not change when consumption was corrected for overreporting.

\section{Discussion}

The present study indicates that, based on biomarkers as a reference for validation of an FFQ, estimates of consumption of vegetables based on one summary question ("summary estimate') are better able to rank persons according to their fruit and vegetable intake than estimates obtained by summing all separate items across each category ('sum estimate'). Our data suggest that this applies to both raw and, even more $\mathrm{SO}_{3}$ cooked vegetables. For firuits, the correlations with biomarkers for summary and sum estimates are comparable. Furthermore, when intake of individual fruits and vegetables is estimated in an FFQ, correction for overreporting seems unnecessary or may even lower correlations with biomarkers. 


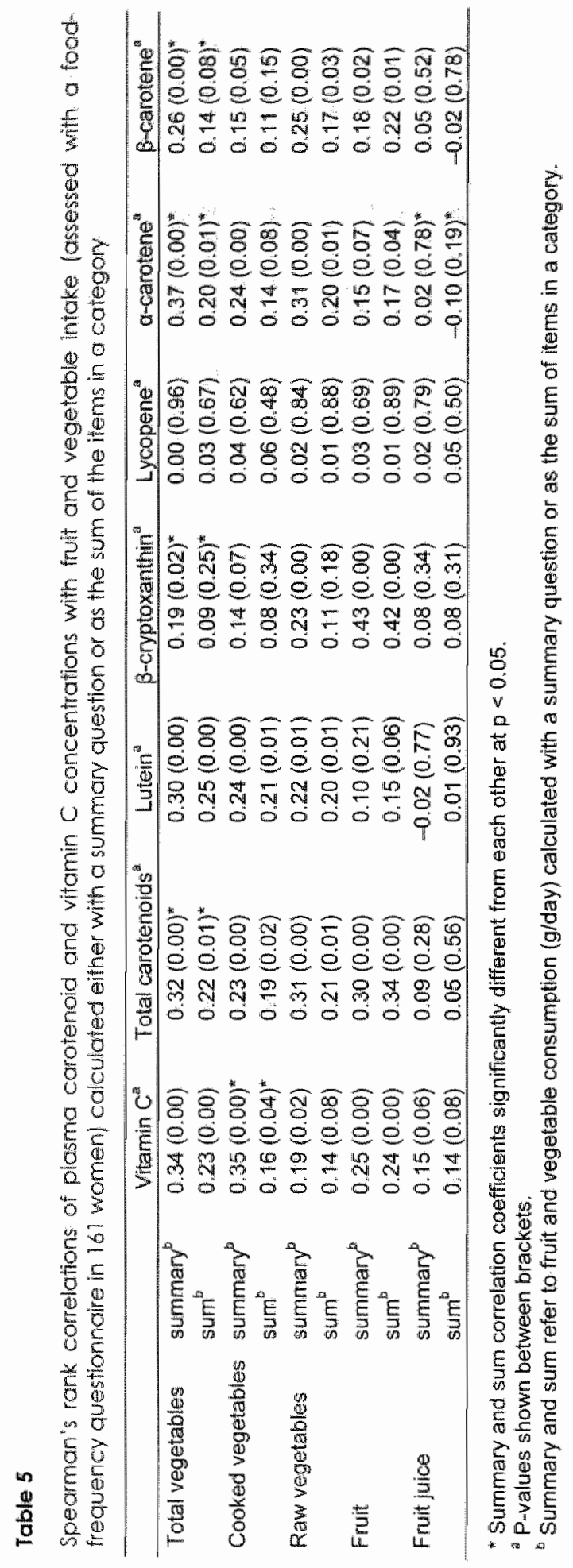




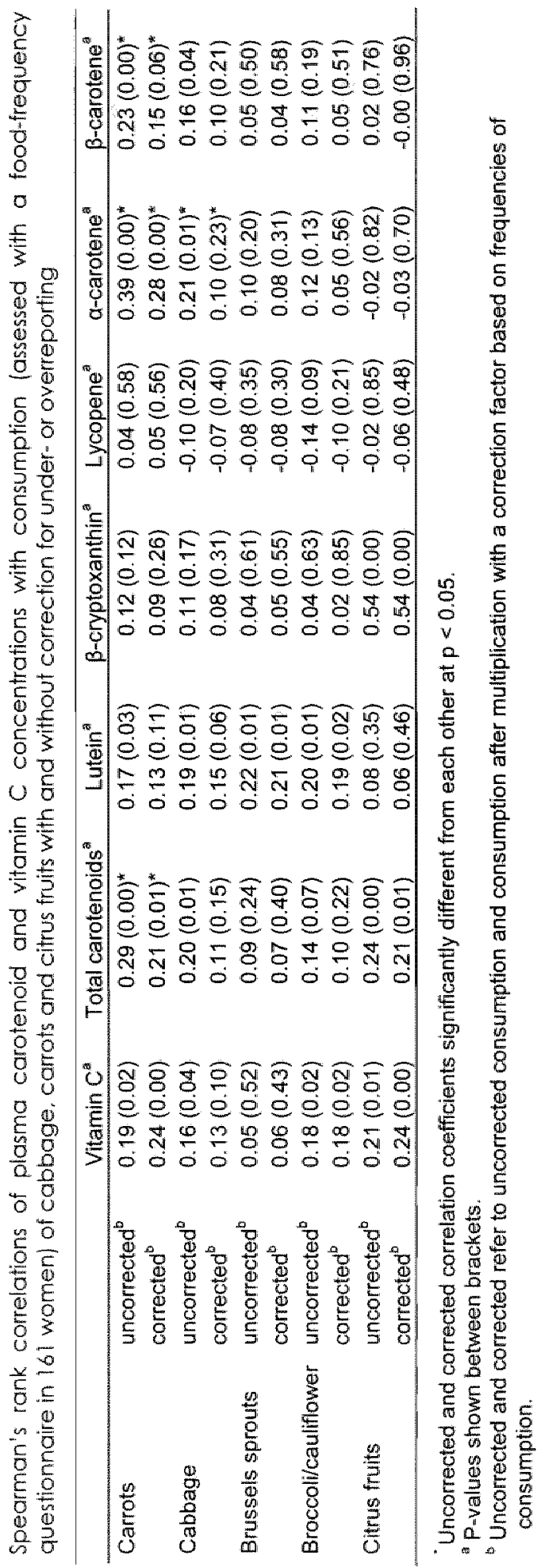


Several possible explanations can be given as to why the summary estimate is as valid as the sum estimate for fruits, whereas this is not the case for vegetables. First, for fruits portion size is easier to indicate because, contrary to vegetables, fruits are mostly served in natural units. Second, it may be easier for subjects to estimate consumption frequencies of specific fruits because the number of different sorts of fruits eaten is usually smaller than the number of different vegetables (31). However the mean correction factor (based on frequencies) for fruits was close to 0.5 , suggesting a high degree of overestimating the frequency of consumption of individual fruits relative to the summary frequency. Rather than overestimating the frequency of consumption of individual sorts of fruits, this could be attributed to the fact that people eat more than one sort of fruit a day. The finding that the sum amount was only $25 \%$ higher than the summary amount supports this idea. In contrast, the mean correction factor was closest to unity for cooked vegetables, although consumption of cooked vegetables expressed in g/day showed the largest difference between summary and sum estimates. This was the result of the great between-subject variation in the correction factor for cooked vegetables, where not, contrary to fruits, almost every subject reported a higher sum than summary frequency.

The observation that correction for overreporting may not improve or even lower correlations with biomarkers may be attributable to the fact that the correction factor includes estimate errors of all separate items. The sum of these errors may likely be higher than the estimate error of a single item, which would reduce the validity of an estimate of a specific fruit or vegetable when correction for overreporting is applied. As already mentioned, the consumption frequency of fruits may be easier to estimate and as a result the error of the correction factor for fruits would probably be less than that of vegetables.

We used biomarkers as a reference method because the errors in biomarkers (e.g. biological variation between persons in uptake or metabolism of vitamins) are to a high degree statistically independent of the errors in intake estimates based on questionnaires. Although the correlations we observed are moderate, the use of biomarkers for our purpose can be justified. Since the variation in our criterion measure (the biomarkers) remains the same when we calculate correlations with either of the two dietary measures, differences between the two correlation coefficients (biomarkers vs. summary/sum amounts or biomarkers vs. corrected/uncorrected estimates of fruit and vegetable consumption) are only a result of the ability of the summary or sum questions to discriminate between persons. However, it should be noted that the biomarkers we used only allow testing whether a questionnaire is suitable for ranking persons according to their fruit and vegetable consumption because these biomarkers are not a measure of absolute intake. For the latter purpose comparison of our results with food records or diaries may be helpful. Our finding of lower summary than sum amounts is in line with food consumption studies in which fruit and vegetable intake measured by short frequency-based screening modules was compared with intake as determined by 3 -day diet records $(45,46)$, repeated 24 -h recalls $(46,47)$, or a more extensive FFQ (48). All these studies showed that the short instruments underestimated fruit and vegetable consumption relative to the reference methods used.

in contrast, screening modules gave slightly better (45) or similar (47) correlations with dietary records or recalls in comparison with an extensive FFQ, indicating that they were able to rank people according to their fruit and vegetable intake. However, because of correlated errors in the screener and reference method these correlations could be overestimated (49). We are aware of only one study in which summary and sum measures of fruit and vegetable consumption were compared with plasma carotenoids. Contrary to our findingls, no substantial differences in correlations between the two measures of consumption were found (46). The different results may either be due to the lower mean fruit and vegetable consumption in their population (50), or to the smaller number of items these authors used for calculating sum amounts which could lead to a sum estimate closer to the summary estimate (51).

The correlations we found between fruit and vegetable consumption and biomarkers were moderate, but comparable to those from several other studies in which fruit and 
vegetable intake was related to plasma carotenoids and/or vitamin $C$. Correlations observod in these studies were approximately between 0.2 and 0.5 , with the exception of llycopene, for which much lower correlations were found $(24-28)$, as we did. A strong point of our study is that the results are not biased by the effect of smoking, nor by the use of vitamin supplements on concentrations of carotenoids and vitamin $C$ in blood, given that all participants were nonsmokers who agreed not to use vitamin supplements. We are aware of the fact that plasma concentrations of carotenoids and vitamin $C$ vary over time $(20,27)$, and that a single measurement may not represent the one-month average. Repeated blood measurements could have increased the correlations we found between fruit and vegetable intake and biomarkers, but we expected this increase would be minor because of the short study period of one month.

Although in literature correlation coefficients are reported with $(25,26,52)$ or without (52-54) adjustment for blood cholesterol levels, we decided not to include this adjustment because these studies showed that correlations between plasma or serum carotenoids and fruit and vegetable or carotenoid intake changed only marginally after adjusting for cholesteroll $(25,26,52-54)$. It is also possible that adjustment for energy intake would yield different correlation coefficients. Because we wanted to assess fruit and vegetable intake elaboraltely. we made the concession not to determine energy intake because this would have resulted in a far more extended questionnaire, increasing the risk that participants would complete it less accurately.

Before generallising the results of the present study, attention should be paid to the high degree of selective participation by subjects who were probably interested in healthy eating. How exactly this has affected our findings is difficult to say. On the one hand, our study population could have completed the questionnaire more carefully than would have been the case for the general population. On the other hand, it is also possible that our study population, being more aware of the healthy properties of fruit and vegetables than the average Dutch population, would be biased toward overreporting their fruit and vegetable intake. In addition, studying a more representative population could also have increased the observed correlation coefficients as a result of the greater range in fruit and vegetable intake we would have measured.

In conclusion, for the purpose of ranking people according to their intake of main groups of fruit and vegetables, it would appear that a small number of brief, general questions on fruit and vegetable intake suffice. This has important implications in the design of $F F Q$ for use in studies related to health education, where total fruit and vegetable consumption is of interest. For epidemiological studies on the relation between single food items and disease or prognosis, correcting individual items with a correction factor based on frequencies does not seem to be advisable, given that this is likely to decrease rather than enhance the ability of an FFQ to rank individuals according to their intake of these items. In view of our specific study population, these findings need confirmation in future studies using more representative populations.

\section{References}

1. Steinmetz KA and Potter JD (1996): Vegetables, fruit, and cancer prevention: a review. $J$ Am Diet Assoc 96, 1027-39.

2. Gandini $S$, Merzenich H, Robertson C and Boyle P (2000): Meta-analysis of studies on breast cancer risk and diet: the role of fruit and vegetable consumption and the intake off associated micronutrients. Eur J Cancer 36, 636-46.

3. Voorrips LE, Goldbohm RA, Verhoeven DT, van Poppel GA, Sturmans F, Hermus RJ and van den Brandt PA (2000): Vegetable and fruit consumption and lung cancer risk 
in the Netherlands Cohort Study on diet and cancer. Cancer Causes Control 11, 10115.

4. Slattery ML, Benson J, Curtin K, Ma KN, Schaeffer D and Potter JD (2000); Carotenoids and colon cancer. Am J Clin Nutr 71, 575-82.

5. Ness AR and Powles JW (1997): Fruit and vegetables, and cardiovascular disease: a review. Int $J$ Epidemiol 26, 1-13.

6. Law MR and Morris $J K$ (1998): By how much does fruit and vegetable consumption reduce the risk of ischaemic heart disease? Eur $J$ Clin Nutr 52, 549-56.

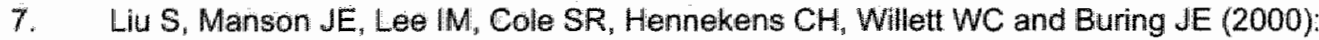
Fruit and vegetable intake and risk of cardiovascular disease: the Women's Health Study. Am J Clin Nutr 72, 922-8.

8. Haralds dottir $\mathrm{J}$ (1993): Minimizing error in the field: quality control in dietary surveys. Eur J Clin Nutr 47(suppl), S19-\$24.

9. Amanatidis S, Mackerras D and Simpson JM (2001): Comparison of two frequency questionnaires for quantifying fruit and vegetable intake. Public Health Nutr 4, 233-9.

10. Tjonneland A, Overvad $K$, Haraldsdottir J, Bang $S$, Ewertz M and Jensen OM (1991): Validation of a semiquantitative food frequency questionnaire developed in Denmark. Int a Epidemiol 20, 906-12.

11. Frongillo EA, Jr. (1999): Validation of measures of food insecurity and hunger. J Nutr $129,506 \mathrm{~s}-509 \mathrm{~s}$.

12. Willett $W$ and Lenart $E$. Reproducibility and validity of food-frequency questionnaires (1998). in Nutritional Epidemiology (ed. Willett W). New York: Oxford University Press.

13. Hunter D. Biochemical indicators of dietary intake (1998). in Nutritional Epidemiology (ed. Willett W). New York: Oxford University Press.

14. van "t Veer P, Kardinaal AF, Bausch Goldbohm RA and Kok FJ (1993): Biomarkers for validation. Eur I Clin Nutr 47(suppl 2), \$58-63.

15. Le Marchand L, Hankin JH, Carter FS, Essling C, Luffey D, Franke AA, Wilkens LR, Cooney RV and Kolonel LN (1994): A pilot study on the use of plasma carotenoids and ascorbic acid as markers of compliance to a high fruit and vegetable dietary intervention. Cancer Epidemiol Biomarkers Prev 3, 245-51.

16. McEligot AJ, Rock CL, Flatt SW, Newman V, Faerber S and Pierce JP (1999): Plasma carotenoids are biomarkers of long-term high vegetable intake in women with breast cancer. J Nutr 129, 2258-63.

17. Maskarinec G, Chan CLY, Meng LX, Franke AA and Cooney RV (1999): Exploring the feasibility and effects of a high-fruit and-vegetable diet in healthy women. Cancer Epidomiol Biomarkers Prev 8, 919-24.

18. Broekmans WM. Klopping Ketelaars IA, Schuurman $C R$, Verhagen $H$, van den Berg $H$, Kok FJ and van Poppel G (2000): Fruits and vegetables increase plasma carotenoids and vitamins and decrease homocysteine in humans. J Nutr 130, 1578-83.

19. Yong LC, Forman MR, Beecher GR, Graubard BI, Campbell WS, Reichman ME, Taylor PR, Lanza E, Holden JM and Judd JT (1994): Rellationship between dietary intake and plasma concentrations of carotenoids in premenopausal women: application of the USDA-NCl carotenoid food-composition database. Am J Chin Nutr $60,223-30$.

20. Cooney RV, Franke AA, Hankin JH, Custer LJ Wilkens LR, Harwood P.J and Le Marchand L (1995): Seasonal variations in plasma micronutrients and antioxidants. Cancer Epidemiol Biomarkers Prev 4, 207-15.

21. Scott KJ, Thumham DI, Hart DJ, Bingham SA and Day K (1996): The correlation between the intake of lutein, lycopene and beta-carotene from vegetables and fruits. and blood plasma concentrations in a group of women aged $50-65$ years in the UK. $\mathrm{Br}$ J Nutr 75, 409-18. 
22. Ritenbaugh $C_{\text {, }}$ Peng $Y$ M, Aickin $M$, Graver $E$, Branch $M$ and Alberts DS (1996) New carotenoid values for foods improve relationship of food frequency questionnaire intake estimates to plasma values. Cancer Epidemiol Biomarkers Prev 5, 907-12.

23. Michaud DS, Giovannucci EL, Ascherio A, Rimm EB, Foman MR, Sampson L and Willett WC (1998): Associations of plasma carotenoid concentrations and dietary intake of specific carotenoids in samples of two prospective cohort studies using a new carotenoid database. Cancer Epidemiol Biomarkers Prev 7, 283-90.

24. Tucker KL, Chen H, Vogel S, Wilson PW, Schaefer EJ and Lammi Keefe CJ (1999): Carotenoid intakes, assessed by dietary questionnaire, are associated with plasma carotenoid concentrations in an elderly population. J Nutr $129,438-45$.

25. Campbell DR, Gross MD, Martini MC, Grandits GA, Slavin JL and Potter JD (1994): Plasma carotenoids as biomarkers of vegetable and fruit intake. Cancer Epidemiol Biomarkers Prev 3, 493-500.

26. Drewnowski A, Rock CL, Henderson SA, Shore AB, Fischler C, Galan P, Preziosi P and Hercberg $S$ (1997): Serum beta-carotene and vitamin $C$ as biomarkers of vegetable and fruit intakes in a community-based sample of French adults. Am J Clin Nutr 65, 1796-802.

27. van Kappel AL, Steghens JP, Zeleniuch Jacquotte A, Chajes V. Toniolo P and Riboli E (2001): Serum carotenoids as biomarkers of fruit and vegetable consumption in the New York Women's Health Study. Public Health Nutr 4, 829-35.

28. Block $G$, Norkus $E_{n}$ Hudes $M$, Mandel $S$ and Helzlsouer $K(2001)$ : Which plasma antioxidants are most related to fruit and vegetable consumption? Am J Epidemiol 154, 1113-8.

29. Mckeown NM, Day NE, Welch AA, Runswick SA, Luben RN "Mulligan AA, McTaggart A and Bingham SA (2001): Use of biologicall markers to validate self-reported dietary intake in a random sample of the European Prospective Investigation into Cancer United Kingdom Norfolk cohort. Am J Clin Nutr 74, 188-96.

30. van Dooren-Flipsen MMH and van Klaveren JD (1999): Evaluatie voedselconsumptiegegevens verzameld met de ANI- en VEG-voedselfrequentievragenlijst. Wageningen: DLO-State Institute for Quality Control of Agricultural Products (RIKILT-DLO).

31. Hulshof KFAM, Kistemaker $C$ and Bouman M (1998): The consumption of food groups by Dutch population groups: food consumption survey 1997-1998 (in Dutch). Zeist: TNO Nutrition and Food Research.

32. Kardinaal AFM, van 't Veer P, Brants HAM, Kruijssen HACM, Hermus RJJ and Kok FJ (1995): Comparison of biomarkers and dietary intake of antioxidants in relation to. myocardial infarction. Nutr Metab Cardiovasc Dis 5, 225-230.

33. Brants HAM, Brug H, van Erp-Baart $M$ and Kistemaker $C$ (1991): Ontwikkeling wan een schriftelijke vragenlijst naar de vitamine B-6-inneming van Nederlandse volwassenen (Voedingspeiling 1990/92) (in Dutch). Zeist: TNO Nutrition and Food Research.

34. Goldbohm RA, van den Brandt PA, Brants HA, van't Veer P, Al M, Sturmans F and Hermus RJ (1994): Validation of a dietary questionnaire used in a large-scalle prospective cohort study on diet and cancer. Eur J Clin Nutr 48, 253-65.

35. Goldbohm RA, van 't Veer $P$, van den Brandt $P A$, van 't Hof MA, Brants HA, Sturmans $F$ and Hermus RJ (1995): Reproducibility of a food frequency questionnaire and stability of dietary habits determined from five annually repeated measurements. Eur J Clin Nutr 49, 420-9.

36. Ocke MC, Bueno de Mesquita HB, Goddijn HE, Jansen A, Pols MA, van Staveren WA and Kromhout D (1997): The Dutch EPIC food frequency questionnaire. I. Description of the questionnaire, and relative validity and reproducibility for food groups. Int $J$ Epidemiol 26(suppl 1), S37-S48.

37. Ocke MC, Bueno de Mesquita HB, Pols MA, Smit HA, van Staveren WA and Kromhout $D$ (1997): The Dutch EPIC food frequency questionnaire. II. Relative validity and reproducibility for nutrients. Int J Epidemiol 26(suppl 1), $\$ 49-\$ 58$. 
38. Speek AJ, Schrijver $\rfloor$ and Schreurs WH (1984): Fluorometric determination of total vitamin $C$ in wholle blood by high-performance liquid chromatography with pre-column derivatization. J Chromatogr 305,53-60.

39. Hess D, Keller HE, Oberlin B, Bonfanti R and Schuep W (1991): Simultaneous determination of retinol, tocopherols, carotenes and lycopene in plasma by means of high-performance liquid chromatography on reversed phase. Int $I$ Vitam Nutr Res 61. $232-8$.

40. Oostenbrug GS, Mensink RP, Hardeman MR, De Vries T, Brouns F and Hornstra $G$ (1997): Exercise performance, red blood cell deformability, and lipid peroxidation: effects of fish oil and vitamin E. J Appl Physiol 83, 746-52.

41. Hulshof KFAM Van der Heijden LJM and Donders-Engelen M (1992): Maten, gewichten en cadenummers 1992. Zeist: TNO Nutrition and Food Research.

42. Donders-Engelen MR, Van der Heijden L and Hulshof KFAM (1997): Measures, weights and code numbers 1997 (in Dutch). Wageningen: Department of Human Nutrition, Wageningen Agricultural University, Wageningen \& Zeist: TNO Nutrition and Food Research.

43. Olkin I and Siotani M (1964): Asymptotic distribution functions of a correlation matrix. Stanford, CA: Stanford University Laboratory for Quantitative Research in Education.

44. Olkin I (1967). Correlation revisited. In Improving experimental design and statistical analysis (ed. Stanley JC). Chicago: Rand McNally.

45. Smith Warner SA, Elmer PJ, Fosdick L. Tharp TM and Randall B (1997): Reliability and comparability of three dietary assessment methods for estimating fruit and vegetable intakes. Epidemiology 8, 196-201.

46. Kristal AR, Vizenor NC, Patterson RE, Neuhouser ML, Shattuck AL and McLerran D (2000): Precision and bias of food frequency-based measures of fruit and vegetable intakes. Cancer Epidemiol Biomarkers Prev 9, 939-44.

47. Field AE, Colditz GA, Fox MK, Byers T, Serdula M, Bosich RJ and Peterson KE (1998): Comparison of 4 questionnaires for assessment of fruit and vegetable intake. Am $J$ Public Health 88, 1216-8.

48. Thompson FE, Kipnis V, Subar AF, Krebs Smith SM, Kahle LL, Midthune D, Potischman $N$ and Schatzkin A (2000): Evaluation of 2 brief instruments and a foodfrequency questionnaire to estimate daily number of servings of fruit and vegetables. Am J Clin Nutr 71, 1503-10.

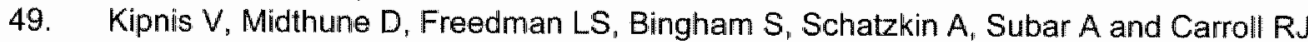
(2001): Empirical evidence of correlated biases in dietary assessment instruments and its implications. Am J Epidemiol 153, 394-403.

50. Kristal AR, Patterson RE, Neuhouser ML, Thornquist M, Neumark Sztainer D, Rock CL, Berlin MC, Cheskin L and Schreiner PJ (1998): Olestra Postmarketing Surveillance Study: design and baseline results from the sentinel site. I Am Diet Assoc $98,1290-6$.

51. Krebs Smith SM, Heimendinger J, Subar AF. Patterson BH and Pivonka E (1995): Using food frequency questionnaires to estimate fruit and vegetable intake: association between the number of questions and total intakes. J Nutr Educ 27, 80-85.

52. Forman MR, Lanza E, Yong LC, Holden JM, Graubard BI, Beecher GR, Meltiz M, Brown ED and Smith JC (1993): The correlation between two dietary assessments of carotenoid intake and plasma carotenoid concentrations: application of a carotenoid food-composition database. Am J Clin Nutr 58, 519-24.

53. Martini MC, Campbell DR, Gross MD, Grandits GA, Potter JD and Slavin JL (1995): Plasma carotenoids as biomarkers of vegetable intake: the University of Minnesota Cancer Prevention Research Unit Feeding Studies. Cancer Epidemiol Biomarkers Prev 4 " $491-6$. 
54. Kardinaal AF, van "t Veer $P$, Brants HA, van den Berg $H$, van Schoonhoven $J$ and Hermus RJ (1995): Relations between antioxidant vitamins in adipose tissue, plasma, and diet. Am J Epidemiol 141,440-50. 

Reproducibility, validity and responsiveness to change of a short questionnaire for measuring intake of fruits and vegetables

Rik P Bogers

Patricia van Assema

Arnold DM Kester

Klaas R Westerterp

Pieter C Dagnelie 


\section{Abstract}

The reproducibility, relaitive validity and responsiveness to change of an eight-item food-frequency questionnaire for measuring consumption of fruit and vegetables was assessed in 157 women (mean age 41 years) in the Netherlands from spring 2001 to spring 2002. Plasma concentrations of vitamin $C$ and total and specific carotenoids served as biomarkers against which validity was assessed. The questionnaire was completed and biomarker concentrations were determined three times: immediately preceding and following a controlled intervention of 1 month aimed at increasing fruit and vegetable consumption, and 1 year after the start of the intervention. The 1-month and 1-year reproducibility of total fruit and vegetable consumption assessed in the control group was 0.80 and 0.79 (Spearman's $r$ ). Correlations between consumption and plasma carotenoids and vitamin $\mathrm{C}$ at baseline were 0.39 and 0.37 , respectively, for fruits and 0.24 and 0.26 , respectively, for vegetables. Correlations between changes in consumption and plasma carotenoids/vitamin $\mathrm{C}$ were $0.32 / 0.33$ for fruits and $0.28 / 0.30$ for vegetables. On the basis of similar correlations reported in the literature, the authors conclude that the questionnaire appears to be suitable for ranking individuals according to their consumption of fruits and vegetables and according to changes in their consumption. However, the validity of the questionnaire remains to be established in males, other age groups, and populations of lower educational levels. 


\section{Introduction}

Many observational studies in humans suggest that consumption of fruit and vegetables is beneficial for the prevention of cancer $(1-4)$ and cardiovascular disease (5 8$)$. On the basis of these findings, public health authorities in several countries have defined recommendied intake levels of these foods. Dutch authorities have recommended intake levels of $200 \mathrm{~g}$ of vegetables and two pieces (approximately $250 \mathrm{~g}$ ) of fruit a clay $(9,10)$. Similar amounts are recommended in other Western countries (11). Since many consumers do not meet these recommendations (12), fruit and vegetable promotion programmes have been launched in order to increase consumption of these foods (13).

Evaluating the effectiveness of these health promotion interventions requires a measuring instrument that is able to determine changes in fruit and vegetable consumption (14). Such an instrument must be short and simple to minimise the participants' efforts and time and thereby maximise participation rates, and to minimise the intervention effect that might emanate from using intensive research methods for assessing dietary intake. For this reason, we decided to develop and validate a concise food-frequency questionnaire (FFQ), a self-administered instrument for estimating habitual intake of fruits and vegetables.

Validation of FFQs can be done in various ways; comparisons with diet records or recalls have most frequently been reported (15). Another method is to compare the results of an FFQ with biochemical markers of dietary intake. The advantage of using biomarkers is that they provide an objective measure of intake whose measurement errors are essentially independent of the errors associated with FFQs (i.e., systematic overestimation or underestimation of consumption frequency or portion size of certain foods) (16). Therefore, correlations between fruit and vegetable consumption determined with a dietary assessment method such as an FFQ, and biomarkers are not artificially inflated as a result of correlated errors in both methods, which can be the case when two similar methodis are compared. Hence, in the present study, we used biomarkers as a method for validation instead of another method based on self-report, such as 24 -h recalls. Frequently used biomarkers for fruit and vegetable intake are levels of carotenoids and vitamin $C$ in blood. A number of studies have shown that blood levels of carotenoids $(17-21)$ and vitamin $C(19,21)$ are correlated with fruit and vegetable intake. Moreover, these biomarkers have been shown to be responsive to changes in fruit and vegetable consumption (22-27). However, correlations between fruit and vegetable intake and concentrations of the above biomarkers are modest, because the biomarkers are also influenced by physiologic factors such as absorption and metabolism.

Short (fewer than 15 items) FFQs designed to assess fruit and vegetable consumption have been used and validated in previous studies. (28-34). However, all of these studies had a cross-sectional design, and only one (33) used biomarkers as an independent reference method. Our study, in contrast, determined fruit and vegetable consumption and plasma concentrations of vitamin $\mathrm{C}$ and carotenoids before and after an intervention aimed at increasing fruit and vegetable consumption. This was done among mothers with primary school-age children, a large population group in the Netherlands. We wanted to validate the FFQ for its ability to rank people according to their usual fruit and vegetable intake and according to changes in their fruit and vegetable intake-that is, to explore relationships between FFQ estimates and biomarker estimates both cross-sectionally and longitudinally. 


\section{Methods}

\section{Study population}

From the population registry of the municipality of Maastricht, we abtained a random sample containing 2,000 addresses of mothers with children aged 7-10 years. A letter was sent inviting the mother and the selected child in each family to participate. An additional 1,100 letter's were distributed via elementary schools in Maastricht. The women had to be apparently healthy nonsmokers who agreed not to use vitamin supplements from 1 month before the first blood collection to the end of the study period. The letter explained that the study's purposes were to develop questionnaires assessing fruit and vegetable intake and to assess determinants of fruit and vegetable consumption (the latter in another part of the project not described here). A total of 207 volunteers were recruited (a 6.7 percent response rate). Data presented in this report concern only the mothers.

\section{Study design}

Approval for the present study was obtained from the medical ethics committee of Maastricht University. The study design is shown in figure 1. In February $2001\left(t_{0}\right)$, an initial FFQ accompanied by some questions on background characteristics (including age, marital status and educational level) was sent to the participants, who returned it by mail. After one month $\left(t_{1}\right)$, this FFQ was sent out again and the participants were asked to complete the FFQ on the day or evening before they came to the study centre to undergo blood sampling for determination of biomarkers. Participants handed in the questionnaire, and a venous blood sample was drawn during the morning. Subsequently, after prestratification on fruit and vegetable intake at to (above or below the median) to minimise initial differences in fruit and vegetable intake, participants were randomly allocated to either a 1-month dietary intervention aimed at increasing their fruit and vegetable consumption or no intervention (the control group). All measurements were repeated immediately after the intervention $\left(t_{2}\right)$ as well as 1 year after the baseline measurements $\left(t_{3}\right)$. Body mass index was calculated as weight $(\mathrm{kg}) /$ height $(\mathrm{m})^{2}$, determined at the study centre.

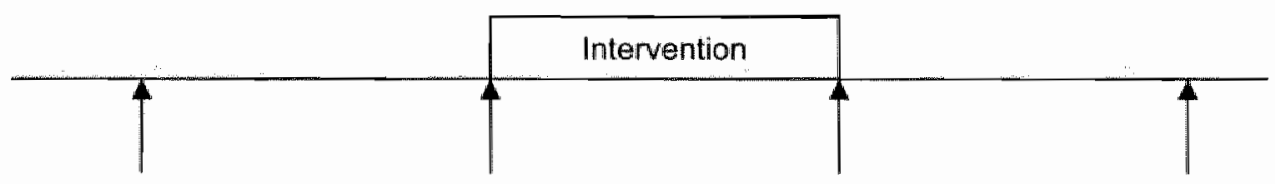

February $2001\left(t_{0}\right)$ : -initial FFQ*

\author{
March $2001\left(t_{1}\right):$ \\ -2nd FFQ \\ -biomarkers
}

April $2001\left(t_{2}\right)$ :

-3rd FFQ

-biomarkers
March $2002\left(t_{3}\right)$ : -4th FFQ

Figure 1. Study design, Maastricht, the Netheriands, 2001-2002

"FFQ, food-frequency questionnaire

Food-frequency questionnaire

The FFQ (figure 2) was based on the FFQ originally described by Van Assema et al. (35). It had a reference period of 1 month and included types or categories of fruits and vegetables consumed most frequently in the Netherlands (36). Potatoes were not explicitly excluded from the category cooked vegetables, because potatoes are considered a staple 
food (not a vegletable) in the Netherlands. Participants were asked to indicate their usual portion size for each category of fruits and vegetables in open-ended questions on number of serving spoons (one serving spoonful $=50-60 \mathrm{~g}$ ), pleces, or glasses (see figure 2). However; the $F F Q$ in figure 2 is shown with close-ended questions for portion size, which makes it possible to read the questionnaire with an optical scanner. We were able to compare portion sizes of cooked vegetables, bananas and tangerines when either open-ended questions or categories were used, and we found that mean portion size did not differ significantly between the two methods (mean portion size in servings for categories and open ended questions, respectively, were 3.0 (standard deviation (SD), 0.8 ) and $3.0(S D, 1.0)$ for cooked vegetables, $0.8(S D, 0.4)$ and $0.8(S D, 0.4)$ for bananas and $0.3(S D, 0.4)$ and $0.4(S D, 0.5)$ for tangerines). Spearman's rank correlation coefficients for correlations between the portion sizes calculated with either method were 0.72 (cooked vegetables), 0.78 (bananas) and 0.80 (tangerines).

Population mean values were substituted for missing values on portion size for any particular item (1.3 percent of all items at $t_{1} t_{2}$ and $t_{3}$ ). Consumption, in servings per day, was calculated by multiplying consumption frequency and portion size. One piece of fruit, one glass of juice or one serving spoonful of vegetables was considered one serving. Population mean values for each item were used to replace missing values for fruit and vegetable intake in servings per day $\left(0.3\right.$ percent of all items at $t_{1}, t_{2}$ and $\left.t_{3}\right)$. Consumption of the various items was summed to obtain totall fruit consumption, total vegetable consumption and fruit and vegetable consumption. Citrus fruit consumption was calculated as consumption of tangerines and other citrus fruit. Consumption of fruit and vegetable juice was considered to comprise mainly fruit juice (37) and thus was included in total fruit consumption and fruit and vegetable consumption.

\section{Dietary interwention}

The aim of the intervention was to accomplish an increase in fruit and vegetable consumption that could be achieved by an intensive nutrition promotion campaign. Participants in the dietary intervention group were asked to eat at least $200 \mathrm{~g}$ of fresh vegetables and two pieces of fruit per day (the Dutch recommended intake level for fruits and vegetables) over a period of 1 month. To increase compliance, packets containing sufficient fruits and vegetables to feed the entire family the recommended amounts were delivered weekly to the participants' homes free of charge, together with a regular newsietter and recipes. Women in the control group received neither fruit and vegetable packets nor further information on fruits and vegetables.

\section{Analysis of biomarkers}

The participants were requested to come to the study centre after fasting overnight. Venous blood samples were drawn between 7:00 a.m. and 11:00 a.m. in wo K2 EDTA-coated plastic tubes (Becton Dickinson Vacutainer Systems, Plymouth, United Kingdom) and were immediately placed on ice in the dark. Total ascorbic acid concentration was determined by high performance liquid chromotagraphy with fluorometric detection according to the method developed by Speek et al. (38). Plasma levels of carotenoids ( $\alpha$-carotene, $\beta$-carotene, lutein. $\beta$-cryptoxanthin lycopene) were analysed with high performance liquid chromotagraphy with UV detection according to Hess et al. (39), with modifications described by Oostenbrug et al. (40). A more detailed description is given elsewhere (41). Although a few respondents (two at $t_{1}$, seven at $t_{2}$ and seven at $t_{3}$ ) were not in the fasting state, exclusion of these persons from analysis did not substantially affect the results. 


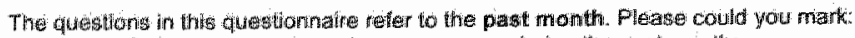

- how of ten you ate wath product on aver age duting the past month:

- how much of a product you took on average on a day when you ale or drank it

Example:

Gwer that you ate baranas on two daws a week during the past mouth, and you look gne banana on such a day, you fill in

\begin{tabular}{|c|c|c|c|c|c|c|c|c|c|c|c|c|c|c|c|}
\hline \multirow[b]{2}{*}{ 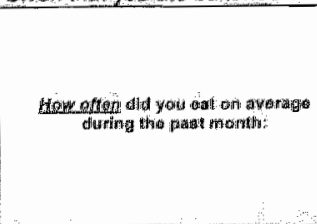 } & & & & & & & & & & \multicolumn{6}{|c|}{ 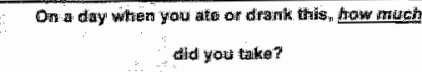 } \\
\hline & 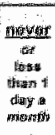 & $\begin{array}{c}1 \cdot 3 \\
\text { ways } \\
\text { month }\end{array}$ & $\begin{array}{c}1 \\
a y \\
a\end{array}$ & $\begin{array}{c}2 \\
2^{2} \\
a\end{array}$ & $\begin{array}{c}y \\
y \\
\text { aty }\end{array}$ & $\begin{array}{c}4 \\
\text { ditays } \\
4\end{array}$ & $\begin{array}{c}5 \\
\text { days } \\
k\end{array}$ & 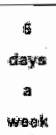 & 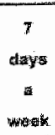 & 1 & 2 & 3 & 4 & $\begin{array}{c}s \\
o n \\
m o s\end{array}$ & \\
\hline Gsomana & $\square$ & $\square$ & $\mathrm{D}$ & (ख) & $\square$ & [1] & $D$ & $\square$ & $\square$ & 四 & $\square$ & $\square$ & a & $\square$ & pieces \\
\hline
\end{tabular}

- If you did not take a product during the past month that case it is not necegsiary to report a portion size.

- In all other cases, piease also mark the amount you eat or drink. Report the amount you yourself eat or drink, and not the amount for the whole farnily.

- Please read carefully every question and choose the answer that suits you best.

\section{Now the questlonthatre begins:}

\begin{tabular}{|c|c|c|c|c|c|c|c|c|c|c|c|c|c|c|c|}
\hline \multirow[b]{2}{*}{ 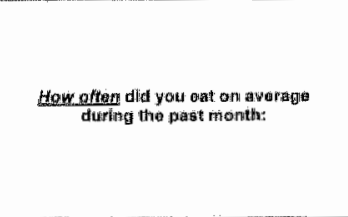 } & & & & & & & & & & \multicolumn{6}{|c|}{ 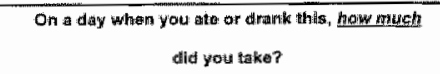 } \\
\hline & 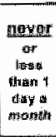 & $\stackrel{1-3}{1-3}$ & thay & $\begin{array}{c}2 \\
\text { days } \\
\text { wealk }\end{array}$ & daybi & $\underset{4}{4}$ & daiys & days: & $\begin{array}{c}7 \\
\text { diays } \\
\text { atomik }\end{array}$ & 1 & 2 & : & 4 & mare & \\
\hline 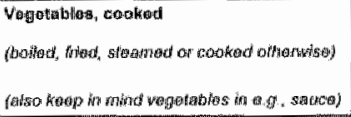 & [] & $D$ & D & $\square$ & $D$ & $D$ & $\square$ & $\square$ & $\square$ & $\square$ & {[]} & $\square$ & $\square$ & $\square$ & $\begin{array}{l}\text { serwing spoone } \\
\gamma=50 \mathrm{gh}\end{array}$ \\
\hline 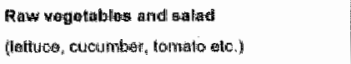 & [] & $\square$ & $\square$ & {$[\square]$} & $\square$ & $\square$ & $\square$ & $\square$ & $\square$ & $\mathrm{a}$ & $\square$ & $\square$ & $\square$ & $m$ & servithy spoons: \\
\hline 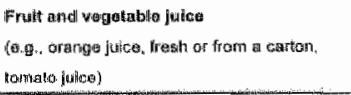 & 口] & $D$ & $\square$ & $\square$ & $\square$ & $\square$ & $\square$ & 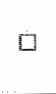 & Da & $\square$ & 때 & $\square$ & $\square$ & $\square$ & glasses \\
\hline Tantigarinit: & $\square$ & $\square$ & $\square$ & $\square$ & $\square$ & 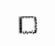 & $m$ & ] & Q & $\square$ & $\square$ & $\square$ & ] & $\square$ & piéecos \\
\hline 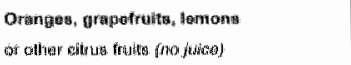 & 17 & $\square$ & 17 & 10 & ¿ & 0 & $\square$ & $\square$ & $\square$ & $\square$ & {[]} & 7 & $\square$ & [D] & pilaces \\
\hline 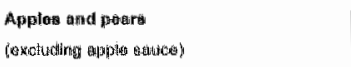 & $\square$ & iti & $\square$ & $\square$ & $\square$ & $\square$ & $\square$ & 7 & $\square$ & Did & $\mathrm{D}$ & $\square$ & $\square$ & $\square$ & pimeor \\
\hline Parranas & $\square$ & $\mathbb{O}$ & m. & $\square$ & $\square$ & $\square$ & $\square$ & 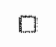 & $\square$ & $\square$ & $\square$ & D & $\square$ & $\mathbb{1}$ & pircess \\
\hline 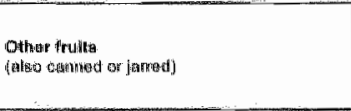 & {[} & $\mathrm{C}$ & $\square$ & {[} & $\square$ & 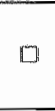 & $\square$ & D & a & 0 & {[} & $\mathbb{1}$ & $\square$ & $\square$ & 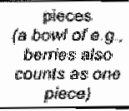 \\
\hline
\end{tabular}

Figure 2. The short foodufrequency questionnaire for assessing fruit and vegetable consumption that was used in the validation study. Maastricht, the Netherlands, 2001-2002 


\section{Data analysis}

Respondents were excluded from further analysis if their FFQs contained more than 20 percent missing values. The data collected at to determine reproducibility were only analysed for control subjects who had less than 20 percent missing values on the $F \mathrm{FQ}$ completed at $t_{3}$ and who had also been included in the analyses at $t_{1}$ and $t_{2}$. Because of the skewed distribution of the dietary intake data, non-parametric statistics were used in the cross-sectional and longitudinal validation analyses. The 1-month and 1-year reproducibility of food items was calculated as Spearman's rank correlation coefficients in control subjects. We calculated agreement in absolute intake by classifying participants according to their fruit and their vegetable consumption in three categories and calculating the percentage agreement in classification between the three measurements. Cutoff points for the categories were 1.5 and 2.5 servings per day for fruits, and 2.5 and 4.0 servings per day for vegetables. These points were chosen to create groups of participants eating approximately the recommended amounts of fruits and vegetables and participants consuming clearly less than or more than this amount.

The effect of the intervention on fruit and vegetable consumption and biomarkers was calculated as the mean change in the intervention group minus the mean change in the control group. The statistical significance of the intervention effects was tested with the MannWhitney $U$ test.

As a measure of validity, Spearman's correlation coefficients between (changes in) dietary intake assessed with the $\mathrm{FFQ}$ and (changes in) plasma carotenoids and vitamin $\mathrm{C}$ were used. Cross-sectionall correlation coefficients were corrected for body mass index. In order to include both participants with clear-cut changes and those with low change or no change in fruit and vegetable consumption, participants from the control group were also included in the longitudinal validation analyses. We verified that intervention and control participants were not essentially different in terms of their plasma response to changes in fruit and vegetable consumption (data not shown). Correlation coefficients were calculated for correlations between biomarkers and total fruit, total vegetable, total fruit and vegetable, and citrus fruit consumption. The latter, more specific correlations were calculated because citrus fruits are known to have an especially high content of vitamin $C$ and $\beta$-cryptoxanthin.

Educational level was classified as low (primary school), middle (high school) or high (polytechnic academy or university). Differences at baseline between the intervention and control group were tested using the chi-squared test for homogeneity (marital status and educational level) or independent samples $t$ test (age and body mass index).

\section{Results}

\section{Participants}

Of the 207 women who agreed to participate, 194 started the study and 191 completed the initial questionnaire ( $t_{0}$; figure 1$)$. The second questionnaire just preceding the intervention was completed by, and a blood sample was obtained from, 174 women (86 participants randomised to the control group and 88 randomised to the intervention group). Immediately after the intervention period ( $t_{2} ;$ figure 1 ), questionnaires and blood sampling were completed by 165 participants ( 77 controls and 88 intervention subjects). Eight respondents were excluded from further analysis because their FFQs contained more than 20 percent missing values (two intervention subjects at $t_{1}$ and two intervention subjects and four control subjects at $t_{2}$ ), leaving a total number of 157 participants. One participant did mot provide enough blood for the analysis of vitamin $C$ at $t_{1}$ and was excluded from the validation analyses with vitamin $C$. The mean age of the 157 women was 41 years (range, 29-50), and 
the mean body mass index was 24.0 (range, 18.7-35.9). Ninety-two percent were married or living with a partner; 45 percent had a high educationall level, 50 percent had an intermediate level and 5 percent had a low level. As expected in a randomised design, the intervention and control groups were similar with regard to those wariables (data not shown). At 1 year of follow-up ( 13 ; figure 1), 149 participants (68 controls and 81 intervention subjects) completed the $\mathrm{FFQ}$ and gave blood. Sixty control subjects had less than 20 percent missing values on the $F F Q$ completed at $t_{3}$ and had also been included in the analyses at $t_{1}$ and $t_{2}$. Reasons for dropping out (after returning the initial questionnaire) were a lack of time or interest $(n=27)$, illiness at the time of blood sampling $(n=6)$, practical reasons (for example, it was not possible to make a suitable appointment for blood collection) $(n=7)$, and personal circumstances or unknown reasons $(n=5)$. Compared with the participants who completed the study, the ones who dropped out were significantly younger (39 years vs. 41 years) and consumed significantly fewer vegetables (2.9 servings per day vs. 3.5 servings per day assessed with the initial FFQ). The 26 controls at $t_{1}$ who did not complete the rest of the study consumed significantly fewer vegetables than the 60 controls who were full participants ( 3.0 servings per day vs. 3.8 servings per day assessed with the initial FFQ).

\section{Table 1}

Fruit and vegetable intakes (serwings/day) of healthy women in March $2001\left(t_{1}\right)$. April 2001 $\left(t_{2}\right)$ and March 2002 ( $\left.t_{3}\right)$ and reproducibility (Spearman's i) of a shorlt food-frequency questionnaire in the control group. Maastricht, the Netherlands

\begin{tabular}{|c|c|c|c|c|c|c|c|c|}
\hline & \multicolumn{2}{|c|}{$t_{1}\left(\right.$ baseline) ${ }^{a}$} & \multicolumn{2}{|c|}{$t_{2}$ (one month) } & \multicolumn{2}{|c|}{4 (one year) $^{b}$} & \multirow[b]{2}{*}{$\begin{array}{c}\text { Correlation } \\
\qquad t_{1^{\prime \prime}} t_{2}\end{array}$} & \multirow[b]{2}{*}{$\begin{array}{c}\text { Correlation } \\
t_{1}-t_{3}\end{array}$} \\
\hline & mean & (SD) & mean & $(\mathrm{SD})$ & mean & (SD) & & \\
\hline Total vegetables & 3.5 & $(1.5)$ & 3.4 & (1.4) & $3.4^{\text {** }}$ & $(1.3)$ & 0.73 & 0.81 \\
\hline Cooked vegetables & 2.3 & $(1.0)$ & 2.2 & $(0.9)$ & $2.3^{*}$ & $(0.9)$ & 0.66 & 0.70 \\
\hline Raw vegetables & 1.2 & $(1.0)$ & 1.2 & $(0.8)$ & 1.1 & $(0.9)$ & 0.78 & 0.77 \\
\hline Total fruits ${ }^{e}$ & 1.8 & $(1.0)$ & $4.7^{*}$ & $(0.9)$ & 1.7 & $(1.0)$ & 0.80 & 0.62 \\
\hline Citrus fruits ${ }^{d}$ & 0.4 & $(0.4)$ & $0.3^{*}$ & $(0.3)$ & 0.4 & $(0.4)$ & 0.81 & 0.58 \\
\hline Applesipears & 0.5 & $(0.5)$ & 0.6 & (0.5) & $0.4^{*}$ & $(0.5)$ & 0.79 & 0.54 \\
\hline Bananas & 0.2 & $(0.2)$ & 0.1 & $(0.2)$ & 0.1 & $(0.1)$ & 0.67 & 0.64 \\
\hline Other fruits & 0.2 & $(0.3)$ & 0.2 & $(0.3)$ & 0.2 & $(0.6)$ & 0.49 & 0.31 \\
\hline $\begin{array}{l}\text { Fruit and vegetable } \\
\text { juice }\end{array}$ & 0.6 & $(0.7)$ & 0.5 & $(0.6)$ & 0.5 & $(0.6)$ & 0.82 & 0.62 \\
\hline $\begin{array}{l}\text { Total fruits and } \\
\text { vegetables }\end{array}$ & 5.4 & $(2.1)$ & $5.1^{*}$ & $(2.0)$ & $5.1^{* *}$ & $(1.9)$ & 0.80 & 0.79 \\
\hline
\end{tabular}

"* "* Significantly different from consumption at $t_{1}$ at " $p<0.05, " p<0.01$ (two-sided; Wilcoxan signed rank test; the comparison between $t_{1}$ and $t_{3}$ is based on 60 participants).

" $n=73$ (only control group).

b $n=60$ (only control group).

"Including fruit juice and vegetable juice.

${ }^{d}$ Excluding juice.

\section{Reproducibility}

Table 1 shows the fruit and vegetable consumption of the controls at $t_{1}, t_{2}$ and $t_{3}$, as well as the reproducibility of the FFQ after 1 month and 1 year. Fruit and vegetable consumption at $t_{2}$ differed from consumption at $t_{1}$ for citrus fruits, total fruits and total fruits and vegetables. Consumption at $t_{3}$ was significantly lower than at $t_{1}$ for total vegetables, cooked vegetables, apples/pears and total fruits and vegetables. Correlation coefficients for correlations between consumption levels measured at $t_{1}$ and $t_{2}$ were $0.66-0.82$, with the 
exception of 'other fruits' $(r=0.49)$. Compared with the 1 -month reproducibility, the 1-year reproducibility was similar for vegetable consumption but lower for fruit consumption.

Table 2 illustrates the reproducibility of the FFQ in terms of absolute agreement between the three measurements. The questionnaire classified $57-74$ percent of the participants in the same category of fruit and vegetable consumption when the $F F Q$ was administered repeatedly. Of the persons who were classified in a different category, most had moved down one category.

\section{Table 2}

Agreement between repeated administrations of a short food-frequency questionnaire after classification of healthy women from the control group $\left[n=73\right.$ at $1, t_{2} ; n=60$ at $4_{3}$ a into three categoriesta according to their fruit and vegetable consumption. Maastricht, the Netherlands, 2001-2002

\begin{tabular}{lcccccc}
\hline & \multicolumn{5}{c}{$\%$ of participants } \\
\cline { 2 - 6 } & Same class & One class up & $\begin{array}{c}\text { One class } \\
\text { down }\end{array}$ & $\begin{array}{l}\text { Two classes } \\
\text { up }\end{array}$ & $\begin{array}{l}\text { Two classes } \\
\text { down }\end{array}$ \\
\cline { 2 - 6 } Vegetables $t_{1}-t_{2}(\%)$ & 59 & 18 & 23 & 0 & 0 \\
Vegetables $t_{1}-t_{3}(\%)$ & 70 & 7 & 23 & 0 & 0 \\
Fruits $t_{1}-t_{2}(\%)$ & 74 & 6 & 18 & 3 & 0 \\
Fruits $t_{1}-t_{3}(\%)$ & 57 & 12 & 28 & 0 & 2 \\
\hline
\end{tabular}

$t_{1}$ : March 2001, $t_{2}$ : April 2001, $t_{3}$ : March 2002,

${ }^{b}$ Class boundaries: for fruits, 1.5 and 2.5 servings/day; for vegetables, 2.5 and 4.0 servings/day. The low: intermediate and high categories at $t_{1}$ included $37 \%, 41 \%$ and $22 \%$ of the participants for fruit consumption and $26 \%, 41 \%$ and $33 \%$ of the participants for vegetable consumption.

"Percentages may not add up to $100 \%$ because of rounding error.

\section{Intervention effects}

Table 3 shows the changes of fruit and vegetable consumption and biomarker concentrations in the intervention group after 1 month of dietary intervention. Mean plasma concentrations in the control group at baseline did not significantly differ from thase in the intervention group. The intervention effect was 1.3 servings per day for vegetables and 1.1 servings per day for fruits. The strongest effects in the categories of fruits and vegetables were observed for citrus fruits and cooked vegetables (data not shown), respectively. Mean plasma vitamin $\mathrm{C}$ and carotenoid concentrations also increased significantly as a result of the intervention. The carotenoid that increased most in concentration was $\beta$-cryptoxanthin.

\section{Relative validity}

Table 4 presents correlations of plasma carotenoid and vitamin $C$ concentrations with fruit and vegetable consumption assessed with the FFQ in the total study population. Although many correlation coefficients reached statistical significance, the degree of correlation was modest $(0-0.57)$. Plasma lycopene concentrations were not correllated with any of the fruit and vegetable categories.

Table 5 shows that in the whole study population, changes in fruit and vegetable consumption were madestly correlated with changes in plasma concentrations of vitamin $C$ and all carotenoids except lycopene. The highest correlation was between changes in citrus fruit consumption and changes in $\beta$-cryptoxanthin $(r=0.46)$. 
Toble 3

Mean frult and vegetable intakes and plasma vitamin $C$ and carotenoid cancentrations in

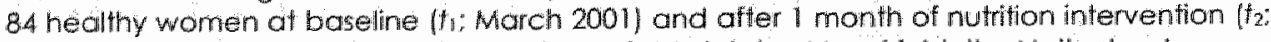
April 2001) aimed at increasing frut and vegetable intake. Madstricht, the Netherlands

\begin{tabular}{|c|c|c|c|c|c|c|}
\hline & \multicolumn{4}{|c|}{ Intake or plasma concentration } & \multicolumn{2}{|c|}{ Intervention effect } \\
\hline & \multicolumn{2}{|c|}{ t (baseline) } & \multicolumn{2}{|c|}{$t_{2}(1$ month $)$} & \multirow[b]{2}{*}{ mean } & \multirow[b]{2}{*}{ (SE) } \\
\hline & mean & $(\mathrm{SD})$ & meain & $(\mathrm{SD})$ & & \\
\hline \multicolumn{7}{|l|}{ Dielary intake (servings/day) } \\
\hline Total vegetables & 3.4 & $(1.7)$ & 4.6 & $(1.4)$ & $1.3^{*}$ & $(0.2)$ \\
\hline Total fruits & 1.9 & (1.1) & 2.9 & (1.2) & $1.1 *$ & $(0.1)$ \\
\hline Citrus fruits" & 0.4 & $(0.5)$ & 0.7 & $(0,6)$ & $0.4^{*}$ & $(0.1)$ \\
\hline Total fruits and vegetables & 5.3 & $(2.3)$ & 7.5 & $(2.0)$ & $2.4^{*}$ & $(0.3)$ \\
\hline \multicolumn{7}{|l|}{ Plasma concentrations (pmo/h) } \\
\hline Vitamin $\mathrm{C}^{3}$ & 55.07 & $(13,90)$ & 61.54 & $(10.68)$ & $10.05^{*}$ & $(1.73)$ \\
\hline Total carotenoids & 2.04 & $(0.81)$ & 2.28 & $(0.91)$ & $0.32^{*}$ & $(0.07)$ \\
\hline a-carotene & 0.18 & $(0.20)$ & 0.19 & $(0.19)$ & $0.03^{*}$ & $(0.01)$ \\
\hline$\beta$-carotene & 0.58 & $(0.48)$ & 0.64 & $(0.44)$ & $0.07 *$ & $(0.03)$ \\
\hline Lutein & 0.39 & $(0.14)$ & 0.48 & $(0.18)$ & $0.09^{*}$ & $(0.02)$ \\
\hline$\beta$-cryptoxanthin & 0.62 & $(0.33)$ & 0.70 & $(0.31)$ & $0.14^{*}$ & $(0.03)$ \\
\hline Lycopene & 0.28 & $(0.11)$ & 0.26 & $(0.11)$ & 0.01 & $(0.02)$ \\
\hline
\end{tabular}

* Intervention effect significantly different from zero al $p<0.01$ (two-sided; Mann-Whitney $U$ test).

"Change in intervention group minus change in control group.

"Including fruit juice and vegetable juice.

${ }^{\circ}$ Excluding juice.

${ }^{d} n=83$.

\section{Discussion}

In the present study, we determined the reproducibility and relative vallidity of a short FFQ designed to measure (changes in) fruit and vegetable intake. After 1 month, the reproducibility of the questionnaire was 0.73 for total vegetable consumption and 0.80 for total truit consumption. After one year, the reproducibility of vegetable consumption was similar $(r=$ 0.81 ). Whereas the reproducibility of fruit consumption was lower than after one month ( $r=$ 0.62 ). With regard to the relative validity of the $F F Q$, positive modest correlations were found between fruit and vegetable consumption and biomarkers and between changes in both measures.

The reproducibility of an FFQ is influenced by properties of the FFQ itself, respondents' memory and actual changes in food intake. Since mean fruit intake did not change from baseline to 1 year after baseline (table 1), it seems likely that individual shifts in fruit consumption would explain the lower reproducibility of fruit consumption 1 year after the first administration of the questionnaire. Alternatively, fruit consumption may be more subject to interindividual variation than vegetable consumption, or respondents may have more difficulties reporting their fruit consumption. 
Table 4

Spearman"s correlation coefficienfs' for comelations between frut and wegetable intake and plasma concentrations of vitamin $C$ and carotenolds determined in March $2001(t)$ in 157 healthy women. Maastricht, the Netherlands

\begin{tabular}{|c|c|c|c|c|c|c|c|}
\hline & Vitamin $C^{b}$ & $\begin{array}{c}\text { Total } \\
\text { carotenoids }\end{array}$ & a-carotene & B-carotene & Lutein & B-oryptoxanthin & Lycopente \\
\hline Total wegetables & $0.26^{* *}$ & $0.24^{\text {kxt }}$ & $0.37^{* *}$ & $0.17 \%$ & $0.26^{*}$ & 0.16 & 0.04 \\
\hline Total fruits: $^{c}$ & $0.37^{* * k}$ & $0.39^{* * k}$ & $0.23^{* *}$ & $0.23^{m * *}$ & 0.13 & $0.42^{* *}$ & -0.00 \\
\hline Cittrus fruits $^{\circledR}$ & $0.32^{* *}$ & $0.27^{* *}$ & 0.06 & 0.04 & 0.03 & $0.57^{2 * *}$ & -0.07 \\
\hline $\begin{array}{l}\text { Total fruits and } \\
\text { vegetables }\end{array}$ & $0.37^{* *}$ & $0.37^{* * *}$ & $0.36^{\text {t* }}$ & $0.23^{* * x}$ & $0.23^{* *}$ & 0.31 ** & 0.02 \\
\hline
\end{tabular}

"p $<0.05 * * p<0.01$ (two-sided).

adjusted for body mass index.

$n=156$.

' Inciuding fruit juice and vegetable juice.

Excluding juice.

Reglarding the validity of the FFQ validating an $F F Q$ as in the present study has both advantages and disadvantages. Measurement errors in FFQ estimates (e.g., overreporting of fruit and vegetable intake) are essentially independent from measurement errors in plasma carotenoid and vitamin $C$ concentrations (caused during collection, processing and analysis of blood samples). This minimises the problem of correlated errors in both methods, which could lead to artificially high correlation coefficients. However, a limitation of using plasma concentration of carotenoids and vitamin $\mathrm{C}$ as biomarkers is that they are influenced not by nutrition alone but also by biological factors such as absorption and metabolism; this causes correlations with fruit and vegetable consumption to be modest (42). Additionally, correlations between FFQ estimates and biomarkers could be confounded by other variables such as plasma cholesterol or body mass index. Adjustment for body mass index was done only in the cross-sectional analyses, because intraindividual changes in biomarkers, used in the longitudinal analyses, are unlikely to be influenced by non-dietary factors. Adjusted correlation coefficients did not differ substantially from unadjusted coefficients (data not shown), indicating that body mass index was not an important confounder. We eliminated the effect of sex, smoking and vitamin supplement use on biomarkers by including in our study only nonsmoking women who did not: use supplements, but we did not control for blood lipid levels, since this has been shown not to substantially alter correlation coefficients between fruit and vegetable intake and blood carotenoids (18-20,43-45). A final limitation in the use of correlation coefficients as a measure of validity is that they can only be interpreted in terms of ranking individulals according to their fruit and vegetable intake, and because of the lack of a 'gold standard' validity of the FFQ in terms of absolute intake cannot be established. This is illustrated by the fact that a substantial part of the participants fell into a different category of absolute intake after the $F F Q$ was administered again after 1 month and 1 year.

Results from a number of previous studies in which FFQs or other instruments to measure fruit and vegetable intake were vallidated have been reported in the literature. An overview was given by Van Assema et al. (35) and Kim and Holowaty (46). To our knowledge, only one study (33) used biomarkers to validate three short FFQs. Therefore, we compare our results mostly with findings from more extensive questionnaires which were used to calculate correlations between fruit and vegetable intake and plasma or serum concentrations of carotenoids and/or vitamin $C(17,18,21,33,47,48)$. Two studies $(18,21)$ found higher correlations between fruit and vegetable consumption and biomarkers. The fact that in both of the above studies participants were selected on the basis of their high or low fruit and vegetable consumption may explain the relatively high correlations seen as compared with 
our study. Correlations similar to or lower than those in the present study were found in four studies $(17,33,47,48)$. Correlations between biomarkers and fruit and vegetable intake measured with dietary histories in which food consumption was recorded in terms of frequencies and quantities $(19,20)$ were similar to the correlations we observed.

\section{Table 5}

Spearman's correlation coefficierits for carrelations between changes in fruit and vegetable intake and changes in plasma concentrations of vitamin $C$ and carotenoids determined between March 2001 ( $f_{1}$ ) and April 200 l $\left[t_{2}\right.$ ) in 157 healthy women, Madstricht, the Netherlands

\begin{tabular}{|c|c|c|c|c|c|c|c|}
\hline & Vitamin $C^{\text {i }}$ & Total car. & a-carotene & $\beta$-carotene & Lutein & $\beta$-cryptoxanthin & Lycopene \\
\hline Totall vegetables & $0.30^{* *}$ & $0.28^{\text {* }}$ & $0.29^{*}$ & $0.20^{\star}$ & $0.28^{* *}$ & $0.29^{* * *}$ & -0.41 \\
\hline Total fruits ${ }^{b}$ & $0.33^{*}$ & $0.32^{\text {nk }}$ & $0.33^{* *}$ & $0.24^{\text {k }}$ & $0.26^{\text {k* }}$ & $0.37^{* *}$ & -0.06 \\
\hline Citrus fruits ${ }^{\circ}$ & $0.30^{\text {** }}$ & $0.32^{\text {n }}$ & $0.21 * *$ & 0.13 & $0.26^{* *}$ & $0.46^{\text {** }}$ & -0.00 \\
\hline $\begin{array}{l}\text { Total fruits and } \\
\text { vegetabless }\end{array}$ & $0.37^{* 2}$ & $0.37^{* *}$ & $0.36^{* *}$ & $0.26^{* *}$ & $0.34^{* * *}$ & $0.39^{* *}$ & -0.08 \\
\hline
\end{tabular}

${ }^{*} p<0.05^{* *} p<0.01$ (two - sided).

$n=156$.

"Including fruit juice and vegetable juice.

${ }^{\circ}$ Excluding juice.

We are aware of only one study that determined the ability of an FFQ to measure changes in food intake (49). This study showed low correlations between changes in intake over a 6-year period as measured with the FFQ and a dietary history $(r=0.22$ and $r=0.12$ for fruits and vegetables, respectively). The few previous studies that related changes in fruit and vegetable consumption to changes in plasma or serum carotenoids or vitamin $C$ all used diet records $(23,24,26)$. Zino et al. (23) found correlations between change in number of servings of fruits and vegetables and change in plasma concentrations of $\alpha$-carotene $(r=0.29)$, $\beta$ carotene $(r=0.09)$ and vitamin $C(r=0.25)$ after 4 weeks of dietary intervention. Maskarinec et al. (26) and Le Marchand et al. (24) found correlations of 0.52 and 0.69 , respectively, between differences in total carotenoids and fruit and vegetable consumption after a 6-month or 3-month intervention period. The latter authors also calculated correlations between changes in total fruit and vegetable intake and plasma concentrations of specific carotenoids and vitamin $\mathrm{C}$ that were generally lower than the correlations we observed, except for lycopene. However, they found reasonably good correlations between some specific (groups of) vegetables and plasma concentrations of specific carotenoids. Differences between correlations found in the above studies and the present study presumably result from differences in intervention effect, study population, time frame and dietary assessment method.

Some of the correlations between changes in fruit and vegetable intake and biomarker concentrations in the present study-for example, between changes in total vegetable consumption and plasma $\beta$-cryptoxanthin concentrations-were unexpected based on the carotenoid contents of the foods. This might have resulted from a concomitant increase in (citrus) fruit consumption with an increase in vegetable consumption after the intervention period.

We did not observe any associations between fruit and vegetable intake and plasma Iycopene concentrations. This lack of association has been found in previous studies $(18,20,33,50)$. A possible explanation may be that major sources of lycopene (including tomatoes, ketchup and pizza) were not asked about separately but either grouped under 'cooked vegetables' and "raw vegetables/salad" or not included in the FFQ. Since tomato consumption assessed with a more elaborate FFQ was not correlated with plasma lycopene concentrations (data not shown), this explanation is not sufficient. Additionally, lycopene may 
possess certain characteristics that make it less sultable as a biomarker for dietary intake, including a relatively low responsiveness of plasma lycopene concentrations to dietary intake (24).

Correlations between biomarkers and fruit and vegetable juice were low (data not shown). Vitamin $C$ and carotenoid content in juice might be lower than in fresh fruit. Alternatively, participants might have wrongly considered certain soft drinks to be fruit juices.

The findings of the present study must be interpreted with caution, because all participants were nonsmoking women with children in the same age group, and only 5 percent had a low educational level. Since the requirements of the study were many, it is likely that most women were highly motivated to participate. Moreover, it tumed out that participants who dropped out of the study before it ended consumed fewer vegetables than participants who fully completed the study. How this selection bias affected the results is unknown, but participants in the present study may have been more aware of their fruit and vegetable consumption andior may have completed the FFQ more accurately than would have been the case in a more representative population; this could have led to higher correlations between FFQ estimates and biomarkers. Generalisation of the findings is further limited by the fact that all measurements in the present study were done in spring. This minimised seasonal influences on biomarkers and fruit and vegetable consumption (and therefore increased the internal validity of our study), but we cannot be sure that the validity and reproducibility of the FFQ in other seasons would be similar to that presented here.

We conclude that the correlations with biomarkers we found are comparable to most correlations found in the studies mentioned above. Thus, our questionnaire appears suitable for ranking individuals according to their fruit and vegetable intake. Our FFQ also seems quite well able to rank persons according to changes in fruit and vegetable intake, but since data from the literature on associations of changes in fruit and vegetable intake with biomarkers are scarce, this is a preliminary conclusion. The reproducibility of the FFQ would appear to be satisfactory, though caution must be taken with regard to its long-term reproducibility for fruit consumption. Since this FFQ is short, cheap and easy to implement, it can be a valuable dietary assessment instrument for epidemiologic studies and for evaluating the effectiveness of fruit and vegetable promotion interventions. However, the relative validity of the $\mathrm{FFQ}$ presented here will have to be extended to males, other age groups and populations of lower educationall levels.

\section{References}

1. Steinmetz KA and Potter JD (1996): Vegetables, fruit, and cancer prevention: a review. $J$ Am Diet Assoc 96, 1027-39.

2. Gandini $S$, Merzenich H, Robertson C and Boyle P (2000): Meta-analysis of studies on breast cancer risk and diet: the role of fruit and vegetable consumption and the intake of associated micronutrients. Eur J Cancer 36, 636-46.

3. Voorrips LE, Goldbohm RA, Verhoeven DT, van Poppell GA, Sturmans F, Hermus RJ and van den Brandt PA (2000): Vegetable and fruit consumption and lung cancer risk in the Netherlands Cohort Study on diet and cancer. Cancer Causes Control 11, 10115.

4. Slattery ML, Benson J, Curtin K, Ma KN, Schaeffer D and Potter JD (2000): Carotenoids and colon cancer. Am J Clin Nutr 71, 575-82.

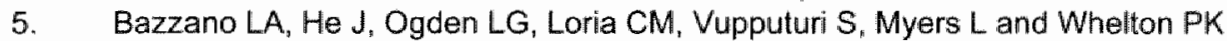
(2002): Fruit and vegetable intake and risk of cardiovascular disease in US adults: the first National Health and Nutrition Examination Survey Epidemiologic Follow-up Study. Am J Clin Nutr 76, 93-9. 
6. Ness AR and Powles JW (1997): Fruit and vegetables, and cardiovascular disease: a review. Int $J$ Epidemiol 26,1-13.

7. Law MR and Morris $\mathrm{JK}$ (1998): By how much does fruit and vegetable consumption reduce the risik of ischaemic heart disease? Eur J Clin Nutr 52, 549-56.

8. Liu S, Manson JE, Lee IM, Cole SR, Hennekens CH, Willett WC and Buring JE (2000): Fruit and vegetable intake and risk of cardiovascular disease: the Women's Health Study. Am J Clin Nutr 72, 922-8.

9. Netherlands Bureau for Food and Nutrition (1992): Practical food stuff guide (in Dutch). The Hague: Voedingscentrum.

10. Commissie Richtiinen Goede Voeding (1986): Guidelines for a healthy diet: recommendations drawn up by the Committee on Guidelines for a Healthy Diet. The Hague: Nutrition Council.

11. Benito $E$ (1992). Overview of dietary recommendations on diet and cancer. in Public education on diet and cancer (eds. Benito E, Giacosa A \& Hill MJ). Dordrecht: Kluwer Academic Publishers.

12. Naska $A$, Vasdekis VG, Trichopoulou $A$, Friel $S$, Leonhauser IU, Moreiras $O$, Nelson M, Remaut AM, Schmitt A, Sekula W, Trygg KU and Zajkas G (2000): Fruit and vegetable availability among ten European countries: how does it compare with the 'five-a-day' recommendation? DAFNE I and II projects of the European Commission. Br J Nutr 84, 549-56.

13. Ammerman AS, Lindquist $\mathrm{CH}$, Lohr $\mathrm{KN}$ and Hersey J (2002): The efficacy of behavioral interventions to modify dietary fat and fruit and vegetable intake: A review of the evidence. Prev Med 35, 25-41.

14. Kristal AR, Beresford SA and Lazovich D (1994): Assessing change in diet-intervention research. Am J Clin Nutr 59, 185s-189s.

15. Willett $W$ and Lenart $E$ (1998). Reproducibility and validity of food-frequency questionnaires. in Nutritional Epidemiology (ed. Willett W). New York: Oxford University Press.

16. van 't Veer P, Kardinaal AF, Bausch Goldbohm RA and Kok FJ (1993): Biomarkers for validation. Eur J Clin Nutr 47(suppl 2), S58-S63.

17. Tucker KL, Chen H, Vagel S, Wilson PW, Schaefer El and Lammi Keefe CJ (1999); Carotenoid intakes, assessed by dietary questionnaire, are associated with plasma carotenoid concentrations in an elderly population. J Nutr 129, 438-45.

18. Campbell DR, Gross MD, Martini MC, Grandits GA, Slavin JL and Potter JD (1994): Plasma carotenoids as biomarkers of vegetable and fruit intake. Cancer Epidemiol Biomarkers Prev 3, 493-500.

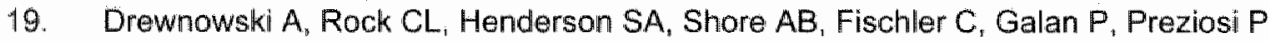
and Hercberg $S$ (1997): Serum betamcarotene and vitamin $C$ as biomarkers of vegetable and fruit intakes in a community-based sample of French adults. Am $J$ Clin Nutr 65, 1796-802.

20. van Kappel AL, Steghens JP, Zeleniuch Jacquotte A, Chajes $V_{n}$ Toniolo $P$ and Riboli $E$ (2001): Serum carotenoids as biomarkers of fruit and vegetable consumption in the New York Women's Health Study. Public Health Nutr 4, 829-35.

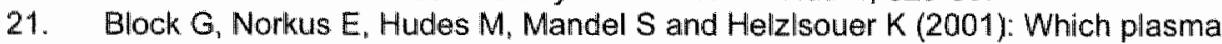
antioxidants are most related to fruit and vegetable consumption? Am J Epidemiol 154, $1113-8$.

22. John JH, Ziebland S, Yudkin P, Roe LS and Neil HA (2002): Effects of fruit and vegetable consumption on plasma aritioxidant concentrations and blood pressure: a randomised controlled trial. Lancet 359, 1969-74.

23. Zino S, Skeaff M, Williams S and Mann J (1997). Randomised controlled trial of effect of fruit and vegetable consumption on plasma concentrations of lipids and antioxidants. BMJ 314, 1787-91. 
24. Le Marchand L, Hankin JH, Garter FS, Essling $C$, Luffey D, Franke AA, Wikens LR, Cooney RV and Kolonel LN (1994): A plot study on the use of plasma carotenoids and ascorbic acid as markers of compliance to a high frut and vegetable dietary intervention. Cancer Epidemiol Biomarkers Piev 3, 245-51.

25. McEligot AJ, Rock CL, Flatt SW, Newman V. Faerber S and Plerce JP (1999): Plasma carotenoids are biomarkers of long-term high vegetable intake in women with breast cancer. J Nutr 129, 2258-63.

26. Maskarinec G, Chan CLY, Meng LX, Franke AA and Cooney RV (4999): Exploning the feasibility and effects of a high-fruit and-vegetable diet in healthy women. Cancer Epidemiol Biomarkers Prev 8, 919-24.

27. Broekmans WM, Klopping Ketelaars IA, Schuurman $C R$, Verhagen $H$, van den Berg $H$, Kok FJ and van Poppel G (2000): Fruits and vegetables increase plasma carotenoids and vitamins and decrease homocysteine in humans. J Nutr 130, 1578-83.

28. Baranowski T, Smith M, Baranowski J, Wang DT, Doyle C, Lin LS, Hearn MD and Resnicow K (1997): Low validity of a seven-item fruit and vegetable food frequency questionnaire among third-grade students. J Am Diet Assoc 97, 66-8.

29. Block $G$, Gillespie $C$, Rosenbaum $E H$ and Jenson $C$ (2000): A rapid food screener to assess fat and fruit and vegetable intake. Am J Prev Med 18, 284-8.

30. Field AE, Colditz GA, Fox MK, Byers T, Serdula M, Bosch RJ and Peterson KE (1998): Comparison of 4 questionnaires for assessment of fruit and vegetable intake. $A \mathrm{~m} \mathrm{~J}$ Public Health 88, 1216-8.

31. Serdula M, Coates R, Byers T, Mokdad A, Jewell S, Chavez M, Mares Periman J,

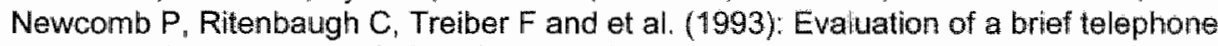
questionnaire to estimate fruit and vegetable consumption in diverse study populations. Epidemiology 4, 455-63.

32. Thompson FE, Kipnis V, Subar AF, Krebs Smith SM, Kahle LL, Midthune D, Potischman $N$ and Schatzkin $A(2000)$ : Evaluation of 2 brief instruments and a foodfrequency questionnaire to estimate daily number of servings of fruit and vegetables. Am J Clin Nutr 71, 1503-10.

33. Resnicow $K_{\text {, Odom }} E_{\text {, Wang }} T$, Dudley WN, Mitchell $D$, Vaughan $R$, Jackson $A$ and Baranowski $T$ (2000): Validation of three food frequency questionnaires and 24-hour recalls with serum carotenoid levels in a sample of African-American adults. Am $J$ Epidemiol 152, 1072-80.

34. Plesko $M$, Cotugna $N$ and Aljadir $L(2000)$ : Usefulness of a brief fruit and vegetable FFQ in a college population. Am $J$ Health Behav 24, 201-8.

35. Van Assema P. Brug J, Ronda G, Steenhuis I and Oenema A (2002): A short dutch questionnaire to measure fruit and vegetable inlake: relative validity among adults and adolescents. Nutr Health 16, 85-106.

36. Hulshof KFAM, Kistemaker $\mathrm{C}$ and Bouman M (1998): The consumption of food groups by Dutch population groups: food consumption survey 1997-1998 (in Dutch). Zeist: TNO Nutrition and Food Research.

37. Kistemaker C, Bouman M and Hulshof KFAM (1998): The consumption of separate products by Dutch population groups: Dutch National Food Consumption Survey 1997 1998 (in Dutch). Zeist. TNO Nutrition and Food Research.

38. Speek AJ, Schrijver J and Schreurs WH (1984); Fluorometric determination of total vitamin $\mathrm{C}$ in whole blood by high-performance liquid chromatography with pre-column derivatization. J Chromatogr 305, 53-60.

39. Hess D, Keller HE, Oberlin B, Bonfanti R and Schuep W (1991): Simultaneous determination of retinol, tocophero/s, carotenes and lycopene in plasma by means of high-performance liquid chromatography on reversed phase. Int J Vitam Nutr Res 61, 232-8. 
40. Oostenbrug $Q S$, Mensink RP, Hardeman MR, De Vhes T, Brouns F and Homstra $G$ (1997): Exercise performance, red blood cell deformability, and lipid peroxidation: effects of fish oil and vitamin E. J Appl Physiol 83, 746-52.

41. Bogers RP, Dagnelie PC, Westerterp KR, Kester ADM, van Klaveren JD, Bast A and van den Brandt PA (2003): Using a correction factor to correct for overreporting in a food-frequency questionnaire does not improve biomarker-assessed validity of estimates for fruit and vegetable consumption. J Nutr 133, 1213-9.

42. Mayne ST (2003): Antioxidant nutrients and chronic disease: use of biomarkers of exposiure and oxidative stress status in epidemiologic research. J Nutr 133(Suppl 3), 9335-940s.

43. Forman MR, Lanza $E_{\mathrm{j}}$ Yong LC, Holden JM, Graubard BI, Beecher GR, Meltiz M, Brown ED and Smith JC (1993): The correlation between two dietary assessments of caratenoid intake and plasma carotenoid concentrations: application of a carotenoid food-composition database. Am J Clin Nutr 58, 519-24.

44. Martini MC, Campbell DR, Gross MD, Grandits GA, Potter JD and Slavin JL (1995): Plasma carotenoids as biomarkers of vegetable intake: the University of Minnesota Cancer Prevention Research Unit Feeding Studies. Cancer Epidemiol Biomarkers Prev 4, 491-6.

45. Kardinaal AF, van 't Veer $P$, Brants $H A$, van den Berg $H_{\text {, }}$ van Schoonhoven $J$ and Hermus RJ (1995): Relations between antioxidant vitamins in adipose tissue, plasma, and diet. Am J Epidemiol 141, 440-50.

46. Kim DJ and Holowaty EJ (2003): Brief, validated survey instruments for the measurement of fruit and vegetable intakes in adults: a review. Prev Med 36, 440-7.

47. Byers T, Trieber F, Gunter E, Coates R, Sowell A, Leonard S, Mokdad A, Jewell S, Miller $D$, Serdula $M$ and et al. (1993): The accuracy of parental reports of their children's intake of fruits and vegetables: validation of a food frequency questionnaire with serum levels of carotenoids and vitamins C, A, and E. Epidemiology 4, 350-5.

48. Michaud DS, Giovannucci EL, Ascherio A, Rimm EB, Forman MR, Sampson L and Willett WC (1998): Associations of plasma carotenoid concentrations and dietary intake of specific carotenoids in samples of two prospective cohort studies using a new carotenoid database. Cancer Epidemiol Biomarkers Prev 7, 283-90.

49. Osler M and Heitmann BL (1996): The validity of a short food frequency questionnaire and its ability to measure changes in food intake: a longitudinal study. Int $J$ Epiderniol $25,1023-9$.

50. Coates RJ "Eley JW, Block G, Gunter EW, Sowell AL, Grossman C and Greenberg RS (1991): An evaluation of a food frequency questionnaire for assessing dietary intake of specific carotenoids and vitamin $E$ among low-income black women. Am J Epidemiol $134,658-71$. 
Explaining fruit and vegetable consumption: the Theory of Planned Behaviour and misconception of personal intake levels

Rik P Bogers

Johannes Brug

Patricia van Assema

Pieter C Dagnelie 


\section{Abstract}

The influence of individuals misconceptions in assessing fruit and vegetable consumption on the ability of the theory of planned behaviour to explain variance in the consumption of these foods was studied. Dutch women (mean age 41 years, $n=159$ ) completed a questionnaire assessing the theory's constructs with regard to the daily consumption of at least two pieces of fruit and $200 \mathrm{~g}$ of vegetables. Consumption was assessed using a self-rated measure and more objectively with a food-frequency questionnaire. Both measures were combined to classify participants according to the accuracy of their self-assessed intake levels ('realists' vs. 'overestimators'). The model explained variation in objective fruit and vegetable intake much better among realists $\left(R^{2}=45 \%\right.$ for fruits and $39 \%$ for vegetables) than among overestimators $\left(R^{2}=18 \%\right.$ and $5 \%$, respectively). Perceived behavioural control was the strongest predictor of intentions and behaviour. When plasma vitamin $C$ and carotenoid concentrations were used as objective indicators for fruit and vegetable intake, the explanatory value of the model was lower, but again more variance was explained among realists than among overestimators. We conclude that awareness of personal behaviour should be taken into account when applying the theory of planned behaviour to explain dietary behaviours as well as to design health education interventions. 


\section{Introduction}

Although fruits and vegetables are a major dietary source of vitamins and fibre, and results of many observational studies in humans suggest that ample consumption of fruit and vegetables may prevent cardiovascular disease (1) and cancer (2), mean consumption of these foods is still below the intake levels recommended by public health authorities $(200 \mathrm{~g}$ of vegetables and two pieces of fruit according to Dutch guidelines) (3). Many people seem not to be aware that their fruit and vegetable consumption is below the recommended level (4). The present paper deals with the influence of an optimistic bias in self-rated fruit and vegetable intake on the strength of the relations between fruit and vegetable consumption and its determinants.

A model that has proved useful in explaining or predicting a variety of behaviours is the Theory of Planned Behaviour (TPB) (5). The TPB originated from the earlier theory of reasoned action (TRA), which states that the likelihood of someone engaging in a particular behaviour can be predicted by their intention to perform that behaviour, which in turn is predicted by attitudes and subjective norms. Attitude refers to the degree to which a person has a favourable or unfavourable evaluation or appraisal of the behaviour in question. Subjective norm refers to the perceived social pressure to perform or not perform a behaviour. In order to extend the scope of the TRA to behaviours that may not be under complete volitional control, the perceived behavioural control construct was introduced as a third predictor of behavioural intention. Perceived behavioural control reflects the perceived ease or difficulty of performing a particular behaviour, and is thought also to have a direct effect on behaviour, which is not mediated by intentions. (5). In a meta-analysis including 185 independent studies on the predictive potential of the TPB for a variety of health-related behaviours, the TPB explained $27 \%$ and $39 \%$ of the variance in behaviour and intention, respectively (6). For complex health-related behaviour such as diet and physical activity, the predictive value of the TPB or the related Attitude-Social influence-Efficacy (ASE) model (7)) may be more limited $(8)$.

Besides the fact that such behaviours could be partly habitual, this may be caused by the fact that what is studied as one behaviour (e.g. fruit consumption) in reality consists of many separate behaviours (e.g. buying, preparing and eating apples, pears, oranges) each of which may have its own determinants. The complexity of dietary behaviour probably also contributes to the fact that people tend to have an unrealistically optimistic view of their own intake levels. For example, a study by Lechner et al. (4) showed that of those people who do not eat the recommended amounts of vegetables and fruits, $88 \%$ and $65 \%$, respectively, think they actually do meet the recommendations. This misconception of their own consumption would be expected to reduce the explained variance in behaviour when an objective measure of behaviour is used instead of a self-rated measure. The above meta-analysis supports this hypothesis: studies using self-reported behavioural measures found an explained variance of $31 \%$ compared to $21 \%$ in studies using objective or abserved behavioural measures (6). Work by Brug et al. showed that psychosocial determinants (outcome belliefs, attitude, social pressure, self-efficacy, modelling) of fat intake were stronger correlates of self-rated fat intake than of fat intake as assessed by a food-frequency questionnaire (FFQ) $(9,10)$. Similar findings have also been reported concerning physical activity (11). Therefore, we hypothesised that in the TPB model a higher percentage of variance should be explained in participants having a realistic view of their fruit and vegetable consumption (in other words, individuals whose self-rated consumption approaches objective consumption) than in participants misjudging their fruit and vegetable intake. Due to the discrepancy between subjective and objective measures of fruit and vegetable intake, we cannot rely on self-ratted measures if we want to know whether someone eats the recommended amounts of fruit and vegetables. A FFQ is a more objective instrument widely used for estimating habitual intake of 
foods (12). Nevertheless, because an FFQ is a self-aclministered assessment instrument, there remains a possibility of bias with respect to the recall of past diet, socially desirable answering, or the (conscious or subconscious) desire to match answers given in an FFQ to answers given in a questionnaire for measuring psychosocial determinants of consumption. Truly objective measures of dietary intake are biochemical markers of consumption (13). frequently used biomarkers for fruit and vegetable consumption being plasma carotenoids and vitamin $\mathrm{C}$. Concentrations of these vitamins were found to correlate with the intake of fruit and vegetables as assessed by dietary questionnaires $(14,15)$, although correlations are moderate due to biological variation between persons in, for example, absorption or metabolism of vitamins. Plasma carotenoid and vitamin $C$ concentrations respond to changes in dietary fruit and vegetable intake and were reported to stabilise within approximately two weeks of changing fruit and vegetable consumption to a new stable level $(16,17)$. To our knowledge, biomarkers have not been used previously as an outcome measure in studies of psychosocial determinants of fruit and vegetable consumption.

The objectives of the present study were to determine the effect of misconception of fruit and vegetable consumption on the explanatory value of the TPB, and to identify which TPB constructs predict intentions and fruit and vegetable consumption. Additionally, we tested the use of biomarkers as a measure of fruit and vegetable consumption in the TPB.

\section{Methods}

\section{Study design}

The study was part of a larger project aimed at testing various methods to assess fruit and vegetable intake in children aged $7-10$ years and their mothers. Approval for the study at large was obtained from the medical ethical committee of the University Hospital in Maastricht. In March 2001, a questionnaire comprising an FFQ about fruit and vegetable consumption, immediately followed by questions assessing TPB constructs and a question about self-rated consumption was sent to the mothers 1-2 weeks before blood sampling. Participants were requested to complete the questionnaire the day or evening before blood sampling. A venous blood sample was taken from the mothers for the analysis of biomarkers.

\section{Participants}

In the present study only data regarding the mothers were used. The women had to be apparently healthy nonsmokers who agreed not to use vitamin supplements from one month before the first blood collection to the end of the study period. Various ways of approaching potential study participants were used such as distribution of invitation letters via mail to households where children aged $T=10$ lived, and recruitment via schools. Recruitment was stopped when $>200$ women were enrolled. The study started with 207 women, of whom 163 women $(79 \%)$ completed it. Respondents were excluded from further analysis because of having FFQs with $>20 \%$ missing values $(n=2)$, or having $>20 \%$ missing values in the questions assessing TPB constructs $(n=2)$, leaving a total number of 159 respondents $(77 \%$ of the initial number of participants). In the analyses on vegetable consumption and determinants, one more participant was excluded because of a high number of missing values in the questions assessing the TPB constructs regarding vegetable consumption. One participant did not complete the question on self-rated vegetable consumption, therefore this participant was excluded from the stratified analyses of vegetable consumption. 


\section{Calculation of fruit and vegetable consumption}

A detailed description of the FFQ and its validity can be found in Bogers et al. (31). The FFQ measured fruit and vegetable intake during the past month and contained questions about consumption of the main fruit and vegetable categories: fruit (one question; including fresh orange and grapefruit juice), cooked vegetables (one question; not including potatoes) and raw vegetables/salad (two questions; not uncluding vegetable juice). Consumption of raw vegetables/salad was asked separately for consumption during the warm meal (which is usually dinner in the Netherlands) and during the cold meal (usually breakfast and lunch). Participants could indicate their consumption frequency by choosing one of seven options ranging from never or less than once per month to 6-7 days a week. Portion sizes could be indicated in pieces (fruits), serving spoons (cooked vegetables) or bowls (raw vegetables, salad). Standard amounts were used for converting household measures to grams (serving spoon $=55 \mathrm{~g}$, bowl $=70 \mathrm{~g}$ ); fruits are expressed in pieces in this study. Frequency and portion size were multiplied to obtain estimates of daily consumption in pieces of fruit, grams of cooked vegetables and grams of vegetables eaten raw and in salads. Consumption of cooked vegetables and raw vegetables/salad was summed to obtain total vegetable consumption.

\section{Assessment of TPB constructs, self-rated consumption and misconception}

For the assessment of the TPB constructs we followed the directions given by Conner and Sparks (18). All constructs were measured directly on seven-point bipolar scales $(-3$ to +3 with only the end points of the scale described with words) for consumption of vegetables and fruits separately, and referred to Dutch recommended intake levels (consumption of at least $200 \mathrm{~g}$ of vegetables and two pieces of fruit per day). The assessment of the constructs is described here for fruit consumption, but was similar for vegetable consumption. First, a neutral value $(0)$ was used to substitute missing values on any of the questions assessing the TPB components. Intention was assessed as the mean of the score of two questions "I intend to eat at least two pieces of fruit a day' and 'I want to eat at least two pieces of fruit a day', with options ranging from $-3=$ 'surely don't" to $3=$ 'surely do'. Attitude was assessed as the mean of four items in terms of 'I think it is (very bad - very good, very unpleasant - very pleasant, tastes very bad - very tasty, wery unhealthy - very healthy) to eat at least two pieces of fruit a day'. Subjective norm was assessed as the mean of four items in terms off 'most people who are important to me ...think I should eat at least two pieces of fruit a day (surely don"t - surely do), ... think it is (very bad - very good) if I eat at least two pieces of fruit a day'. The same two questions were asked regarding family members. Perceived behavioural control was assessed as the mean of two items: "I find eating at least two pieces of fruit a day is (very hard - very easy)' and 'Do you think you are able to eat at least two pieces of fruit a day? (surely don't - surely do)'.

Misconception of the participants" own fruit and vegetable consumption was determined as follows: consumption was assessed 'objectively' with the FFQ and dichotomised in 'less than two pieces' or 'two or more pieces' of fruit a day. Self-rated consumption was determined with the question 'Do you think you eat insufficient or sufficient amounts of fruit? (insufficient - sufficient)', scored as -3 to +3 and dichotomised as 'sufficient' when a participant scored 1,2 or 3 and as 'insufficient' when the score was zero or less. Participants with congruent objective and subjective (dichotomous) scores were categorised as 'realists', and participants with incongruent scores as 'overestimators or underestimators'.

\section{Analysis of biomarkers}

Venous blood samples were collected after an overnight fast between 7:00 and 11:00 a.m. in two $K_{2}$ EDTA-coated plastic tubes. (Becton Dickinson Vacutainer Systems, Plymouth, United Kingdom). Both tubes were immediately placed on ice in the dark. Total ascorbic acid was determined by high performance liquid chromatography with fluorometric detection 
according to the method of Speek el al. (19). Plasma carotenoids were analysed with high performance liquid chromatography with UV detection according to Hess et al. (20), with modifications described by Oostenbrug et al. (21).

\section{Statistical analyses}

Statistical analyses were performed using the SPSS program (version 10.0; SPSS Inc, Chicago, IL). Cronbach's $\alpha^{x} s$ or inter-item correlations were calculated to determine the internal consistency of the subscales for the TPB constructs. Path diagrams were constructed by performing two linear regression analyses: firstly, intention to eat recommended amounts of fruits or vegetables was regressed onto attitude, subjective norm and perceived behavioural control; secondly, consumption of fruits or vegetables was regressed onto intention, attitude, subjective norm and perceived behavioural control. The second regression analysis was first done with self-rated consumption of fruits and vegetables as dependent variables, and subsequently with the objective measures (the FFQ and the biomarkers). The analyses with objective fruit and vegetable consumption and biomarkers as dependent variables were repeated for participants having a realistic view of their own fruit and vegetable consumption and separately for participants misjudging their own consumption. The explained variance in fruit and vegetable consumption served as a measure of the performance of the models. Partial regression plots and Cook's distances were used to identify outliers, and where necessary path analysies were rerun without outliers. Only if the results without outliers were considerably different from the results including outliers is this mentioned in the description of the results.

\section{Results}

The mean age of the women was 41 (SD 4 , range 29 to 50 ) years. Mean body mass index was 24.1 (SD 3.5 , range 18.7 to 36.1 ) $\mathrm{kg} / \mathrm{m}^{2}$. Ninety-one percent were married or living together with their partner, $42 \%$ had a high educational level (polytechnic, university), $52 \%$ an intermediate level (high school) and 6\% a low level (elementary school). Descriptive statistics for the TPB constructs and fruit and vegetable consumption are shown in Tablle 1. The distributions of attitude, perceived behavioural control and intention were skewed to the right for fruit and wegetables, indicating that most participants had positive scores for these variables. All scores were lower for fruit than for vegetable consumption. The percentage of misconception was higher for vegetable $(68 \%)$ than for fruit consumption $(40 \%)$. Misconception almost exclusively took the form of overestimation, except for two participants who underestimated their vegetable intake. Because of the small number of underestimators, we only show data for overestimators in the stratified analyses. With respect to the consumption of fruits, overestimators had more positive attitudes, a greater perceived control and a stronger intention, and higher self-rated and objective consumption. With respect to vegetable consumption, overestimators had a greater perceived control, a higher self-rated consumption and a lower objective consumption. The lower fruit consumption of realists compared to overestimators was a result of the fact that $86 \%$ of the realists ate less than two pieces of fruit a day (of whom $79 \%$ ate less than one piece), whereas for vegetable consumption $45 \%$ of the realists ate less than $200 \mathrm{~g}$ of vegetables a day. 
Toble 1

Descriptive statistics of the TPB constructs and fruil and vegetable consumption

\begin{tabular}{|c|c|c|c|c|c|c|c|c|}
\hline & \multicolumn{4}{|c|}{ Total } & \multicolumn{2}{|c|}{ Realists } & \multicolumn{2}{|c|}{$\begin{array}{c}\text { Over- } \\
\text { estimators }\end{array}$} \\
\hline & $\begin{array}{l}\text { No. of } \\
\text { iterns }\end{array}$ & $\alpha^{\mathrm{a}}$ & Mean & (SD) & Mean & (SD) & Mean & $(\mathrm{SD})$ \\
\hline \multicolumn{9}{|l|}{ Fruit $(n=159 / 95 / 64)^{b}$} \\
\hline Attitude ${ }^{c}$ & 4 & 0.70 & 1.88 & $(0.90)$ & $1.64^{* *}$ & 0.87 & 2.23 & 0.83 \\
\hline Subjective norm ${ }^{c}$ & 4 & 0.73 & 0.62 & $(1.20)$ & 0.54 & 1.24 & 0.73 & 4.15 \\
\hline $\begin{array}{l}\text { Perceived behavioural } \\
\text { control }^{c}\end{array}$ & 2 & $0.5 \|^{d}$ & 1.20 & $(1.51)$ & $0.64^{* *}$ & 1.51 & 2.04 & 1.06 \\
\hline Intention & 2 & $0.80^{d}$ & 1.54 & $(1.47)$ & $1.21 * *$ & 1.52 & 2.03 & 1.25 \\
\hline Self-rated consumption ${ }^{\circ}$ & 1 & & 0.33 & $(2.27)$ & $-1.08^{\text {** }}$ & 1.85 & 2.42 & 0.59 \\
\hline Consumption FFQ (pcs/day) & 1 & & 1.13 & $(0.83)$ & $0.98^{*}$ & 0.98 & 1.34 & 0.45 \\
\hline \multicolumn{9}{|l|}{ Vegetables $(n=158 / 51 / 104)^{t, \text { a }}$} \\
\hline Attitude $^{\mathrm{c}}$ & 4 & 0.80 & 2.44 & $(0,65)$ & 2.41 & 0.70 & 2.45 & 0.64 \\
\hline Subjective norm ${ }^{\mathrm{C}}$ & 4 & 0.77 & 0.92 & $(1.25)$ & 1.08 & 1.14 & 0.88 & 1.28 \\
\hline $\begin{array}{l}\text { Perceived behavioural } \\
\text { contral }^{c}\end{array}$ & 2 & $0.71^{d}$ & 2.10 & $(1.14)$ & $1.80^{*}$ & 1.36 & 2.25 & 1.00 \\
\hline Intention ${ }^{c}$ & 2 & $0.93^{d}$ & 2.28 & $(1.18)$ & 2.21 & 0.98 & 2.30 & 1.28 \\
\hline Self-rated consumption ${ }^{c}$ & 1 & & 1.90 & $(1.33)$ & $1.08^{* * * *}$ & 1.78 & 2.34 & 0.73 \\
\hline Consumption FFQ (g/day) & 3 & & 152 & $(68)$ & $193^{* * *}$ & 88 & 130 & 42 \\
\hline
\end{tabular}

$* * * * *$ Realists and overestimators significantly different from each other (independent samples $t$ thest) at ${ }^{*} \mathrm{p}<0.05,{ }^{* *} \mathrm{p}<0.01,{ }^{* * *} \mathrm{p}<0.001$

${ }^{2}$ Cronbach's $\alpha$.

${ }^{b}$ Total study population, realists and overestimators, respectively.

${ }^{c}$ Measured on scales from -3 to +3 .

dinter-item correlation coefficient.

- Total of realists and overestimators does not add up to 158 because of two underestimators and one person excluded because of an unknown self-rated consumption.

Table 2 shows the correlations between the TPB components for fruit and vegetable consumption separately. All constructs were significantly correlated, except perceived behavioural contral and subjective norm for fruit consumption. For both behaviours, subjective norm showed the lowest correlation with intention. Attitude and perceived behavioural control correlated with intention to a similar degree.

Attitudie, subjective norm and perceived behavioural control explained $44 \%$ and $51 \%$ of the variance in the intention to eat at least two pieces of fruit or at least $200 \mathrm{~g}$ of vegetables, respectively (Figure 1). Perceived behavioural control was the strongest predictor of both intentions. The prediction by perceived control was better for the intention to eat vegetables than for the intention to eat fruits; subjective norm was the weakest predictor for both these intentions (Figure 1). Explained variance in the intention to eat at least two pieces of fruit was higher in overestimators $\left(R^{2}=64 \%\right)$ than in realists $\left(R^{2}=31 \%\right)$. Attitude was the most important predictor in overestimators and the least important predictor in realists, where perceived control was the most important (Figure 2A). The intention to eat at least $200 \mathrm{~g}$ of vegetables was predicted equally well among realists $\left(R^{2}=56 \%\right)$ and overestimators $\left(R^{2}=54 \%\right)$ Perceived control was the most influential predictor in both groups. Subjective norm was a predictor in overestimators but not in realists (Figure 2B). 


\section{Table 2}

speoman's comelotion coefficients between the constructs of the theory of planned behoviouro

\begin{tabular}{lcccc} 
& Attitude & Subjective norm & PBC & Intention \\
\hline Attitude & & $0.27^{\text {*** }}$ & $0.68^{* * *}$ & $0.62^{* *}$ \\
Subjective norm & $0.36^{* *}$ & & $0.20^{*}$ & $0.29^{* * *}$ \\
PBC & $0.62^{* *}$ & 0.11 & & $0.74^{\text {** }}$ \\
Intention & $0.64^{* *}$ & $0.35^{\text {*** }}$ & $0.57^{* *}$ & \\
\hline
\end{tabular}

", " Correlation coefficients significantly different from zero at * $p<0.05, * *<<0.01$.

"Correlation coefficients for fruit are shown below the diagonal, those for vegetablles above the diagonal.

PBC. perceived behavioural control.

Of the variance in self-rated consumption of fruits and of vegetables, the model could explain $46 \%$ and $33 \%$, respectively (Figure 1). Intention did not predict self-rated fruit consumption and was neglatively related to self-rated vegetable consumption. After the exclusion of four outliers however, intention was no longer related to self-rated vegetable consumption $(\beta=-0.09 ;$ n. s.). The only significant influence on both self-rated behaviours was from perceived control, with regression coefficients of 0.56 for fruits and 0.71 for vegetables, which did not change after outliers had been excluded (Figure 1).

The TPB explained $37 \%$ of the variance in fruit consumption measured with the FFQ. The explained variance was higher for realists $\left(R^{2}=45 \%\right)$ than for overestimators $\left(R^{2}=18 \%\right.$; Figure 2A). After exclusion of one outlier in the realist group, the regression coefficients for intention, attitude, subjective norm and perceived control became $0.25,0.36,-0.11$ and 0.30 , respectively, and $\mathrm{R}^{2}$ changed to $49 \%$. The explained variance in vegetable consumption measured with the $\mathrm{FFQ}$ was $10 \%$ in the total study population. In realists, the explained variance was $39 \%$ and in overestimators $5 \%$ (Figure 2B). There was a significant effect of perceived control but not of intention on vegetable consumption in realists.

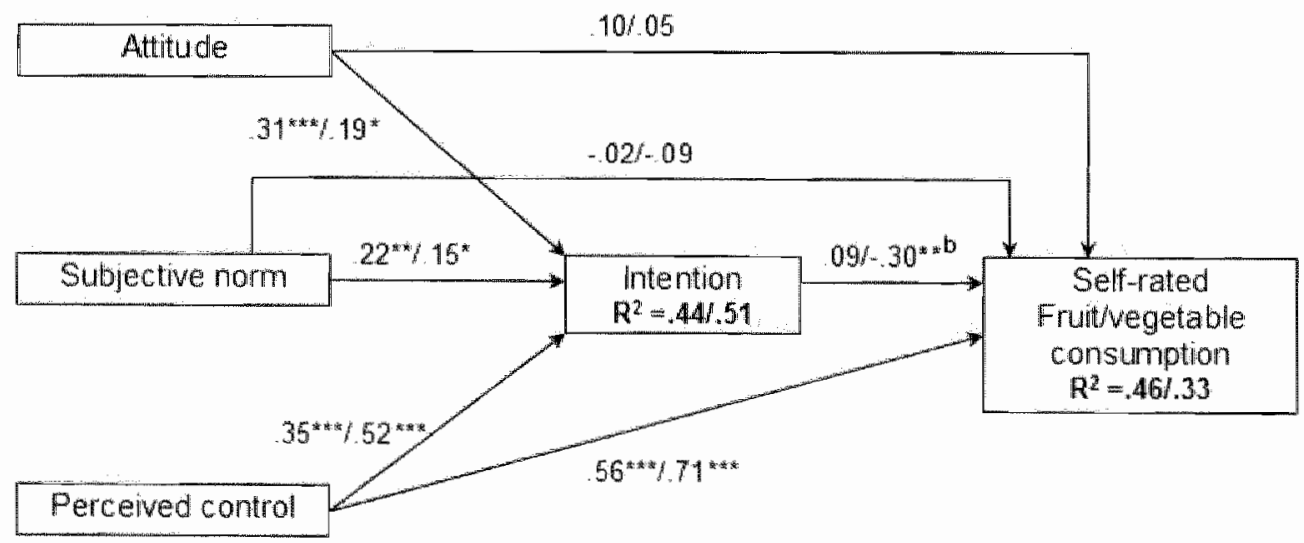

Figure 1. Path analyses for self-rated consumption af fruit/vegetables for the folal study population

******* Regression coefficients significantly different from zero at *p<0.05**p<0.01***<<0.001.

The path coefficients are standardised regression coefficients and are shown for fruit / vegetable intake.

${ }^{b}$ changed to non-significant after outliers had been excluded. 
Figure 3 shows path analyses with concentrations of plasma carotenoids and vitamin $\mathrm{C}$ as end variables. The explained variance in biomarker concentrations ranged from $3 \%$, when vitamin $C$ was regressed on TPB components regarding vegetable consumption (Figure 3D), to $13 \%$ when carotenoids were regressed on components regarding fruit consumption (Figure $3 \mathrm{~A}$ ). With the exception of the model shown in figure $3 \mathrm{~B}_{1}$ explained variance was higher in the realists (overall $F$-values significant at $p<0.05$ ) than in the overestimators (no significant F-values). The only significant predictors were the intention to eat fruits and the intention to eat vegetables, both of which predicted plasma vitamin $\mathrm{C}$ concentrations only in the realisits.

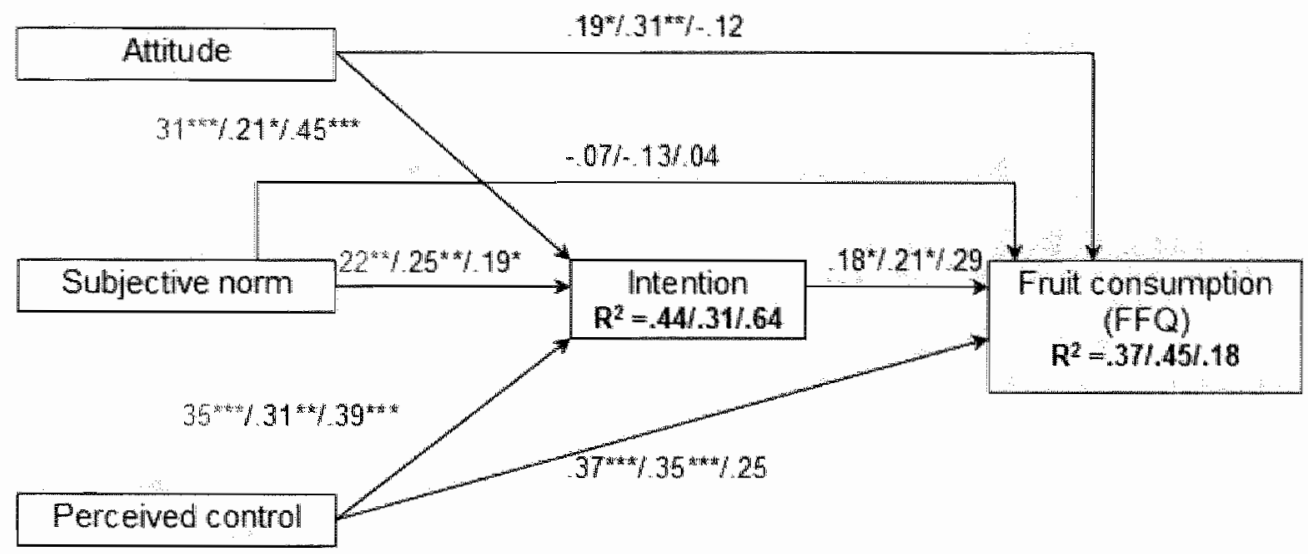

Figure $2 \mathrm{~A}$

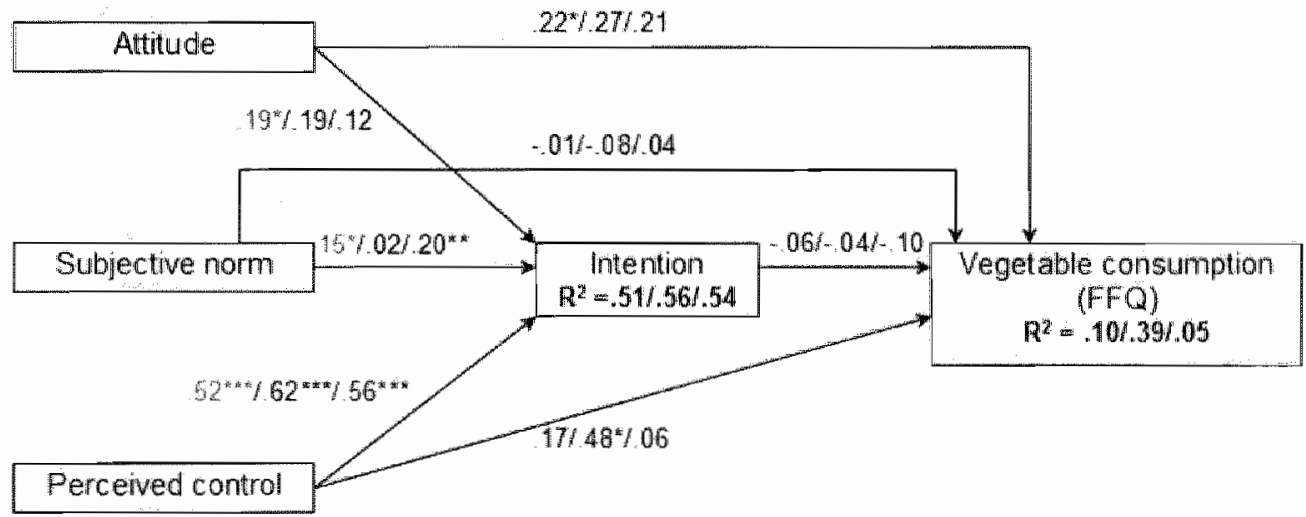

Figure 2B

Figure 2. Path analyses far fruit and vegetable consumplion measured with a food. frequency questionnaire, for the total study population, realists, and overestimatorse is

A.: Fruits

B: Vegetables

${ }^{*} * * * * *$ Regression coefficients significantly different from zero at ${ }^{* *}<<0.05^{* *} p<0.01^{* * *} p<0.001$.

a The path caefficients are standardised regression coefficients and are shown for the total study population / realists / overestimators.

bata repeated from figure 1 are shown in grey. 

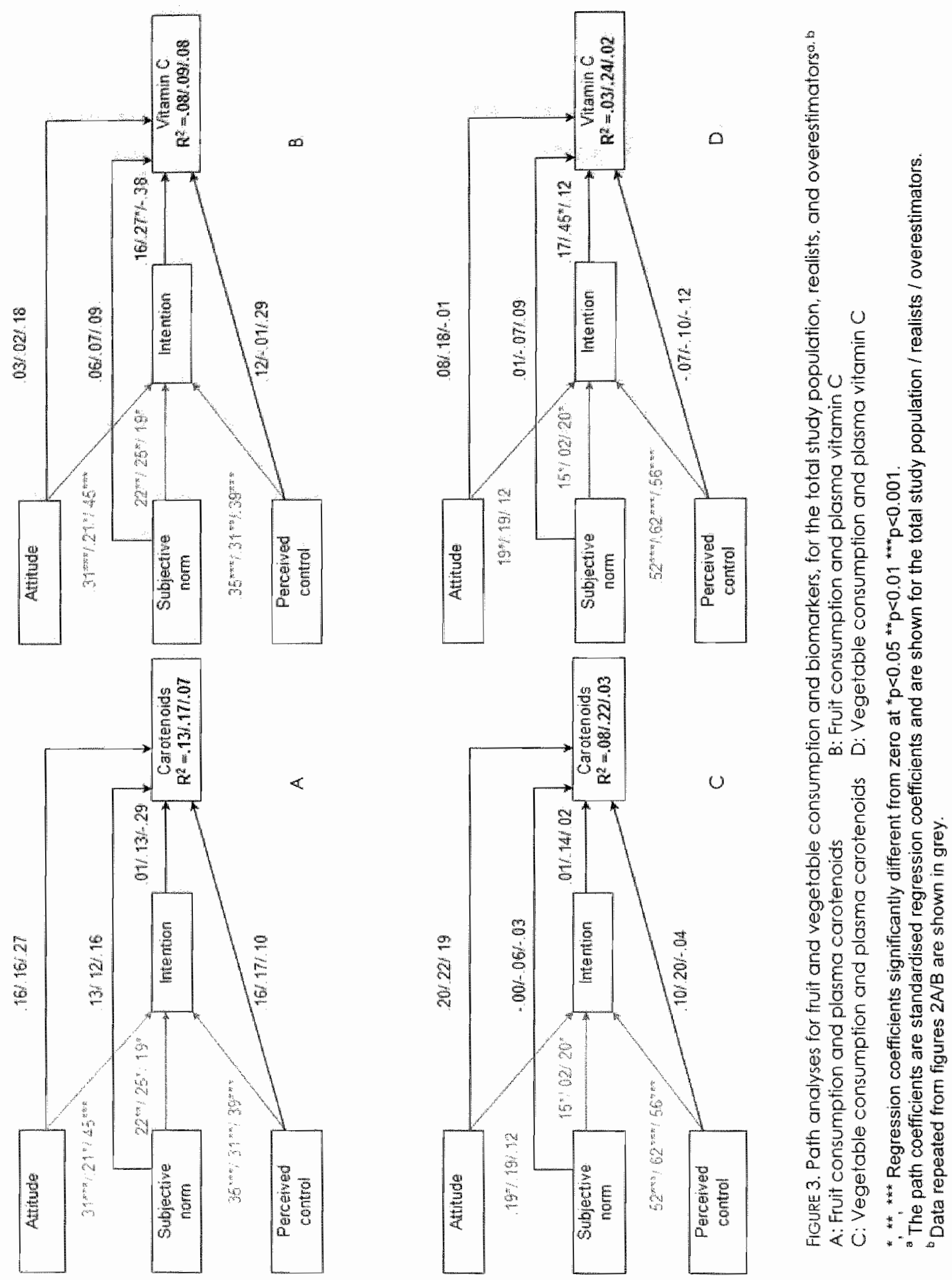


\section{Discussion}

This study examined the influence of people's misconceptions about their own fruit and vegetable intake on the explanatory value of the TPB model. About half of the variation in the intention to eat fruit or vegetables could be explained by the model. Of the variation in selfrated consumption, $46 \%$ could be explained for fruits and $33 \%$ for vegetables. When fruit and vegetable intake was measured with an FFQ, the explained variance was considerably lower, especially for vegetables. Stratified analyses, however, showed that the model was better able to explain variation in FFQ-based fruit and vegetable intake in realists than in overestimators. Perceived behavioural control seemed the most important predictor of both intentions and fruit and vegetable consumption. When biomarkers were used as an alternative measure of fruit and vegetable intake, the explanatory value of the TPB was very low, but again the explained variance was higher in realists than in overestimators.

These results are in line with those of previous research (4) which showed that psychosocial determinants of fruit and vegetable consumption predicted self-rated consumption much better than consumption estimated with an FFQ. From this it follows that the explanatory value of the TPB is higher for realists (whose self-rated consumption approaches objective consumption) than for overestimators. Similar findings have been reported for fat intake (9). Lechner et al. (4) discussed that even the 'objective' FFQ could still lead to some degree of overestimation. We ruled out this possibility by also using truly independent biomarkers as dependent variables, and confirmed the results found with the FFQ.

Intentions to eat fruit and vegletables were predicted by attitudes, subjective norms and perceived behavioural control. This is consistent with the determinants of the intention to eat fruit and vegetables that were found in a previous study by Brug et al. (8). Subjective norm was the weakest predictor of intention, as has also been found in other studies on determinants of fruit and vegetable consumption (8), as well as in studies on the intention to eat healthier food $(22,23)$ and several other behaviours $(6,24)$. It has been suggested that other social influences than the subjective norm concept in the TPB may be more important determinants of eating behaviours, like direct social pressure/support or descriptive norms $(6,25)$. Perceived behavioural control was the strongest predictor of intention, which confirms earlier findings $(6,24)$. Also consistent with the theory (5) and previous research (8) are the observed direct association between perceived control (or perceived barriers (26)) and selfrated and objective fruit and vegetable consumption, and the association between intention and objective fruit consumption.

Contrary to what the TPB states, and to the results from the above studies $(8,26)$, selfrated fruit and vegetable consumption and objective vegetable consumption were not predicted by intentions. Dietary behaviours are often reganded as habitual, which could certainly weaken the intention - behaviour relationship (27). This could be particularly true for vegetable consumption, because vegetables normally constitute a part of the evening meal in the Netherlands, whereas fruits are usually eaten between meals. Another explanation may be derived from the speculation by Randall and Wolff (28) that the inability to enact one's intention may be due to various personal and environmental control factors. In their metaanalysis of applications of the TRA and TPB, they found that the intention-behaviour relationship declined sharply over time in the area of alcohol/drug-related activities. In terms of fruit and vegetable consumption (which was not studied by the above authors), consumption is the most distal in a sequence of actions (buying, preparing, eating), so that external and personal control factors influencing buying and preparing could possibly weaken the relation between the intention to eat fruit and vegetables and the actual eating behaviour. A final explanation could result from the fact that we measured intention to eat at least the 
recommended intake levels, whereas consumption was measured as a continuous variable, which could have caused lack of correlation between intention and behaviour. For vegetable consurrution, part of the explanation may also lie in the fact that the variation in intention and consumption in our study was fairty low.

Another discrepancy with the original TPB is that in our data, objective fruit and vegetable consumption as measured by the FFQ was directly correlated with attitude. Direct associations between attitude and behaviour have been reported previously for abjective consumption of salads $(4,8)$ and self-ratted consumption of processed vegetables and fruits (4). The direct association between attitudes and behaviour could reflect the influence of (habitual) behaviour on attitudes instead of attitudes predicting behaviour as the TPB postulates. This reverse route has been suggested by several authors (e.g., Myers (29). Another possible explanation is that the attitude construct may comprise components that do not exert their influence on behaviour through intentions. Lien et al. (26) argued that taste could be a purelly emotional/hedonic experience that may not be mediated by a salient cognitive process.

We performed separate regression analyses for realists and overestimators, allowing us to study determinants of fruit and vegetable consumption in people who are aware of their fruit and vegetable intake and in those who overestimate it. We unexpectedly found a much higher percentage of explained variance in the intention to eat fruit among overestimators $\left(R^{2}=64 \%\right)$ than among realists $\left(\mathbb{R}^{2}=31 \%\right)$. This difference was mainly accounted for by a higher regression coefficient for attitude in overestimators. It is possible that overestimators generally try to give a more consistent impression of their behaviour, intentions and attitudes, leading to the high $\mathrm{R}^{2}$ we observed. However, since we did not observe this for the intention to eat vegetables, this explanation does not go beyond speculation.

Contrary to the realists, perceived control did not predict fruit and vegetable intake in the overestimators. Ajzen states that prediction of behaviour from perceived behavioural control should improve to the extent that perceptions of behavioural control realistically reflect actual control (5). Perceived control could approach actual control to a higher extent in realists than in overestimators. The latter think they are in controll of eating the recommended amounts of fruit and vegetables, although this may not actually be the case.

To our knowledge, this is the first study of psychosocial determinants of fruit and vegetables consumption to use biochemical markers of dietary intake as an alternative outcome measure. However, the degree of explained variance in biomarker concentrations was low. This is probably because other (biological) factors also determine plasma concentrations of biomarkers, resulting in a moderate correlation between fruit and vegetable consumption and its biomarkers. Plasma carotenoids have been reported to change within two weeks when daily fruit and vegetable intake is increased, after which they remained stable $(16,17)$. Therefore, differences in time frame reflected by carotenoids and the FFO would reduce correlations between both measures only if the diet is changed within the month covered by the FFQ, and especially in the last two weeks preceding blood sampling. Plasma vitamin $\mathrm{C}$ concentrations have also been shown to change within two weeks after daily fruit and vegetable consumption was increased (16). However, because plasma vitamin $C$ concentrations seem to be sensitive to more recent vitamin $C$ intake (30), this would make this measure less suitable as a biomarker for fruit and vegetable intake during one month if intake from day to day during this period is not constant. Nevertheless, the results provided by the biomarkers also showed that the TPB model explained variance of biomarkers better in pealists than in overestimators.

We assessed the TPB components directly, according to the directions given by Conner and Sparks (18), and used a validated FFQ. For a correct interpretation of the results, however, the following points should be borne in mind. Firstly, we assessed all TPB constructs with respect to the consumption of at least two pieces of fruit or $200 \mathrm{~g}$ of vegetables. We did this (rather than asking questions about increasing fruit and vegetable consumption) to ensure that not only persons who wanted to increase their fruit and vegetable 
consumption would score high on the questions about the TPB constructs, but also those who already consumed enough fruit and vegetables. A drawback of this formulation of the questions is that fruit and vegetable consumption should actually be assessed as being either below or above the recommended amounts, to be in agreement with the TPB constructs. We chose not to do this because this would result in every overestimator having the same fruit and vegetable intake (i.e. below the recommended level), which would make it impossible to answer our research question.

Secondly, the classification of participants into realists and overestimators depends on self-assessed consumption and consumption measured with the FFQ. Self-rated consumption as formulated in our questionnaire would depend both on the participants' perception of what constitutes a sufficient amount, and on their perceptions of how their intake compares with this amount. The participants were repeatedly confronted with reference amounts of fruit and vegetables as they read the questions assessing the TPB constructs, which could have made them more conservative in their self-rated consumption. However, it was not mentioned in the questions that the reference amounts were in fact identical to the recommended intake levels. Since the proportion of participants. who overestimated their fruit and vegetable consumption was quite high, the effect of reading reference amounts in other questions may not have been strong in the present study. Alternatively, the participants may have been unable to accurately assess their fruit and vegetable intake, for instance as a result of lack of knowledge of what is included in the groups of fruits and vegetablles. We deliberately did not provide them with this information in order not to bias the participants" self-assessment. Regarding the objectively assessed consumption, based on previous results the FFQ appears suitable to rank persons according to their fruit and vegetable consumption, although the validity of the FFQ in terms of classifying persons into meeting the recommended intake or not was not determined (31). Since an FFQ is also a self-administered instrument, problems with a correct classification of persons into realists or overestimators would emerge if errors (e.g., overestimation) in subjective and objective assessment of fruit and vegetable consumption were correlated, leading to a higher percentage of realists. If this was the case in the present study, this would imply an even higher percentage of overestimation in reality.

Thirdly, the study population was self-selected and consisted of nonsmoking women with predominantly intermediate or higher education who may already have had an interest in healthy eating and fruit and vegetable consumption in particular, and who may have been eating more fruit and vegetables than an average population (32). In this population, determinants of fruit and vegetable intake could be different from those in a more representative population or in other subgroups of the population. However, this lack of generalisability may have only attenuated the abserved influence of misconception on the explanatory value of the TPB, because in a more representative (thus less health - conscious) population, the level of overestimation of fruit and vegetable consumption might be even higher.

The first implication of our findings is that objective measures of dietary intake have added value in studies of the determinants of fruit and vegetable consumption and of dietary behaviour in general, in view of the different results obtained compared to self-rated measures. Secondly, studies aimed at identifying determinants of food consumption should take the awareness of personal intake levels into account, since associations between potential determinants and behaviour depend on realistic self-assessed intake levels. Since we found a high prevalence of misconception of fruit and vegetable consumption, for the practice of health education, our data support the notion that a necessary first step in programs aimed at increasing fruit and vegetable intake is making people aware of their (inadequate) fruit and vegetable consumption. Finally, the results of our study suggest that

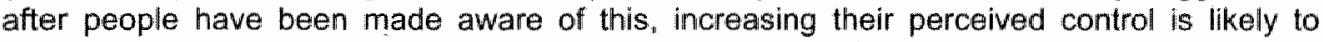
generate the greatest increase in intention and consumption. This may be done by e.g. increasing the availability of fruit and vegetables (as is done in school fruit programs (33)) and 
providing practical information on how to prepare fruits and vegetables in an easy and quick way (8).

\section{References}

1. Ness AR and Powles JW (1997): Fruit and vegetables, and cardiovascular disease: a review. Int $J$ Epidemial 26, 1-13.

2. Steinmetz KA and Potter JD (1996): Vegetables, fruiti, and cancer prevention: a review. $\checkmark$ Am Diel Assoc 96, 1027-39.

3. Hulshof KFAM, Kistemaker $\mathrm{C}$ and Bouman M (1998): The consumption of food groups by Dutch population groups: food consumption survey 1997-1998 (in Dutch). Zeist: TNO Nutrition and Food Research.

4. Lechner $L$, Brug $J$ and De Vries $H$ (1997): Misconceptions of fruit and vegetable consumption: differences between objective and subjective estimation of intake. J Nutr Educ 29, 313-20.

5. Ajzen I (1991): The theory of planned behavior. Organ Behav Hum Decis Process 50, 179-211.

6. Armitage $\mathrm{CJ}$ and Conner M (2001): Efficacy of the Theory of Planned Behaviour: A meta-analytic review. Br J Soc Psychol 40, 471-99.

7. De Vries $H_{1}$ Dijkstra $M$ and Kuhlman $P$ (1988): Self-efficacy: the third factor besides attitude and subjective norm as a predictor of behavioural intentions. Health Res 3 , 273-82.

8. Brug J, Lechner $\mathrm{L}$ and De Vries H (1995): Psychosocial determinants of fruit and vegetable consumption. Appetite 25, 285-96.

9. Brug J, Assema PV, Kok G, Lenderink T and Glanz K (1994): Self-rated dietary fat intake: association with objective assessment of fat, psychosocial factors, and intention to change. J Nutr Educ $26,218-23$.

10. Brug $\mathrm{J}$ and Van Assema $P$ (2001). Beliefs about fat: Why do we hold beliefs about fat and why and how do we study these beliefs? in Food, People and Society: $A$ European perspective of consumers' food choices (eds. Frewer $L$, Risvik $\mathbb{E}$ \& Schifferstein H). Heidelberg: Springer-Verlag.

11. Ronda G, Van Assema P and Brug J (2004): Stages of change, psychological factors and awareness of physical activity levels in the Netherlands. Health Promot Int 16. 305-14.

12. Willett WC (1994): Future directions in the development of food-frequency questionnaires. Am J Clin Nutr 59, 171 $\mathrm{s}^{4} 174 \mathrm{~s}$.

13. van 't Veer P. Kardinaal AF, Bausch Goldbohm RA and Kok FJ (1993); Biomarkers for validation. Eur J Clin Nutr 47(suppl 2), S58-S63

14. Campbell DR, Gross MD, Martini MC, Grandits GA. Slavin JL and Potter JD (1994): Plasma carotenoids as biomarkers of vegetable and fruit intake. Cancer Epidemiol Biomarkers Prev 3, 493-500.

15. Drewnowski $A_{1}$ Rock $C L$, Henderson SA, Shore AB, Fischler $C$, Galan P, Preziosi P and Hercberg $S$ (1997): Serum beta-carotene and vitamin $C$ as biomarkers of vegetable and frult intakes in a community-based sample of French adults. Am J Clin Nutr $65,1796-802$.

16. Zino S, Skeaff M, Williams S and Mann J (1997): Randomised controlled trial of effect of fruit and vegetable consumption on plasma concentrations of lipids and antioxidants. BMJ 314, 1787-91.

17. Yeum KJ, Booth SL, Sadowski JA, Liu C, Tang G, Krinsky NI and Russell RM (1996): Human plasma carotenoid response to the ingestion of controlled diets high in fruits and vegetables. Am J Clin Nutr 64, 594-602. 
18. Conner $M$ and Sparks $P$ (1996). The theory of planned behaviour and health behaviours. in Predicting health behaviour: Research and practice with social cognition models (eds. Conner M \& Norman P). Buckingham: Open University Press.

19. Speek AJ, Schrijver J and Schreurs. WH (1984): Fluorometric determination of total vitamin $C$ in whole blood by high-performance liquid chromatography with pre-column derivatization. $J$ Chromatogr $305,53-60$.

20. Hess D, Keller HE, Oberlin B "Bonfanti R and Schuep W (1991): Simultaneous determination of retinol, tocopherols, carotenes and lycopene in plasma by means of high-performance liquid chromatography on reversed phase. Int J Vitam Nutr Res 61, 232-8.

21. Oostenbrug GS, Mensink RP, Hardeman MR, De Vries T, Brouns F and Hornstra G (1997): Exercise performance, red blood cell deformability, and lipid peroxidation: effects of fish oil and vitamin E. I Appl Physiol 83,746-52.

22. Oygard $L$ and Rise $J(1996)$ : Predicting the intention to eat healthier foods among young adults. Health Educ Res 11, 453-61.

23. Conner $M$, Norman $P$ and Bell $R$ (2002): The theory of planned behavior and healthy eating. Health Psychol 21, 194-201.

24. Godin $G$ and Kok $G$ (1996): The theory of planned behavior: a review of its applications to health-related behaviors. Am J Health Promot 11, 87-98.

25. Povey $R$, Conner $M$, Sparks $P$, James $R$ and Shepherd $R(2000)$; The theory of planned behaviour and healthy eating: Examining additive and moderating effects of social influence variables. Psychol Health 14, 991-1006.

26. Lien N, Lytle LA and Komro KA (2002): Applying theory of planned behavior to fruit and vegetable consumption of young adolescents. Am I Health Promot 16, 189-97.

27. Aarts $H$, Paulussen $T$ and Schaalma H (1997): Physical exercise habit: on the conceptualization and formation of habitual health behaviours. Health Educ Res 12 , 363-74.

28. Randall DM and Wolff JA (1994): The time interval in the intention-behaviour relationship: Meta-analysis. Br J Soc Psychol 33, 405-18.

29. Myers DG (2002). Behaviour and attitudes. in Social psychology (ed. Myers DG). New York: MaGraw-Hill.

30. Jacob RA, Skala JH and Omaye ST (1987): Biochemical indices of human vitamin C status. Am I Clin Nutr 46, 818-26.

31. Bogers RP, Dagnelie PC, Westerterp KR, Kester AD, van Klaveren JD, Bast A and van den Brandt PA (2003): Using a correction factor to correct for overreporting in a foodfrequency questionnaire does not improve biomarker-assessed validity of estimates for fruit and vegetable consumption. $J$ Nutr 133, 1213-9.

32. Thompson RL, Margetts BM, Speller VM and MCVey D (1999): The health education authority"s health and lifestyle survey 1993: Who are the low fruit and vegetable consumers? J Epidemiol Community Health 53, 294-9.

33. Eriksen $K_{4}$ Haraldsdottir $J$, Pederson $R$ and Flyger HV (2003): Effect of a fruit and vegetable subscription in Danish schools. Public Health Nutr 6, 57 63. 



\section{Psychosocial predictors of increases in fruit and vegetable consumption}

Rik P Bogers

Patricia van Assema

Johannes Brug

Arnold DM Kester

Pieter C Dagnelie 


\section{Abstract}

Baseline psychosocial predictors of changes in fruit and vegetable consumption were studied in 83 healthy mothers (mean (SD) age 41 (4) years) with children aged 7-10 years who formed the experimental group of a randomised controlled trial. To induce changes in consumption, fruit and vegetables were provided free of charge during one month. Short-term changes during this month and long-term changes one year after baseline relative to $a$ control group $(n=72)$ were determined with a validated food-frequency questionnaire. Short-term changes in fruit consumption (mean (SE)) were 144 (16) g/day, and were positively associated with perceived costs and with perceived health benefits of fruit for the mothers' children, and negatively associated with perceived behavioural control. Short-term changes in vegetable consumption were $68(11) \mathrm{g} / \mathrm{day}$, and were positively related with the intention to eat at least $200 \mathrm{~g}$ of vegetables and taste preferences of the children. Long-term changes were significant only for vegetable consumption $(28$ (10) g/day), and were positively related to perceived behavioural control and perceived health benefits of vegetables for the children, and tended to be negatively related to perceived costs of vegetables. It is concluded that fruit and vegetable consumption may be encouraged by influencing the above variables. 


\section{Introduction}

Despite the evidence that fruit and vegetable consumption contributes to the prevention of cardiovascular disease (1) and cancer (2), most people in the US and NorthernEuropean countries do not meet the consumption levels $(200 \mathrm{~g}$ of vegetables and two pieces of fruit, or an equivalent of five portions of fruits and vegetables per day) recommended by public health authorities $(3,4)$. Therefore, it is desirable to stimulate the public to increase the intake of fruits and vegetables. This should be done by using a systematic approach based on knowledge aboul determinants of the (low) consumption of fruits and vegetables (5).

The focus of the present study is on psychosocial determinants of changes in intake. Various studies have studied psychosocial determinants of fruit and vegetable consumption, but with one exception (6) all of these studies had a cross-sectional design, and most studies investigated potential determinants of present behaviour, e.g. $(7-17)$. Although these studies have contributed to our understanding of what factors are associated with fruit and vegetable consumption, they do not answer the question of what psychosocial factors predict change in fruit and vegetable intake. Therefore, we conducted a longitudinal study in which baseline psychosocial factors were used to predict changes in fruit and vegetable consumption. These changes were induced by providing fruit and vegetables free of charge and asking study participants to consume the recommended amounts.

The single longitudinal study that we are aware of which associated baseline psychosocial variables with intervention effects on fruit and vegetable consumption showed that the latter were positively associated with baseline positive attitudes and responsibility for food shopping and preparation (6). In the absence of more longitudinal studies, the crosssectional data on psychosocial determinants of fruit and vegetable consumption can also be used to identify hypotheses about possible predictors of change. Previous research showed that people eat more fruits and/or vegetables when they like the taste (7-11), perceive (thealth) benefits of eating fruits and vegetables $(9,12,13)$, have a higher intention (10), more favourable attitudes $(10,14,15)$ and a higher self-efficacy $(10,11,14)$ in terms of eating fruit and vegetables, perceive more social support or stronger norms to eat fruits and vegetables $(10,11,14)$, and have more correct knowledge of the recommended intake levels for fruits and vegetables $(8,11,14)$. People eat less fruits and vegetables when they perceive more barriers (12-14) and are not aware of their insufficient consumption (16). The price of fruits and vegetables has also been negatively related to consumption (17), and Anderson et al. (18) reported that the cost of food was perceived as a barrier to greater consumption of fruits and vegetables. In families with children, fruit and vegetable consumption is also influenced by the children's taste preferences (19), and associations between children's fruit and vegetable intake and beliefs in mothers concerning disease prevention related to fruit and vegetable consumption have been reported (20).

The aims of the present study were to study baseline psychosocial predictors of shortterm and long-term changes in fruit and vegetable consumption after enhancing the availability of fruits and vegetables at home. We used data from a larger study among mothers with primary school age children.

\section{Methods}

\section{Study population}

The present study was part of a larger randomised controlled trial aimed at studying determinants of fruit and vegetable intake and validating questionnaires to measure fruit and 
vegetable intake in mothers with primary school age children $(21,22)$. Because the larger study included assessments of biomarkers of fruit and vegetable consumption in blood (not reported in the present study) potential participants had to be apparently healthy, nonsmoking women. Various ways of approaching potential study participants were used, such as distribution of invitation letters via mall to households where children aged 7-10 lived, and recruitment via schools. The total study started with 207 participants.

Study design

Approval for the present study was obtained from the medical ethics committee of Maastricht University. An initial questionnaire, which was returned by the participants by mail, was sent out in February 2001, including a food-frequency questionnaire (FFQ) and questions on age, educational level and marital status. Participants were randomly allocated to an experimental or control group after pre-stratification on fruit and vegetable intake (below vs. above median) determined with the initial FFQ.

A second questionnaire was sent out to experimental and control participants in March 2001 (baseline), agailn containing the $\mathrm{FFQ}$, which was used to calculate baseline fruit and vegetable consumption, and questions on psychosocial determinants. Participants handed in the questionnaire at the study centre and were then told if they were randomised to the experimental group or the controll group. A questionnaire identical to the second (baseline) questionnaire was completed directly following the experimental period as well as one year after the start of the experimental period.

\section{Induction of changes in fruit and vegetable consumption}

Participants were asked to consume a daily amount of at leas $200 \mathrm{~g}$ of vegetables and two pieces of fruit (the Dutch recommended intake level) over a period of one month. Packets containing recommended amounts of fruits and vegetables for each family member were dellivered each week at the participants' homes free of charge during that month, together with a weekly newslletter and recipes. In addition, participants were asked to use selfmonitoring, supported by a tool that was designed for the present study, as a means to encourage ample consumption of fruits and vegetables.

\section{Dietary assessment}

Fruit and vegetable consumption (excluding potatoes) was determined with a validated eight-item FFQ designed for measuring fruit and vegetable consumption, with a reference period of one month (23). Fruit and vegetable juice was not included in fruit and vegetable consumption in the present study, because the fruit and vegetable packets did not contain any fruit or vegetable juice. Portion size was expressed in grams by multiplying the number of servings reported for each item with the appropriate serving size in grams.

\section{Assessment of psychosocial and demographic variables}

Psychosocial constructs were measured separately for fruits and for vegetables. A literature search identified potential psychosocial predictors of fruit and vegetable consumption, which were assessed in the present study. Attitude (three items), subjective norm (four items), perceived behavioural control (wo items), and intention (two items) were measured directly on seven-point bipolar scales $(-3$ to +3 , with only the end points of the scale described with words), and referred to Dutch recommended intake levels (consumption of at least $200 \mathrm{~g}$ of vegetables and two pieces of fruit per day) (see (22). Scores on each construct were calculated as the mean of all items used to measure a construct. All constructs had acceptable internal consistency (Cronbach's a 0.57-0.96). We also measured taste perceptions related to fruit and vegetables (i.e. I think eating at least two pieces of fruit/200 $\mathrm{g}$ 
of vegetables a day tastes very bad $(-3)$ - is very tasty $(+3)^{\text {"; }}$, social support (i.e. "most people who are important to me encourage me to eat at least two pieces of fruit/200 $\mathrm{g}$ of vegetables daily" and "other family members encourage me to eat at least two pieces of fruit/200 $\mathrm{g}$ of vegetables daily (surely don't $(-3)$ - surely do $(+3) ; \alpha=0.80$ for fruits and 0.81 for vegetables)"; perceived costs (i.e. 'do you think fruit/vegetables is/are expensive or cheap?' (very expensive $(-3))$ to (very cheap $(+3)$; responses were inverted so that more positiwe values indicate higher perceived costs): perceived health benefits for child (i.e. "do you think that your child must eat sufficient fruit/vegetables to be healthy?" (surely don't $(-3)-$ surely do $(+3)$ ); and taste perceptions of child (i.e. 'my son/daughter thinks fruit/vegelables' (is very tasty $(-3)$ - tastes very bad $(+3)$ ). Further, knowledge of recommended intake levels was assessed by asiking 'what, according to you, is the guideline for the amount of fruit/vegetables you should eat daily?", with open response options (... pieces of fruit $/ \ldots$ grams of vegetables a day). Persons giving answers of two pieces of fruit or $200 \mathrm{~g}$ of vegetables or more were classified as having correct knowledge, those giving an answer below the recommended amounts as not having correct knowledge. Awareness of fruit and vegetable consumption was assessed as follows: consumption was assessed 'objectively" with the FFQ and dichotomised in "less than two pieces' or 'two or more pieces' of fruit (less or more than $200 \mathrm{~g}$ of vegetables) a day. Self-rated consumption was determined with the question 'Do you think you eat insufficient or sufficient amounts of fruit (vegetables)? (insufficient - sufficient)", scored as -3 to +3 and dichotomised as "sufficient' when a participant scored 1,2 or 3, and as 'insufficient" when the score was zero or less. Participants with congruent objective and subjective dichotomised scores were categorised as 'realists', and participants with incongruent scores as 'overestimators' of 'underestimators'. Educational level, the only demographic variable assessed in the present study as a possible covariate, was defined as the highest completed education, and was categorised into high, intermediate or low. Body mass index was calculated from weight and height measured by the researchers at the study centre as weight $(\mathrm{kg}) /$ height ${ }^{2}(\mathrm{~m})$.

\section{Statistical analysis}

The data collected one month after baseline were only analysed for persons of whom baseline data were available, and data collected one year after baseline were only analysed for persons of whom we had data both at baseline and one month follow-up. Respondents were excluded from further analysis if their FFQs or questions on psychosocial constructs contained more than 20 percent missing values. Remaining missing values were substituted with population means in the case of dietary data (maximum: $n=6$ for portion size of "other fruits'), or with a neutral value (zero) in any of the questions assessing psychosocial constructs (maximum: $n=3$ per item). Participants with a missing value on the question of knowledge of recommended intake ( $n=2$ for fruits and $n=3$ for vegetables) were classified as "not knowing the recommendation'.

Parameter-free statistical tests were used if variables were not normally distributed. The Mann-Whitney $U$ test or $t$ test was used to evaluate statistical significance of changes in fruit or vegetable consumption in the experimental group relative to the control group. If changes in consumption significantly differed between both groups (as we aimed to assess determinants of program-induced changes), variables that best predicted changes in fruit and vegetable consumption in the experimental group were selected using backward linear regression analysis, with a threshold p-value for removall of 0.10 . Dependent variables in the models were the changes in consumption. Independent variables in the starting model were intention "attitude, subjective norm, perceived social support, perceived behavioural control perceived costs, taste perceptions, awareness of sufficiency of own consumption, perceived health benefits for child, taste perceptions of child, knowledge of the recommended intake, and educational level. Baseline fruit and vegetable consumption was included as a covariate. Regression models were checked for normality, linearity and homogeneity of variance. 
Participants with an absolute studentised deleted residual greater than 3.5 were identified as outliers (24). They were excluded from the analysis and models rerun until no outliers were left.

\section{Results}

Of the 207 women who agreed to participate 192 completed the initial questionnaire. One hundred and seventy-four women completed the second questionnaire preceding the experimental period ( 86 controls and 88 participants from the experimental group). immediately after the experimental period, questionnaires were completed by 165 participants ( 77 controls and 88 participants from the experimental group). Eight respondents were excluded from further analysis because their FFQs contained more than 20 percent missing values ( $n=2$ participants from the experimental group at baseline, and $n=2$ participants from the experimental group and $n=4$ control participants immediately after the experimental period), and one control and one participant from the experimental group were excluded because they provided insufficient responses (more than 20 percent missing walues) on the questionnaire assessing psychosocial variables, leaving a total number of 155 participants ( $81 \%$ of the initial number; 72 controls and 83 participants from the experimental group). Data collected one year after baseline were analysed for 134 participants $(70 \%$ of the initial number; 59 controls and 75 participants from the experimental group). In the analyses on vegetable consumption, one participant from the experimental group was excluded because of a high number of missing values in the questions assessing the psychosocial constructs regarding vegetable consumption.

The 83 women randomised to the experimental group had a mean age of 41 (4) years and a mean body mass undex of $23.9(3.4) \mathrm{kg} / \mathrm{m}^{2}$. Five percent had a $10 \mathrm{w}, 55 \%$ an intermediate $e_{\text {and }} 40 \%$ a high educational level. Ninety-one percent of the women were living with a partner. Table 1 presents baseline characteristics of the experimental group. Mean scores on most psychosocial constructs at baseline were positive, with the exception of perceived social support. Fruit and vegetables were on average perceived to be expensive. The highest positive scores both for fruits and for vegetables were observed for the perceived health benefits for the participants' children.

The change in fruit and vegetable consumption between baseline and the end of the fruit and vegetable deliveries was significantly higher in the experimental group than in the control group (Table 2). The proportion of participants who reported meeting the recommended intake levels also was significantly higher in the experimental group at the first measurement after the experimental period. In contrast, one year after baseline the change was only statistically significant for vegetable consumption, though mainly as a result of a decrease in vegetable consumption in the control group. 


\section{Table 1}

Baseline characteristics of the experimental group $(n=83)$

\begin{tabular}{|c|c|c|c|c|}
\hline & \multicolumn{2}{|c|}{ Fruit } & \multicolumn{2}{|c|}{ Vegetables } \\
\hline & $\begin{array}{l}\text { Mean or } \\
\text { percentage }\end{array}$ & (SD) & $\begin{array}{l}\text { Mearn or } \\
\text { percentage }\end{array}$ & (SD) \\
\hline Consumption at baseline (g/day) & 175 & $(108)$ & 183 & (94) \\
\hline $\begin{array}{l}\% \text { of participants eating } 2 \text { pieces of fruit } \\
\text { ore }>200 \mathrm{~g} \text { of vegetables at baseline }\end{array}$ & 23 & & 33 & \\
\hline $\begin{array}{l}\% \text { of participants knowing the } \\
\text { recommended intake }\end{array}$ & 81 & & 82 & \\
\hline Intention & 1.7 & $(11.4)$ & 2.4 & $(1.0)$ \\
\hline Attitude & 2.1 & $(0.9)$ & 2.6 & $(0.5)$ \\
\hline Subjective norm & 0.6 & $(1.2)$ & 0.9 & $(1.1)$ \\
\hline Sociall support & -1.1 & $(1.6)$ & -0.5 & $(1.6)$ \\
\hline Perceived behavioural control & 1.4 & (1.5) & 2.2 & $(1,1)$ \\
\hline Perceived costs & 0.7 & (1.1) & 0.4 & $(1.1)$ \\
\hline Taste perceptions & 1,7 & $(1.2)$ & 2.4 & $(0.8)$ \\
\hline $\begin{array}{l}\% \text { of participants aware of sufficiency of } \\
\text { own consumption }\end{array}$ & 72 & & 45 & \\
\hline Perceived thealth benefits for chilld & 2.4 & $(1,2)$ & 2.6 & $(0.7)$ \\
\hline Taste perceptions child ${ }^{\mathrm{a}}$ & 1.5 & (1.4) & 0.6 & $(1.5)$ \\
\hline
\end{tabular}

${ }^{a}$ As reported by the mother.

\section{Table 2}

Changes in fruit and vegefable consumption after the period of enhanced availability of fruits and vegetables, compared to baseline consumption

\begin{tabular}{|c|c|c|c|c|c|}
\hline & \multicolumn{2}{|c|}{$\begin{array}{l}\text { Intervention } \\
\text { group }\end{array}$} & \multicolumn{2}{|c|}{$\begin{array}{l}\text { Change relative to } \\
\text { control group }\end{array}$} & \multirow[t]{2}{*}{$\begin{array}{l}\text { P-value for } \\
\text { difference }\end{array}$} \\
\hline & Mean & (SD) & Mean & $(S E)$ & \\
\hline \multicolumn{6}{|l|}{ Immediately after experimental period } \\
\hline Change in fruit consumption (g/day) & 139 & $(129)$ & 1.44 & $(46)$ & $0.00^{\circ}$ \\
\hline Change in vegetable consumption (g/day) & 62 & $(84)$ & 68 & $(11)$ & $0.00^{\mathrm{d}}$ \\
\hline $\begin{array}{l}\text { Change in percentage of participants eating } \\
2 \text { pieces of fruit at follow-up }\end{array}$ & 37 & & 37 & & $0.00^{\circ}$ \\
\hline $\begin{array}{l}\text { Change in percentage of participants eating } \\
200 \mathrm{~g} \text { of vegetables at follow-up }\end{array}$ & 40 & & 37 & & $0.00^{\mathrm{c}}$ \\
\hline \multicolumn{6}{|l|}{ One year after start of experimental period" } \\
\hline Change in fruit consumption ( $g /$ day) & 10 & (99) & 23 & $(48)$ & $0.20^{\mathrm{d}}$ \\
\hline Change in vegetable consumption (g/day) & 7 & $(75)$ & 28 & $(10)$ & $0.01^{d}$ \\
\hline $\begin{array}{l}\text { Change in percentage of participants eating } \\
2 \text { pieces of fruit at follow-up }\end{array}$ & -4 & & -4 & & $0.85^{\circ}$ \\
\hline $\begin{array}{l}\text { Change in percentage of participants eating } \\
200 \mathrm{~g} \text { of vegetables at follow-up }\end{array}$ & 7 & & 6 & & $0.15^{\mathrm{C}}$ \\
\hline
\end{tabular}

\footnotetext{
${ }^{a} \mathrm{~N}=72$ controls and 83 intervention participants.
}

$\mathrm{b} N=59$ controls and 75 intervention participants.

DDifferences between intervention and control group tested with Mann-Whitney test.

dDifferences between intervention and control group tested with independent samples $f$ test. 
Tables 3 and 4 provide the results of the backward regression analyses performed to select predictors of change in fruit and vegetable consumption in the experimental group. Regression coefficients indicate the increase or decrease in fruit and vegetable consumption after the experimental period compared to baseline associated with a unit increase in the independent variables. Table 3 shows predictors of short-term changes in fruit and vegetable consumption. A larger increase in fruit consumption in the experimental group was observed in women who, at baseline, consumed less fruits, considered fruit to be expensive, had a low perceived control, or perceived more health benefits for their child of eating fruit. Changes in vegetable consumption were, in addition to baseline consumption, explained by the intention to eat at least $200 \mathrm{~g}$ of vegetables and the women's children taste perception of vegetables.

\section{Table 3}

Predictors of change in frut and vegetable consumption in the intervention group ( $n=8$ 1) measured immediately after the intervention period

\begin{tabular}{|c|c|c|c|c|}
\hline Independent variables & $\begin{array}{l}\text { Standar- } \\
\text { dized } \beta\end{array}$ & $\beta$ & $p$-value & $\begin{array}{c}\text { Model adj. } R^{2} \text { / Change in adj. } \\
R^{2} \text { when variable omitted }\end{array}$ \\
\hline Fruits $(n=81)^{i}$ & & & & 0.34 \\
\hline Consumption at baseline & -0.26 & -0.28 & 0.03 & 0.03 \\
\hline Perceived costs & 0.38 & 41.63 & 0.00 & 0.14 \\
\hline Perceived behavioural control & -0.24 & -19.01 & 0.05 & 0.03 \\
\hline Health benefits for child & 0.19 & 18.85 & 0.05 & 0.03 \\
\hline Vegetables $(n=82)^{b}$ & & & & 0.48 \\
\hline Consumption at baseline & -0.72 & -0.65 & 0.00 & 0.49 \\
\hline Intention to eat $\geq 200 \mathrm{~g} / \mathrm{d}$ wegetables & 0.19 & 15.7 & 0.03 & 0.03 \\
\hline Taste perceptions child ${ }^{\text {a }}$ & 0.18 & 10.3 & 0.03 & 0.03 \\
\hline
\end{tabular}

"Two outliers excluded.

'As reported by the mather.

Table 4 shows that changes in vegetable consumption in the experimental group one year after baseline were positively associated with perceived behavioural control and perceived health benefits of eating vegetables for the participants" children. Changes tended to be neglatively associated with perceived costs $(p=0.07)$. Since no significant long-term change in frulit consumption was observed, predictors of this variable were not studied.

\section{Discussion}

We studied which psychosocial variables measured at baseline predicted changes in fruit and vegetable consumption. Perceived costs of fruit, perceived behavioural control, and perceived health benefits for the participants' child were significant predictors of short-term changes in fruit consumption. Short-term changes in vegetable consumption were predicted by the intention to eat at least $200 \mathrm{~g}$ of vegetables, and the children's taste perceptions (as reported by the mothers). Smaller long-term changes in vegetable consumption were predicted by perceived behavioural control, perceived health benefits for the child, and perceived costs of vegetables (the latter not significantly). 
Table 4

Predictors of change in vegetable consumption in the intervention group $(n=7$ th measured one year after the start of the intervention period

\begin{tabular}{lcccc}
\hline Independent variables & $\begin{array}{c}\text { Standar- } \\
\text { dized } \beta\end{array}$ & $\beta$ & p-value & $\begin{array}{c}\text { Model adj. } R^{2} / \text { Change in adj. } \\
R^{2} \text { when variable omitted }\end{array}$ \\
\hline Comsumption at baseline & & & & 0.55 \\
Perceived behavioural control & -0.75 & -0.58 & 0.00 & 0.51 \\
Perceived health benefits for child & 0.21 & 13.52 & 0.02 & 0.03 \\
Perceived costs & 0.19 & 22.51 & 0.02 & 0.03 \\
\hline
\end{tabular}

Before elaborating on the findings, some methodological issues will be discussed in order to facilitate a correct interpretation of the results. First, all the participants agreed at the beginning of the study to consume amounts of fruits and vegetables in accordance with the recommendations if allocated to the experimental group. This may have resulted in the observed small amount of variance in changes in fruit and vegetable consumption that was explained by other predictors than baseline consumption, and may have influenced the results through individual differences in the tendency to comply with their agreement to consume the recommended amounts. However, since we wanted to induce changes in fruit and vegetable consumption without affecting psychosocial variables, increasing availability of fruits and vegetables (though this likely also increased perceived control) was considered the best option. Second, although fruit and vegetable consumption was assessed with a validated FFQ, the possibility that the intervention affected the participants' reporting of their consumption cannot be excluded. However, as reported in a previous study (23), we also found an increase in biochemical markers of fruit and vegetable intake in the intervention group, which most likely resulted from a real increase in consumption. Finally, generalisation of our findings is limited, because the present study was performed in a selective study population, i.e. mostly intermediate or highly educated nonsmoking women with children, who were possibly more health-conscious than a more representative population.

Changes in consumption were strongly (negatively) related with fruil and vegetable consumption at baseline, which was to be expected since the women who already consumed relatively large amounts of fruits and vegetables did not have to increase their consumption much to comply with the recommended intake levels, whereas women who atte small amounts at baseline had to make larger changes. Perceived behavioural control and perceived costs of fruits and vegetables were associated with changes in fruit and vegetable consumption. The observation that persons with a low control who consider fruits as expensive showed the highest short-term increases in fruit consumption may have been the result of the provision of free fruits during the experimental period. This free provision of fruits and vegetables seem to have helped respondents to overcome financial barriers and low levels of perceived control. One year after baseline the associations between perceived costs and perceived behavioural control with changes in vegetable consumption were in the opposite direction, which was to be expected since the intervention that improved availabiltiy had stopped.

Cost considerations thus seem to play an important role in the consumption of fruits and vegetables. This is consistent with a previous study which, using linear programming, predicted that the proportion of energy from fruits and vegetables decreases when a lower budget is available for the purchase of foods (17). Also, intervention studies showed that reducing the price of (healthy) foods affects their consumption; $\Theta .9$. price reductions of $50 \%$ resulted in a four-fold increase in fresh fruit sales and a two-fold increase in baby carrot sales in two secondary school cafeterias (25). However, in a low-income group in the UK, affordability of fruit and vegetables was not a clear cause of low consumption (26), and in a national sample of adults in the US, the importance of cost in food behaviour was not related to fruit and vegetable consumption (7). Our study population was not a specific low-income 
group, but apparently vegetables were perceived as expensive foods, possibly because they may be compared with cheaper alternatives. Because of contradictory findings, wre suggest that the influence of price on consumption of fruits and vegetables be further explored.

Perceived behavioural control and intention have been found to predict fruit and vegetable consumption in cross-sectional studies $(10,11,14)$. In line with these studies, we found that these variables also predicted changes in consumption. Thus, it seems warranted to develop interventions that are aimed at increasing perceived control and intention.

Two variables we found as predictors of change (i.e. the child's taste perceptions of vegetables as reported by the mother and perceived health benefits of fruits and vegetables for her child) concern the influence that children have on their mothers." fruit and vegetable consumption. The influence of children on their mothers" fruit and vegetable consumption has been found before in focus group research (19). Since vegetables in the Netherlands are mainly eaten during dinner as part of a meal (27), mothers with children who do not like vegetables may be less prone to serve large amounts of vegetables at dinner. Mothers who think their children must eat fruits to be healthy may either want to give a good example to their children, or may have a higher concern for healthy eating in general. The above findings would suggest that fruit and vegetable promotion may be more effective if it also affects mothers' beliefs of the health benefits of fruits and vegetables for their children, and if it makes the taste of vegetables more attractive to children.

We are aware of only one longitudinal study that examined baselline predictors of intervention effects on fruit and vegetable consumption (6). In this study, baseline attitudes and responsibility for food shopping and preparation were found to be independent predictors of changes in fruit and vegetable consumption after an intensive nutritional intervention designed to inform participants concerning the benefits of fruits and vegetables, to improve attitudes, encourage feelings of self-efficacy, provide sociall support, and to reduce perceived barriers to increased consumption of fruits and vegetables. The aim and type of this intervention contrast to the present study, because we wanted to induce changes in consumption mainly by improving fruit and vegetable availability. This may account for the different results found in the above and the present study. In addition, differences between study populations may have led to different results.

A number of psychosocial variables known to be associated with fruit and vegetable consumption in cross-sectional studies (such as taste $(7-11)$, attitude $(10,14,15)$, social influence $(10,11,14)$, awareness of own consumption (16), and knowledge of recommendations $(8,11,14)$ ) were not found to predict changes in fruit and vegetable consumption in the present study. This may be due to the fact that participants had committed themselves, at the start of the study, to eat the requested amounts of fruit and vegetables during the experimental month. Such an experimental setting leaves less space for internal motivators such as attitudes that may increase consumption of fruits and vegetables. Alternatively, other variables than the above variables may play a more important role if individuals want to increase their fruit and vegetable consumption.

In conclusion, our study is one of the first studies relating psychosocial variables at baseline to changes in intake of fruits and vegetables. Our findings suggest that consumption of fruits and vegetables may be encouraged by reducing their (perceived) price, enhancing the intention and control that persons perceive to have over their fruit and vegetable consumption, and possibly -in mothers with children- by emphasising health benefits for their children and making vegetables more attractive to their children.

\section{References}

1. Ness AR and Powles JW (1997): Fruit and vegetables, and cardiovascular disease: a review. Int $I$ Epidemiol 26, 1-13. 
2. Steinmetz KA and Potter JD (1996): Vegetables, fruit, and cancer prevention: a review. $J$ Am Diet Assoc 96, 1027-39.

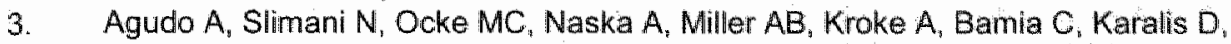
Vineis P, Palli D, Bueno-de-Mesquita HB, Peeters PH, Engeset D, Hiartaker A. Navarro $C_{4}$ Martinez Garcia C, Wallstrom P, Zhang JX, Welch AA, Spencer E, Stripp $C$, Overvad K, Clavel-Chapelon F, Casagrande $C$ and Riboli $E(2002$ ): Consumption of vegetables, fruit and other plant foods in the European Prospective Investigation into Cancer and Nutrition (EPIC) cohorts from 10 European countries. Public Health Nutr 5 , $1179-96$.

4. Li R, Serdula M, Bland $S$, Mokdad A, Bowman B and Nelson D (2000): Trends in fruit and vegetable consumption among adults in 16 US states: Behavioral Risk Factor Surveillance System, 1990-1996. Am J Public Health 90, 777-81.

5. Brug J, Schaalma H, Kok G, Meertens RM and Van der Molen HT (2000). Gezondheidsvoorlichting en gedragsverandering: een planmatige aanpak. Assen: Van Gorcum.

6. Langenberg $P$, Ballesteros $M_{1}$ Feldman $R$, Damron D, Anliker $J$ and Havas $S(2000)$ : Psychosocial factors and intervention-associated changes in those factors as correlates of change in fruit and vegetable consumption in the Maryland WIC 5 a day promotion program. Ann Behav Med 22, 307-15.

7. Glanz K, Basil M, Maibach E, Goldberg J and Snyder D (1998); Why Americans eat what they do: taste, nutrition, cost, convenience, and weight control concerns as influences on food consumption. I Am Diet Assoc 98, 1118-26.

8. Krebs Smith $S M$, Heimendinger J, Patterson BH, Subar AF, Kessler R and Pivonka $E$ (1995): Psychosocial factors associated with fruit and vegetable consumption. Am $J$ Health Promot 10, 98-104.

9. Satia JA, Kristal AR, Patterson RE, Neuhouser ML and Trudeau E (2002):

Psychosocial factors and dietary habits associated with vegetable consumption. Nutrition 18, 247-54.

10. Brug J, Lechner $L$ and De Vries H (1995): Psychosocial determinants of fruit and vegletable consumption. Appetite 25, 285-96.

11. Van Duyn MA, Kristal AR, Dodd K, Campbell MK, Subar AF, Stables G, Nebeling L. and Glanz K (2001): Association of awareness, intrapersonal and interpersonal factors, and stage of dietary change with fruit and vegetable consumption: a national survey. Am J Health Promot 16, 69-78.

12. Hagdrup NA, Simoes EJ and Brownson RC (1998): Fruit and vegetable consumption in Missouri: Knowledge, barriers and benefits. Am J Health Behav 22, 90-100.

13. Trudeau E, Kristal AR, Li S and Patterson RE (1998): Demographic and psychosocial predictors of fruit and vegetable intakes differ: implications for dietary interventions. $J$ Am Diet Assoc 98, 1412-7.

14. Havas $S$, Treiman $K$, Langenberg $P$, Ballesteros M. Anliker J Damron D and Feldman $R$ (1998): Factors associated with fruit and vegetable consumption among women participating in WIC. J Am Diet Assoc $98,1141-8$.

15. Thompson RL, Margetts BM, Speller VM and McVey D (1999): The health education authority"s health and lifestyle survey 1993: Who are the low fruit and vegetable consumers? J Epidemiol Community Health 53, 294-9.

16. Lechner L, Brug J and De Vries H (1997): Misconceptions of fruit and vegetable consumption: differences between objective and subjective estimation of intake. I Nutr' Educ 29, 313-20.

17. Darmon $N_{x}$ Ferguson EL and Briend A (2002): A cost constraint alone has adverse effects on food selection and nutrient density: an analysis of human diets by linear programming. J Nutr 132, 3764-71. 
18. Anderson AS, Cox DN, McKellar S, Reynolds J, Lean ME and Mela DJ (1998): Take Five, a nutrition education intervention to increase fruit and vegetable intakes: impact on attitudes towards dietary change. Br $J$ Nutr $80,133-40$.

19. Uetrecht CL, Greenberg M, Dwyer J IM, Sutherland S and Tobin S (1999): Factors influencing vegetable and fruit use. Implications for promotion. Am I Health Behav 23, $172-81$.

20. Gibson EL, Warde $J$ and Watts $C J(1998)$. Fruit and wegetable consumption, nutritional knowledge and beliefs in mothers and children. Appetite 31, 205-28.

21. Bogers RP, Dagnelie PC, Westerterp KR, Kester AD, van Klaveren JD, Bast $A$ and van den Brandt PA (2003): Using a correction factor to correct for overreporting in a foodfrequency questionnaire does not improve biomarker-assessed validity of estimates for fruit and vegetable consumption. J Nutr 133, 1213-9.

22. Bogers RP, Brug J, van Assema $P$ and Dagnelie PC (2004): Explaining fruit and vegetable consumption: the theory of planned behaviour and misconception of personal intake levels. Appetite 42, 157-66.

23. Bogers RP, Van Assema P, Kester AD, Westerterp KR and Dagnelie PC (2004): Reproducibility, validity, and responsiveness to change of a short questionnaire for measuring fruit and vegetable intake. Am J Epidemiol 159, 900-9.

24. Weisberg S. Applied linear regression (John Wiley \& Sons, New York, 1985).

25. French SA (2003): Pricing effects on food choices. J Nutr 133, 841S-843S.

26. Dibsdall LA Lambert N, Bobbin RF and Frewer LJ (2003): Low-income consumers" attitudes and behaviour towards access, availability and motivation to eat fruit and vegetables. Public Health Nutr 6, 159-68.

27. Kistemaker C. Hulshof KFAM and Bouman M (1998): The consumption of food groups per meall characterization: food consumption survey 1997-1998 (in Dutch). Zeist: TNO Nutrition and Food Research. 
Family-related influences on fruit and vegetable consumption in seven to ten-year-old children

Rik P Bogers

Patricia van Assema

Jan Joosten

Johannes Brug

Pieter C Dagnelie 


\section{Abstract}

In order to increase children"s fruit and vegetable consumption, more knowledge is needed about determinants of intake and about factors predicting changes in intake. The present study explored the influence of family-related factors on (changes in) fruit and vegetable consumption in children aged 7-10 years. The study population consisted of 158 mother-child pairs (mean age mothers $41 \pm 4$ years). Mothers completed a vallidated foodfrequency questionnaire about their own and their children's fruit and wegetable consumption, and a questionnaire assessing variables concerning home availability of fruit and vegetables, meal structure, food socialisation, parenting style, food-related parenting practices, and demographic factors. Positive associations were observed between children's fruit consumption and their mothers' fruit consumption, strict obligation rules to eat fruit and vegetables, adherence to a special diet, perceived home avallability of fruit, and the mothers: educational level. Children with employed mothers consumed less fruit than children with nonworking mothers. Children's consumption of vegetables was positively associated with their mother's vegetable consumption and negatively associated with adherence to a special diet. Changes in children's fruit consumption, which were induced in an experimental group ( $n=82)$ by increasing availability of fruit and vegetables at home, were not related to any of the variables under study. Changes in vegetable consumption were lower in children from families that grew their own produce and higher in families in which the father worked at irregular times. The findings indicate that several family-related factors influence consumption of fruits and vegetables in children. 


\section{Introduction}

A high consumption of fruts and vegetables is associated with a lower risk of certain types of cancer (1) and cardiovascular disease (2). Therefore, several national and international organisations, including the World Health Organisation have recommended to consume a daily amount of at least $400 \mathrm{~g}$ of fruits and vegetables (3). However, these recommendations are not met by a considerable part of populations in many industrialised countries $(4,5)$. A low fruit and vegetable consumption is also apparent in children $(6,7)$. Especially children should be encouraged to eat more fruits and vegetables, because in addition to the prevention of chronic diseases, sufficient consumption of fruits and vegetables in childhood can help to establish healthy food habits and preferences $(8,9)$.

in order to increase children"s fruit and vegetable consumption, more knowledge is needed about determinants of intake (10), and about factors that can predict changes in intake. Various authors have pointed towards the importance of the family and parents in the composition of children"s diets (11-14). In a review, Nicklas et al discriminate between at least five ways in which parents can influence their children's fruit and vegetable consumption: controlling the availability and accessibility; meal structure; food modelling; food socialisation practices; and parenting style and food-related parenting practices (14). The present paper focuses on these family-reated factors, which will be briefly further introduced below.

Availability refers to the presence of fruits and vegetables at home, while accessibility concerns whether fruits and vegetables are avallable in a form location and time that facilitates their consumption (15). Previous studies have found positive associations between avallability and accessibility and children's fruit and vegetable consumption (15-19). Furthermore, eating home grown produce, which might overcome problems of availability and affordability, was also associated with high intake of fruits and vegetables in adults (20).

Meal structure includes the number of eating occasions, how often parents cook dinner, the frequency of a family dinner, and companions of children at meals (14). Gillman et al. showed that the frequency of eating dinner together as a family was positively associated with fruit and vegetable consumption in older children and adolescents (21). Stanek et al. showed that children who had companionship at mealtime ate more servings of the basic food groups, including fruits and vegetables (22). Meal duration has also been shown to mediate social facilitation of food intake (23) and is associated with the number and rate of verbal and physical food intake-related encouragements and discouragements mothers give to their children (24).

In a process called parental food socialisation, parents' preferences, beliefs and attitudes toward food can shape their children's food consumption. This can be achieved by modelling, which is a concept from social learning theory and refers to the fact that in this case- children learn behaviours by watching others. Parental modelling and consumption of fruit and vegetables by parents have been shown to be associated with children's fruit and vegetable intake (25-27). Children may also model their parents" attitudes and beliefs. DeBourdeaudhuij et al. (28) showed that social interactions around food in families (e.g. the extent to which the foods that adolescents asked to bring from the store were healthy or unhealthy) were related with adolescents' fruit and vegetable consumption. Furthermore, mothers' nutritional knowledge and beliefs about the health benefits of fruit and vegetables for food in generall) for their children were positively related to their children's fruit intake (29).

Parenting style and parenting practices refer to general and domain specific behavioural methods used by parents to maintain, modify, or control chilldren's behaviours (30). Literature on parenting sityle usually identifies a dimension of parental warmth, acceptance or involvement, and a dimension of parental control or strictness. Based on these dimensions, three broad types of parents and styles of child rearing and discipline have been 
identified: authoritarian, permissive, and authoritative (31). Authoritarian parents value obedience and respect for authority. They typically use restrictive forms of control like physical punishment to teach their children respect (31). Kremers et al. (32) showed that adolescents with authoritarian parents consumed less fruit than adolescents from parents who primarily used authoritative or induggent (i.e. permissive and involved) parenting styles. An authoritative parenting style, a constellation of parent attributes that includes emotional support, high standards, appropriate autonomy granting, and clear, bi-directional communication, has been related to multiple positive child outcomes (33). Two studies found positive associations between an authoritative parenting style and adolescents fruit (and vegetable) intake (32,34), whereas two other studies in younger children did not $(25,27)$.

Regarding parenting practices, Fisher et al. (26) concluded that the extent to which parents pressure children to consume foods may discourage fruit and vegetable intake among young girls, but three other studies did not show an association between parent foodrelated practices (food rules, parental control) and children's fruit and vegetable consumption $(25,27,28)$. Although parenting practices can be regarded as socialisation techniques, the present study discriminates them from parental food socialisation because parenting practices are thought of as a more direct way of socialising children's food habits.

The objective of the present study is to explore the relative influence of fruit and vegetable availability, meal structure, parental modelling, parental food socialisation, and parenting styles and practices on fruit and vegetable consumption of elementary school children. We used baseline data from a randomised controlled study to assess cross-sectional associations between children's fruit and vegetable intake and family-and parent-related factors. In addition, we studied which factors predicted changes in fruit and vegetable consumption in an experimental group in which changes were induced. Although the focus of the paper is not on demographic predictors of fruit and vegetable intake, some demographic variables were also studied because we wanted to explore the influence of family-related factors independent of demographic differences between families, and because socioeconomic stattus may confound the association between parenting style and children's fruit and vegetable consumption. Furthermore, we hypothesised that some demographic factors such as parental employment status may compete with parental and household obligations such as food purchase and preparation. The present study adds to the existing knowledge in two ways. First, various sorts of parental influence are assessed simultaneously, and second, parent-related determinants of changes in children's fruit and vegetable consumption are explored.

\section{Methods}

\section{Study population}

The present study uses data from a larger randomised controlled study among mothers and their children. From the population registry of the municipality of Maastricht, a random sample was obtained containing 2000 addresses of children aged $7-10$ years. Various ways of approaching potential study participants were used, such as distribution of invitation letters via mail to households whit children aged 7-10, and recruitment via schools. Recruitment was stopped when more than 200 mother-child pairs were enrolled. The study started with 207 participants. Only healthy, nonsmoking mothers were included because the larger study also comprised analysis of biochemical markers of fruit and vegetable intake in blood (35). 
Approval for the study was obtained from the medical ethics committee of Maastricht University. An initial questionnaire, which was returned by the mothers by mail, was sent out in February 2001, including questions on background characteristics, meal structure, parenting styles, adherence to special diets, availability of home-grown produce, and a validated concise food-frequency questionnaire (FFQ) (35). Participants were randomly allocated to the experimentall or control group after prestratification on the mother's fruit and vegletable intake (below vs. above median) determined with the initial FFQ.

A second questionnaire was sent out in March 2001 (baseline), again containing the $F F Q$, which was used to calculate baseline fruit and vegetable consumption, and questions on home availability of fruits and vegetables, parenting food-related practices, and mothers' attitude towards fruit and vegetables. After the mothers handed in the questionnaire at the study centre they were tolld if they were randomised to the experimental group or the control group. A questionnaire identical to the second (baseline) questionnaire was completed directly following the period of induced increased fruit and vegetable consumption as well as one year after baseline. All questionnaires were completed by the mothers.

\section{Experimental period}

Mothers and children in the experimental group were asked to consume a daily amount of at least $200 \mathrm{~g}$ (mothers) or $150 \mathrm{~g}$ (children) of vegetables and two pieces of fruit (the Dutch recommended intake levels) over a period of one month. At the start of the study, all mothers agreed that they and their child would eat the requested amounts if they were randomised to the experimental group. Packets containing recommended amounts of fruits and vegetables for each familly member were delivered each week at the participants' homes free of charge, together with a weekly newsletter and recipes. In addition, mothers and children in the experimental group were asked to self-monitor their fruit and vegetable consumption as a means to encourage ample consumption.

\section{Variables}

\section{Fruit and vegetable consumption}

Fruit and vegetable consumption was determined with a validated eight-item FFQ designed for measuring fruil and vegetable consumption, with a reference period of one month. The FFQs which assessed the children's fruit and vegetable consumption were completed by the mothers. Details of the FFQ and the procedure used to calculate fruit and vegetable consumption are described in Bogers at al. (35). In the present study, portion size was expressed in grams by multiplying the number of serwings reported for each item with the appropriate serving size in grams. Fruit consumption (excluding juice) was calculated as the sum of five items: tangerines; other citrus fruits; apples and pears; bananas; other fruit. Vegetable consumption was calculated as the sum of cooked vegetables (excluding potatoes) and raw vegetables.

\section{Perceived home availability of fruits and vegetables}

One item assessed on a seven-point bipolar scale whether respondents usually had fruit/vegetables available at home (perceived availability), with possible answers ranging from never $(-3)$ to always $(+3)$. Another item indicated if families grew their own fresh produce (growing own produce).

\section{Meal structure}

Two items referred to meal structure. The first item indicated which family members usually had dinner together. Because of limited variation in the answers, two categories were made in which every child could be placed: the child having dinner with one of the parents, or 
with both parents. The second item concerned the duration of dinner at weekdays ( $<15$ min, $15-30 \mathrm{~min}, 30-45 \mathrm{~min},>45$ min; dichotomised in $<30 \mathrm{~min}$ vs. $>30 \mathrm{~min}$ ).

\section{Parental food socialisation}

Three items addressed parental food socialisation. As a measure of the mother's attitude and beliefs regarding fruit and vegetable consumption, we combined five items (on seven-point bipolar scales ranging from -3 for negative answers to +3 for positive answers): "I think it is (very bad - very good, very unpleasant - very pleasant, tastes very bad - very tastly, very unhealthy - very healthy, ) to eat at least two pieces of fruit a day' and 'do you think your that your child must eat sufficient fruit/vegetables to be healthy?' (surely don't - surely do). Cronbach's $\alpha$ 's for these five items were 0.65 for fruit consumption and 0.78 for vegetable consumption. Mothers could also indicate whether their child adhered to one of the following special diets: vegetarian, vegan, macrobiotic, anthroposophic, religious, organic, biologicdynamic, or other diet. Finally, the mother's fruit and vegetable consumption measured with the FFQ was used as a proxy for maternal modelling.

\section{Parenting style and practices}

Two dimensions of parenting style were measured: maternal involvementaffection, and restrictive control. The scales that were used to assess these dimensions were adopted from Vermaes et al. (36). Maternal involvement and affection was assessed with two subscales that measured emotional involvement between mother and child ( 9 items) and affection expression of the mother towards her child (8 items). Restrictive control was determined with two subscales that assessed the use of punishment (5items) and the degree to which the mother values conformity of her child to existing demands, rules, and norms of the parents, family and society (10 items). A higher score on the restrictive control and involverment and affection scales indicated a more restrictive style or a more involved/affectionate parenting style, respectively. A principal component analysis of the 32 items in the present study revealed that involvement/affection and restrictive control were indeed two separate factors. Two items were excluded from the scales because of a low correlation with either scale or a high improvement in consistency of the scalle if the item was deleted. The internal consistencies expressed as Cronbach's $\alpha$ of the final scales as used in the present analyses were 0.84 (involvement/affection) and 0.85 (restrictive control).

The measurement of food-related parenting practices was performed with a questionnaire developed by Hupkens et al. (37). This questionnaire assessed whether mothers allow their children never, sometimes or always to eat 20 common foods, whether they oblige their children sometimes or always to eat these foods, or whether they don't care. Separate questions were asked for cold meals, dinner, or between meals. We added two foods to the original list, being fruit with cold meals and fruit with dinner. Together with three original items (cooked vegetables at dinner, warm vegetables at dinner, and fruit between meals) food rules regarding fruit and vegetables concerned five situations. Only these food rules were analysed. Two variables were created from the five items that reflected how strict the mothers were in obliging their child to eat fruit and vegetables. Strict obligation rules were defined as the number of situations in which children were always obliged to eat fruit and vegetables. Lenient obligation rules were defined as the number of situations in which children were sometimes obliged to eat fruit and vegetables.

\section{Demographic and family characteristics}

In addition to the abowe variables, a number of demographic and family characteristics were measured. First sex of the child was included in the analyses. Second, the highest educational level of the mother was categorised into low (primary school and vocational training), intermediate (secondary school and vocational education), and high (higher education), and dummy variables were created for the intermediate and high educational level. Third, we asked the employment status of the mother and father. Two dummies were 
created that indicated whether the mother and her partner were employed. Finally, as an indication of irregular working times of the mother or father, it was asked whether their standard working times were between seven a.m. and seven p.m. Dummy variables were made that indicated the mother and the father had irregular working hours $(=1 \mathrm{vs}$. 0 for regular times/not working). We also asked how many hours a week the parents worked but since inspection of children's mean frutt and vegetable consumption revealed no differences between different categories ( $<25$ hours/week and $>25$ hours/week) for mothers, and since only three fathers were placed in the first category, we did not further analyse this variable.

\section{Statistical analyses}

Children were included in the analyses if their FFQs contained less than $20 \%$ missing values. Further missing values on any of the variables described above were imputed with mean population values in the case of continuous variables, or modal values in the case of categorical variables. The maximum number of missing values that was imputed was five for one item of the restrictive control scale.

Pearson's correlation coefficients were calculated between and among family-related factors and children's fruit and vegetable consumption. To explore which variables are associated with the children's consumption of fruit and of vegetables at baseline, linear regression analyses were performed. First, only demographic and family characteristics were analysed. Second, sets of variables relating to perceived home availability of fruits and wegetables, meal structure, parental food socialisation, and parenting style and practices were added to demographic and family characteristics in four separate models. Finally in order to remain statistical power, predictors with a $p$-value $<0.10$ from these models were added simultaneously to the demographic and family characteristics in one final model, with 0.05 as cutoff level of significance.

The same procedure was followed for the children in the experimental group only, to explore which variables predicted changes in fruit and vegetable consumption. Children's fruit or vegetable consumption at baseline served as a covariate.

All regression models were checked for linearity, normality and homogeneity of variance of the residuals. Multivariate outliers, defined as observations with an absolute studentised deleted residual greater than 3.5, were excluded until no outliers were left. Multivariate outliers from all models were excluded from each analysis so that all analyses refer to the same persons.

\section{Results}

Of the 207 women who agreed to participate, 194 started the study " of whom 191 completed the initial questionnaire. Of these participants, 176 women (87 participants randomised to the control group and 89 randomised to the experimental group) completed the second questionnaire just preceding the experimental period. Nine participants were excluded from further analysis because their baseline FFQs contained $>20$ percent missing values $(n=5$ control group, $n=4$ experimental group) Three participants were excluded because of a large number of missing values on questions about either parenting style, parenting practices or attitude, leaving a total number of 164 participants ( $n=80$ controls, $n=84$ experimental group). Six persons ( $n=4$ controls, $n=2$ experimental group) were excluded because they were multivariate outliers. Cross-sectional analyses were thus performed on 158 persons ( $n=76$ controls, $n=82$ experimental group). Immediately after the experimental period, 83 of the 84 participants in the experimental group included in the cross-sectional analyses completed a third (follow-up) questionnaire. After exclusion of one participant who had a follow-up FFQ with $>20 \%$ missing values, 82 participants were included in the longitudinal analyses. 
Table 1

Description of the study population and familywelated variables

\begin{tabular}{|c|c|c|c|c|c|}
\hline & \multirow{2}{*}{$\begin{array}{c}\text { Posisible } \\
\text { range }\end{array}$} & \multicolumn{2}{|c|}{$\begin{array}{l}\text { Total study } \\
\text { population }^{\text {a }}\end{array}$} & \multicolumn{2}{|c|}{$\begin{array}{c}\text { Experimental } \\
\text { group }\end{array}$} \\
\hline & & Mean $/ \%$ & $(\mathrm{SD})$ & Mean $/ \%$ & (SD) \\
\hline \multicolumn{6}{|l|}{ Children's frult and vegetable consumption } \\
\hline Child's fruit consumption $(\mathrm{g} / \mathrm{d})$ & & 149 & $(96)$ & 169 & $(103)$ \\
\hline Child's vegetable consumption $(\mathrm{g} / \mathrm{d})$ & & 98 & $(51)$ & 103 & $(61)$ \\
\hline$\Delta$ Child's fruit consumption (g/d) & & & $=$ & 101 & (99) \\
\hline$\Delta$ Child's vegetable consumption (g/d) & & - & - & 36 & (54) \\
\hline \multicolumn{6}{|l|}{ Demographic and family characteristics } \\
\hline Sex (\% boys) & & 48 & & 50 & \\
\hline Age child (years) & & 8.7 & $(1.1)$ & 8.6 & $(1.1)$ \\
\hline Age mother (years) & & 40.9 & (3.9) & 411.3 & $(4.2)$ \\
\hline Mothers living with partner $(\%)$ & & 91 & & 90 & \\
\hline Low educational level mother $(\%)$ & & 22 & & 27 & \\
\hline Intermediate educational level mother (\%) & & 34 & & 34 & \\
\hline High educational level mother $(\%)$ & & 44 & & 49 & \\
\hline Mother employed $(\%)$ & & 75 & & 76 & \\
\hline Employed mothers working at irregular times $(\%)$ & & 18 & & 13 & \\
\hline Partner employed $(\%)$ & & 83 & & 83 & \\
\hline Employed partners working at irregular times (\%) & & 14 & & 18 & \\
\hline
\end{tabular}

\section{- Table continues on page 93.}

Table 1 provides details of the study population. The children's reported fruit consumption was $149 \pm 96 \mathrm{~g} / \mathrm{day}$, and their vegetable consumption $98 \pm 51 \mathrm{~g} / \mathrm{day}$. Eleven percent of the children adhered to a special diet, which was usually a vegetarian diet. Most of the mothers lived with a partner "and most mothers $(75 \%)$ and their partners $(83 \%)$ were employed. The majority of the children had dinner with both parents. The mothers on average scored positive on the involvement/affection scalle and slightly negative on the restrictive control scale.

Table 2 shows Pearson correlations between the continuous variables that were measured. The children's fruit consumption correlated positively with perceived availability of fruit at home, mothers" attitude toward fruit, mothers' fruit and vegetable consumption, and strict obligation rules to eat fruit and vegetables. Fruit consumption correlated negatively with maternal restrictive control and lenient obligation rules to eat fruit and vegetables. Children's vegetable consumption was positively correlated with their mother's attitude with respect to fruit and vegetables, mothers' fruit and vegetable consumption, and strict obligation rules. Children's vegetable consumption was negatively correlated with maternal involvernent/affection. 
Table 1

(continued)

\begin{tabular}{|c|c|c|c|c|c|}
\hline & \multirow{2}{*}{$\begin{array}{c}\text { Possible } \\
\text { range }\end{array}$} & \multicolumn{2}{|c|}{$\begin{array}{l}\text { Total study } \\
\text { population }\end{array}$} & \multicolumn{2}{|c|}{$\begin{array}{c}\text { Experimental } \\
\text { group }\end{array}$} \\
\hline & & Mean $1 \%$ & $(\mathrm{SD})$ & Mean /\% & $(\mathrm{SD})$ \\
\hline \multicolumn{6}{|l|}{ Home availability } \\
\hline Availability fruit & $(-3,+3)$ & 2.66 & $(1.00)$ & 2.82 & $(0.63)$ \\
\hline Avallability vegetables & $(-3,+3)$ & 2.51 & $(0.95)$ & 2.46 & $(1.08)$ \\
\hline Growing own produce $(\%)$ & & 9 & & 9 & \\
\hline \multicolumn{6}{|l|}{ Meal structure } \\
\hline Dinner duration $>30 \min (\%)$ & & 29 & & 29 & \\
\hline Children eating warm meal with both parents (\%) & & 82 & & 82 & \\
\hline \multicolumn{6}{|l|}{ Parental foad socialization } \\
\hline Adherence to special diet $(\%)$ & & 11 & & 12 & \\
\hline Mother's attitude fruit & $(-3,+3)$ & 2.01 & $(0.78)$ & 2.12 & $(0.75)$ \\
\hline Mother's attitude vegetables & $(-3,+3)$ & 2.47 & $(0.61)$ & 2.55 & $(0.56)$ \\
\hline Mothers fruit consumption $(\mathrm{g} / \mathrm{d})$ & & 164 & $(105)$ & 173 & $(107)$ \\
\hline Mother's vegetable consumption ( $g / d$ ) & & 181 & $(81)$ & 188 & (95) \\
\hline \multicolumn{6}{|l|}{ Parenting style and practices } \\
\hline Maternal involvement/affection & $(-3,+3)$ & 2.16 & $(0.62)$ & 2.14 & $(0.65)$ \\
\hline Maternal restrictive control & $(-3,+3)$ & -0.11 & $(0.88)$ & -0.20 & $(0.82)$ \\
\hline Lenient obligation rules & $(0,5)$ & 1.17 & $(1.81)$ & 1.122 & $(1.83)$ \\
\hline Strict obligation rules & $(0,5)$ & 1.78 & $(2.06)$ & 2.02 & $(2.08)$ \\
\hline
\end{tabular}

asedin cross-sectional analyses $(n=158)$.

${ }^{b}$ Used in longitudinal analyses $(n=82)$.

Table 3 shows multivariate associations between the children's fruit consumption and family-related factors at baselline. Model 1 , in which only demographic and familly characteristics were entered, showed that fruit consumption was lower in families with an employed mother and partner. Fruit consumption was higher if the mother was highly educated and if the partner worked at irregular times. In subsequent models the various family-related factors were entered (i.e. perceived home availability of fruits and vegetables, meal structure, parental food socialisation, and parenting style and practices). Significant positive associations were found with perceived home availability of fruits, adherence to a special diet, the mother's fruit consumption, and strict obligation rules to eat fruit and vegetables. The above associations remained statistically significant in the final model in which the demographic variables and significant variables from models $2-5$ were entered, although the relation with perceived availability became less strong. Moreover, the observed association with the mothers' educational level decreased and the relation with working status of her partner disappeared, which was mainly a result of the presence of the mothers' fruit consumption in the same model.

Table 4 shows multivariate associations between the children's vegetable consumption and family-related factors at baseline. There were no significant associations with demographic and family characteristics. Subsequent models revealed negative relations with adherence to a special diet and maternal involvement/affection, and a positive relation with mothers' vegetablle consumption. The association between children's vegetable consumption and maternal involvementaffection disappeared when it was entered in one model with mothers' vegetable consumption and adherence to a special diet. 


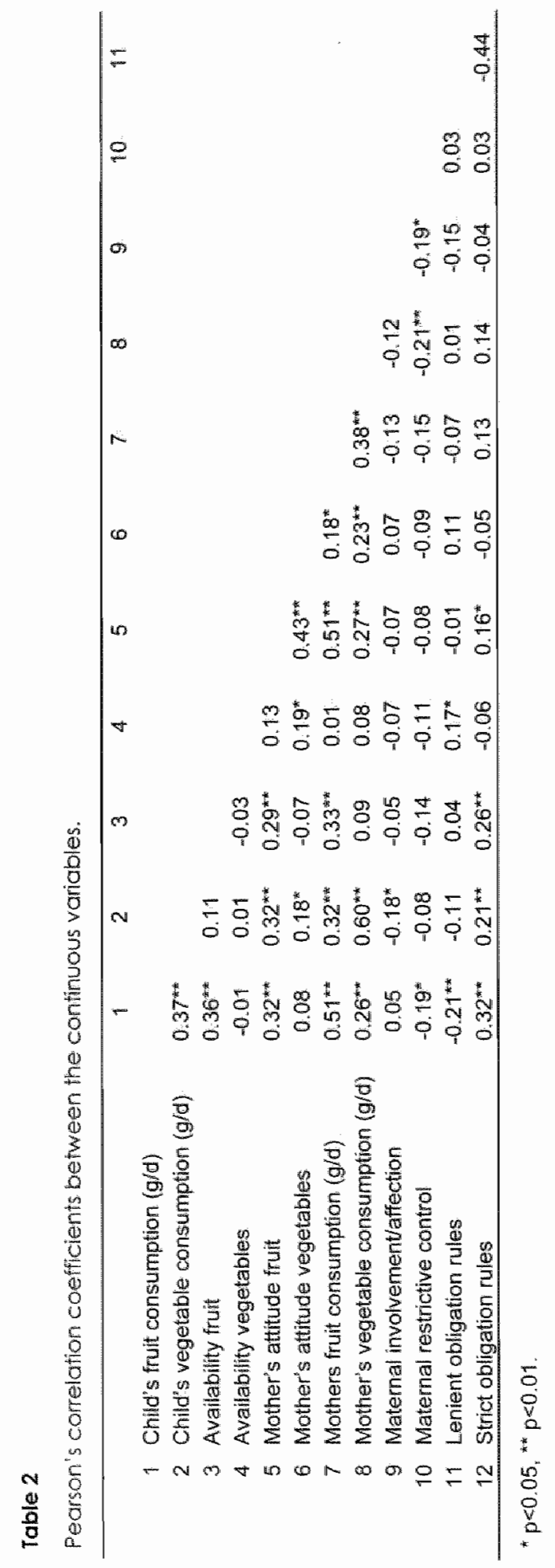


During the experimental period the children increased their consumption of fruit and vegetables with $101 \pm 99 \mathrm{~g} / \mathrm{day}$ and $36 \pm 54 \mathrm{~g} /$ day, respectively. Table 5 shows the results of the regression analyses for changes in fruit consumption. None of the variables except baseline fruit consumption were associated with changes in fruit consumption.

Table 6 shows associations between children's changes in vegetable consumption and family-related factors. Changes were higher in families in which the partner worked at irregular times. Further ${ }_{3}$ there was a negative association between changes in vegetable consumption and the growing of own produce. None of the other variables predicted changes.

\section{Discussion}

The objective of the present study was to explore which family-and parent-related factors are related with children's fruit and vegetable consumption. Cross-sectional analyses showed positive associations between children's fruit consumption and their mother's fruit consumption, strict obligation rules to eat fruit and vegetables, adherence to a special diet, and perceived home availability of fruit. Children with a highly educated mother consumed more fruit than children with mothers with a low educational level, and children with an employed mother consumed less fruit than children with mothers who did not have a job. Children's consumption of vegetables was positively associated with their mother's vegetable consumption and negatively associated with adherence to a special diet. Induced changes in children's fruit consumption were not predicted by any of the variables under study. Changes in vegetable consumption were lower in children from families that grew their own produce and higher in families in which the father worked at irregular times.

The amounts of fruit and vegetables the mother consumed were the strongest correlate of their children's consumption. This is in line with previous research showing that parental fruit and vegetable consumption (26,38-40), or fruit consumption (29) was associated with children's fruit (and vegetable) intake. Also for other foods or nutrients, e.g. fat intake (41) or high-fat foods (38), a resemblance between familly members has been observed. Hannon et al. (38) suggested that the family food preparer influences the eating habits of their family members by preparing the majority of the food that the family eats. Indeed, in our study mostly the mothers, with or without assistance of their partner, were responsible for food preparation. Mothers may also serve as role models for their children. Modelling has been shown to be associated with children's fruit and vegetable consumption $(25,27)$. However, these associations do not prove causality; children may also influence their mother's consumption of fruit and vegetables. De Bourdeaudhuij and Van Oost indeed showed that children may significantly influence family food decisions $(42,43)$. Further, shared environmental factors may determine both the mother's and children's consumption. As a final explanation, the strong association may also in part have resulted from the fact that the children's fruit and vegetable consumption was reported by their mothers. 


\section{Table 3}

Associations between children's fruit consumption and family-related faclors at baseline $(n=158)^{\text {a }}$

\begin{tabular}{|c|c|c|c|c|c|c|c|}
\hline & Modet 1 & Model 2 & Model 3 & Model 4 & Model 5 & Final $\mathrm{m}$ & odel \\
\hline & $\mathrm{RCs}^{\mathrm{ti}}$ & $\mathrm{RCs}$ & $\mathrm{RCs}$ & $\mathrm{RCs}$ & RCs & $\mathrm{RCs}$ & $\mathrm{RC}^{2}$ \\
\hline $\begin{array}{l}\text { Demographic and family } \\
\text { characteristics }\end{array}$ & & & & & & & \\
\hline Sex child $\left(0=\right.$ boy $_{n} 1=$ girl) & $-0.13^{*}$ & $-0.17^{\text {kik }}$ & $-0.14^{* *}$ & $-0.14^{*}$ & -0.09 & $-0.11^{*}$ & -21.27 \\
\hline $\begin{array}{l}\text { Intermediate educational } \\
\text { level mother }\end{array}$ & 0.10 & 0.10 & 0.07 & 0.09 & 0.05 & 0.05 & 10.05 \\
\hline $\begin{array}{l}\text { High educational level } \\
\text { mother }\end{array}$ & $0.30^{* * *}$ & $0.29^{* * *}$ & $0.18^{*}$ & $0.28^{\star \star *}$ & $0.24^{* * i k}$ & $0.18^{* * *}$ & 35.01 \\
\hline $\begin{array}{l}\text { Employment status mother } \\
(0=\text { not working, } 1=\text { working })\end{array}$ & $-0.18^{* *}$ & $-0.19^{* *}$ & $-0.18^{* \cdots *}$ & $-0.19^{* * i k}$ & $-0.19^{* *}$ & $-0.19^{m+k}$ & -40.96 \\
\hline $\begin{array}{l}\text { Irregular working times } \\
\text { mother ( } 0=\text { regular } \\
\text { times/does not work } \\
1=\text { yes) }\end{array}$ & -0.12 & -0.04 & -0.06 & -0.12 & -0.10 & 0.00 & 0.46 \\
\hline $\begin{array}{l}\text { Employment status partner } \\
(0=\text { not working, } 1=\text { working })\end{array}$ & $-0.17^{\text {witk }}$ & $-0.14^{*}$ & -0.04 & $-0.17^{\star}$ & -0.10 & -0.02 & -5.41 \\
\hline $\begin{array}{l}\text { Irregular working times } \\
\text { partner ( } 0=\text { regular } \\
\text { times/does not wark, } \\
1=\text { irregular times) }\end{array}$ & $0.18^{* *}$ & $0.14^{\star}$ & $0.13^{\text {* }}$ & $0.18^{* *}$ & $0.17^{\text {wik }}$ & $0.12^{\star}$ & 34,69 \\
\hline Home availability & & & & & & & \\
\hline Growing own praduce & & 0.11 & & & & & \\
\hline Porceived availability fruit & & $0.33^{* * * i}$ & & & & $0.16^{* *}$ & 15.82 \\
\hline Food socialization & & & & & & & \\
\hline Special diet child & & & $0.14^{* *}$ & & & $0.17^{\star \star *}$ & 50.36 \\
\hline $\begin{array}{l}\text { Mothers fruit consumption } \\
(\mathrm{g} / \mathrm{d})\end{array}$ & & & $0.42^{* * * *}$ & & & $0.40^{* * * *}$ & 0.37 \\
\hline Mother's attitude fruit & & & 0.11 & & & & \\
\hline
\end{tabular}

- Table continues on page 97. 
Tabile 3

[Continued]

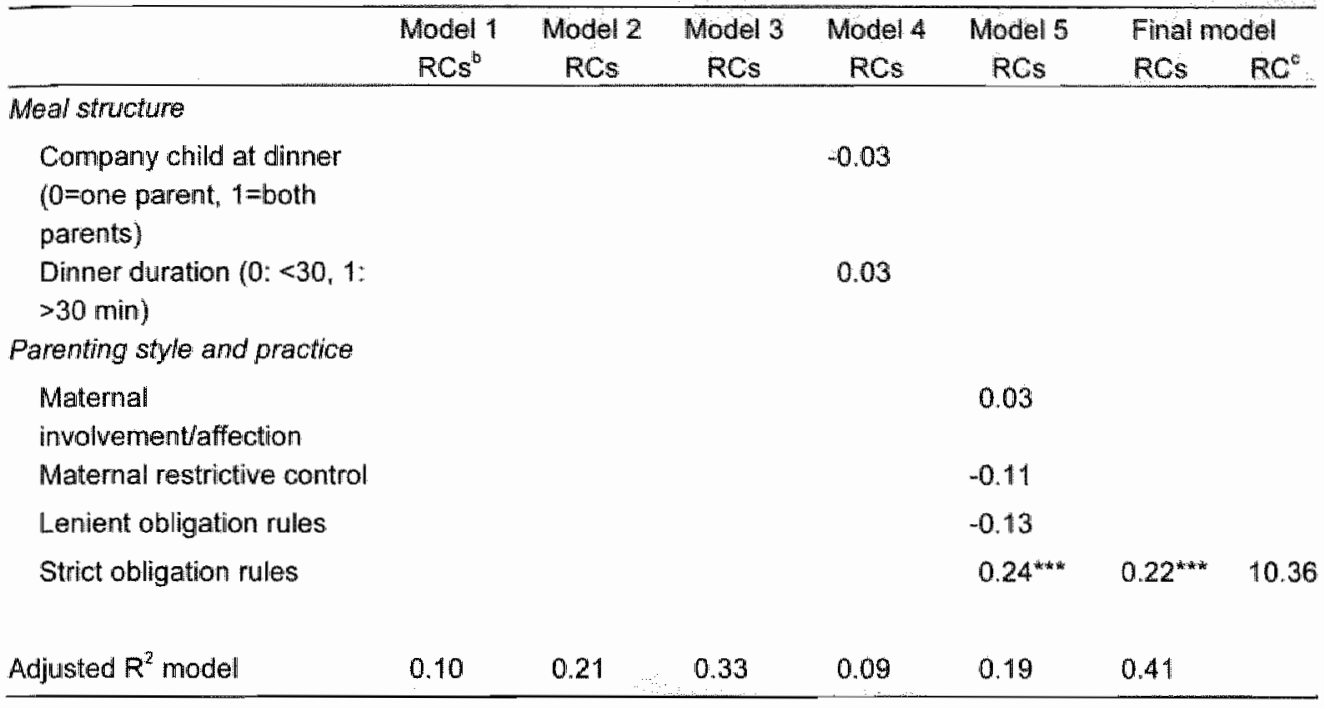

" $p<0.10 * * p<0.05 * * * p<0.01$.

a In model 1 only demographic variables were entered. In models 2-5 blocks of variables were added to demographic variables. The final model includes demographic variables and variables with a $p$-value $<0.10$ from models $2-5$.

${ }^{b} \mathrm{RC}_{\mathrm{s}}$ : standardized regression coefficient.

${ }^{c} \mathrm{RC}$ : regression coefficient.

Strict obligation rules to eat fruit and vegetables were positively associated with the children's consumption of fruit. This finding contradicts previous work by Fisher et al. (26), who found that the use of pressure to consume foods was negatively associated with fiveyear-old girls' fruit and wegetable intake. Another study (25) showed an association, albeit weak ( $r=0.17$ ) between parental control measured with an 11-item scale and children's consumption of juice, but not of fruit and vegetables. A study by Young et al. (27), using a modified version of the above scale, did not find an association either. Finally, De Bourdeaudhuij (44) did not find a relationship between the obligation to eat a "proper meal" in childhood and healthy food patterns in adolescence. Divergent results between our study and the above studies may have resulted from wariation in the way that food-related parenting practices were operationalised. We measured obligation rules to eat firuit and vegetables, while the above studies used measures that indicated parental control over food in general. General obligation rules in the present study were not associated with children's fruit and vegetable consumption (data not shown). Alternatively, the association found in the present study may be a result of the fact that mothers with children not wanting to eat fruit might adjust the food rules in a more lenient direction to avoid conflicts with their child. The fact that the use of lenient obligation rules to eat fruit and vegetables am opposed lo strict rules- was not associated with consumption, might indicate that strict food rules may lead to a higher consumption of fruit and vegetables. Kremers et al. (32) suggested that a high level of parental control in child feeding may have a positive outcome on dietary behaviour of children who are raised in a authoritative context. We could not confirm this hypothesis, since in our study the positive association of fruit consumption with strict obligation rules to eat fruit and vegetables in our study was independent of the two dimensions of parenting style, i.e. 
maternal inwolvement/affection and restrictive control. Moreover, in line with two previous studies $(25,27)$ but contrary to two other studies $(32,34)$, parenting style was not related to children's: fruit and vegetable consumption. Unfortunately, the size of our study population did not allow us to stratify the analyses according to the dimensions of parenting style in order to explore a moderating effect of parenting style on parenting practices.

\section{Table 4}

Associations between children's vegetable consumption and family-related factors at bosieline $n=158]^{\circ}$

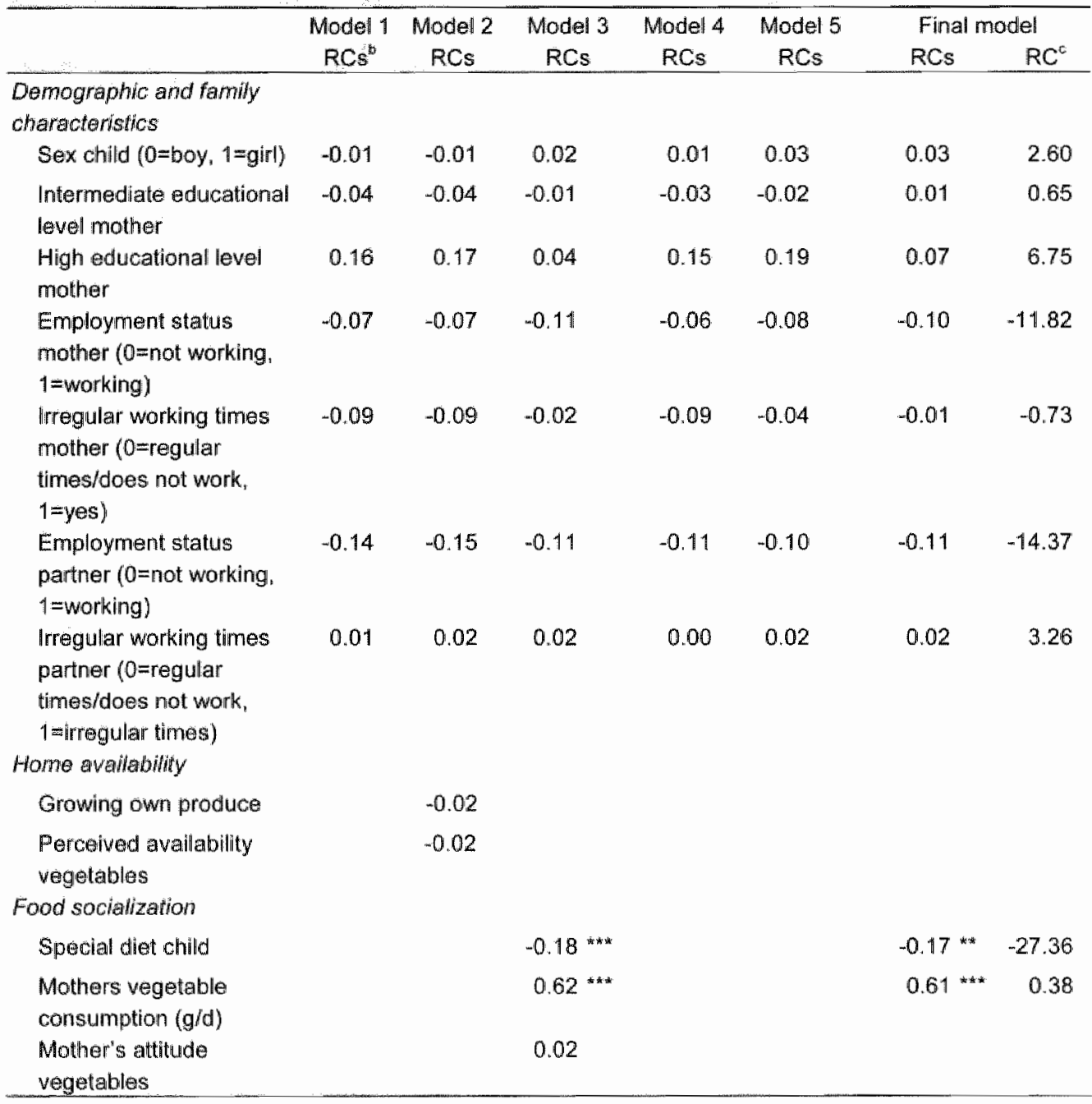

- Table continues on page 99. 


\section{Table 4}

[Continued]

\begin{tabular}{|c|c|c|c|c|c|c|c|}
\hline & \multirow{2}{*}{$\begin{array}{l}\text { Model } 1 \\
\mathrm{RCs}^{\mathrm{t}}\end{array}$} & \multirow{2}{*}{$\begin{array}{c}\text { Model } 2 \\
\mathrm{RCs}\end{array}$} & \multirow{2}{*}{$\begin{array}{c}\text { Model } 3 \\
\text { RCs }\end{array}$} & \multirow{2}{*}{$\begin{array}{l}\text { Model } 4 \\
\text { RCs }\end{array}$} & \multirow{2}{*}{$\begin{array}{c}\text { Model } 5 \\
\text { RCs }\end{array}$} & \multicolumn{2}{|c|}{ Final model } \\
\hline & & & & & & $\mathrm{RCs}$ & $R C^{\circ}$ \\
\hline \multicolumn{8}{|l|}{ Meal structure } \\
\hline $\begin{array}{l}\text { Company child at dinner } \\
(0=\text { one parent, } 1=\text { both } \\
\text { parents })\end{array}$ & & & & 0.08 & & & \\
\hline $\begin{array}{l}\text { Dinner duration }(0:<30 \\
1:>30 \mathrm{~min})\end{array}$ & & & & 0.09 & & & \\
\hline \multicolumn{8}{|l|}{$\begin{array}{l}\text { Parenting style and } \\
\text { practice }\end{array}$} \\
\hline $\begin{array}{l}\text { Maternal } \\
\text { involvement/affection }\end{array}$ & & & & & -0.20 & -0.08 & -6.82 \\
\hline $\begin{array}{l}\text { Maternal restrictive } \\
\text { control }\end{array}$ & & & & & -0.06 & & \\
\hline Lenient obligiation rules & & & & & -0.10 & & \\
\hline Strict obligation rules & & & & & 0.14 & & \\
\hline Adjusted $\mathrm{R}^{2}$ model & 0.02 & 0.01 & 0.36 & 0.02 & 0.07 & 0.41 & \\
\hline
\end{tabular}

* $p<0.10^{* *} p<0.05^{* * *} p<0.01$.

" In model 1 anlly demographic variables were entered. In models $2-5$ blocks of variables were added to demographic variables. The final model includes demographic variables and variables with a $\mathrm{p}$-value < 0.10 from models $2-5$.

${ }^{\mathrm{b}} \mathrm{RC}_{\mathrm{s}}$ : standardized regression coefficient.

${ }^{\circ} \mathrm{RC}$; regression coefficient.

The observed association between children's fruit, but not vegetable consumption and their mothers" educational level is in line with a previous study (29). However, a relation between parents' educational level with vegetable, but not fruit consumption has also been shown (39). In our study, the above association was partly explained by the mothers' own fruit. consumption. This has also been shown previously (40), and may imply that encouraging mothers to eat more fruit might reduce socio-economic differences in children's fruit consumption. The association of children's fruit consumption and perceived home availability of fruit was also partly explained by mothers' frut consumption and strict obligation rules to eat fruit and vegetables. The fact that availability of fruit was related to children's fruit consumption is in line with previous studies (15-19), and underlines the importance of home availability of fruit and vegetables, which is something over which parents have control.

Children with working mothers consumed less fruit than children with mothers who did not have a job. Exploration of the data did not reveal a difference in fruit consumption between children with mothers working full-time or part-time. This finding contrasts to a previous study that did not show a relationship between maternal employment and diets of two to five-year-old children (45). Since the difference was not observed for vegetable consumption "mothers' employment did not likely result in a reduced meal quality. A potential explanation might be that working mothers may be less present at home to encourage their children to eat fruit. 
Table 5

Associations between changes in children's $(n=82)$ fruit consumption and family-related factors af baseline in the experimental group

\begin{tabular}{|c|c|c|c|c|c|}
\hline & $\begin{array}{l}\text { Model } 1 \\
\text { RCs }^{\$}\end{array}$ & $\begin{array}{l}\text { Model } 2 \\
\text { RCs }\end{array}$ & $\begin{array}{l}\text { Model } 3 \\
\text { RCs }\end{array}$ & $\begin{array}{l}\text { Model } 4 \\
\text { RCs }\end{array}$ & $\begin{array}{l}\text { Model } 5 \\
\text { RCs }\end{array}$ \\
\hline \multicolumn{6}{|l|}{ Demographic and family characteristics } \\
\hline Baseline fruit consumption & $-0.40^{* * \cdots * k}$ & -0.36 & -0.46 & -0.40 & $-0.39^{\cdots \cdots}$ \\
\hline Sex child $(0=$ boy, $1=$ girl $)$ & -0.13 & -0.10 & -0.14 & -0.16 & -0.14 \\
\hline Intermediate educational level mother & 0.02 & 0.02 & 0.01 & 0.00 & 0.00 \\
\hline High educational level mother & -0.09 & -0.11 & -0.08 & -0.06 & $=0.14$ \\
\hline $\begin{array}{l}\text { Employment status mother }(0=\text { not } \\
\text { working, } 1=\text { working })\end{array}$ & -0.04 & -0.03 & -0.05 & -0.06 & 0.00 \\
\hline $\begin{array}{l}\text { Irregular working times mother } \\
(0=\text { regular times/does not work. } 1=\text { yes) }\end{array}$ & 0.13 & 0.14 & 0.12 & 0.11 & 0.17 \\
\hline $\begin{array}{l}\text { Employment status partner }(0=\text { not } \\
\text { working, } 1=\text { working) }\end{array}$ & 0.13 & 0.12 & 0.15 & 0.06 & 0.20 \\
\hline $\begin{array}{l}\text { Irregular working times partner } \\
(0=\text { regular times/does not work } \\
1=\text { irregular times) }\end{array}$ & 0.07 & 0.06 & 0.05 & 0.11 & 0.04 \\
\hline \multicolumn{6}{|l|}{ Home availability } \\
\hline Growing own produce & & -0.06 & & & \\
\hline Perceived availlability fruit & & -0.08 & & & \\
\hline
\end{tabular}

- Table continues on page 101.

Of the parental food socialisation variables, in addition to the mothers' fruit and vegetable consumption, the adherence of the child to a special diet was positively associated with fruit consumption. Twenty children followed a special diet, which in most cases meant that they consumed a vegetarian or organic diet. This might indicate a higher interest in (healthy) food in these families. However, adherence to a special diet was negatively related with vegetable consumption. This finding is surprising given the relatively high amount of vegetable foods in a vegetarian diet, and we cannot think of a satisfying explanation.

Although mothers' attitudes: for fruit and wegetables were positively correlated with children's fruit and vegetable consumption "the multivariate model did not show these associations. This most likely results from the simultaneous entering of mothers' attitudes with their fruit and vegetable consumption in one model, since mothers' attitudes were also correlated to their own fruit and vegetable consumption. However, contrary to us, $_{\text {, Gibson el }}$ al. (29) reported an association between mothers' beliefs on health benefits of fruit and vegetables/food for their children with children's fruit and vegetable intake, which was independent of mothers' fruit and vegetable intake. Meal duration and companionship of children during dinner were not associated with children"s fruit and vegetable consumption. Stanek et al. (22) showed that children with company at mealtime, whether they ate with parents or siblings, ate more fruit and vegetables. However in our study almost all children ate dinner with at least one parent, so they all had company and experienced some form of parental supervision during the meal. 


\section{Table 5}

(Continued)

\begin{tabular}{cccccc} 
Model 1 & Model 2 & Model 3 & Model 4 & Model 5 \\
RCs $^{\circ}$ & RCs & RCs & RCs & RCs \\
\hline
\end{tabular}

Food socialization

Special diet child

Mothers fruit consumption (g/d)

0.13

Mother's attitude fruit

$-0.04$

Meal structure

Company child at dinner $(0=0$ ne parent.

$-0.16$

$1=$ both parents)

Dinner duration $(0:<30,1:>30 \mathrm{~min})$

Parenting style and practice

Maternal inwolvementraffection

$-0.11$

Maternal restrictive control

Lenient obligation rules

Strict obligation rules.

$-0.02$

Adjusted $R^{2}$ model

0.12

0.11

0.10

0.14

0.10

${ }^{*} p<0.10^{* *} p<0.05^{* * *} p<0.01$.

${ }^{a}$ In madel 1 only demographic variables were entered. In models 2-5 blocks of variables were added to demographic variables. The final model includes demographic variables and variables with a $p$-value $<$ 0.10 from models $2-5$.

${ }^{\mathrm{B}} \mathrm{RC}_{\mathrm{s}}$ : standardized regression coefficient.

None of the variables that were studied predicted changes in fruit intake, and the only factors that were found to significantly predict change in vegetable consumption was whether the family disposed of home grown produce, and whether the father had irregular working times. Eating home grown produce has been shown to be positively associated with high intake of fruits and vegetables in adults (20). However, we found a negative relationship with change in vegletable intakes after adjustment for baseline consumption. Possibly the families with a vegetable garden already had ample disposal of fresh vegetables and were not encouraged to eat more by our provision of extra vegetables. We can only speculate for a potential explanation of the fact that children with fathers who worked at irregular times showed a higher change in vegetable consumption. Possibly in those families fathers might have been less present during dinner, and therefore the mothers less often had to adjust the meal to the wishes of their partners.

It is surprising that we found no other predictors of changes in fruilt and vegetable consumption. Since we also had data on parenting practices used during the experimental period, we could test post-hoc if parenting practices reported during the experimental period could explain changes in children's fruit and vegetable consumption. This was not the case. A possible explanation for vegetables might be that the parents prepared larger servings of vegetables and that changes in meal composition (which we did not measure) were responsible for the increased vegetable consumption in children. Alternatively, children might only have increased their fruit and vegetable consumption because we asked them to do so. 


\section{Table s}

Associations between changes in children's $(n=82)$ vegelable consumption and familyrelated factors at boseline in the experimental groupa

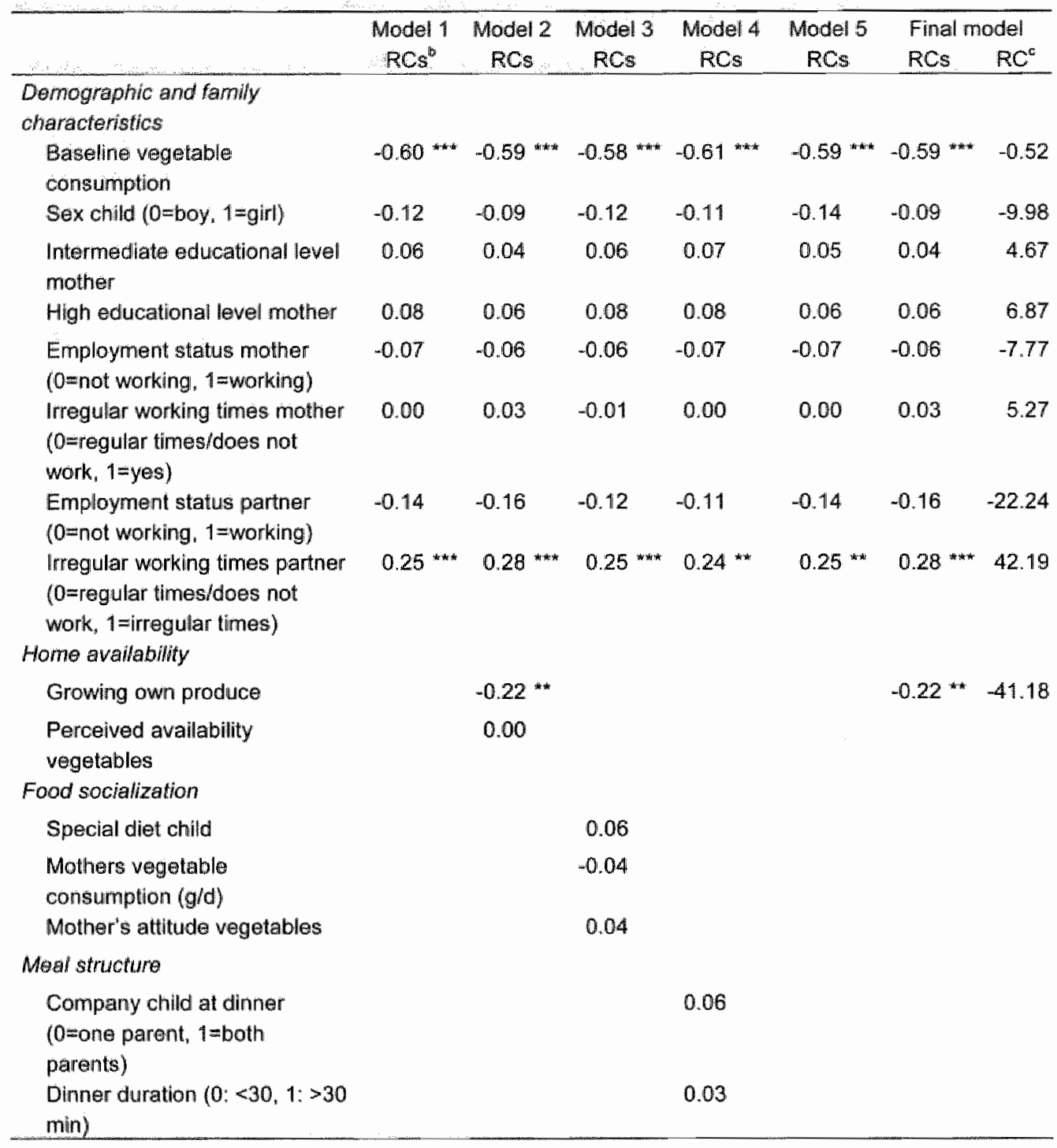

- Table continues on page 103. 


\section{Table 6}

(Continued)

\begin{tabular}{|c|c|c|c|c|c|c|c|}
\hline & \multirow{2}{*}{$\begin{array}{c}\text { Model } 1 \\
\mathrm{RCs}^{\mathrm{b}} \\
\end{array}$} & \multirow{2}{*}{$\begin{array}{c}\text { Model } 2 \\
\text { RCs }\end{array}$} & \multirow{2}{*}{$\begin{array}{c}\text { Model } 3 \\
\text { RCs }\end{array}$} & \multirow{2}{*}{$\begin{array}{c}\text { Model } 4 \\
\text { RCs }\end{array}$} & \multirow{2}{*}{$\begin{array}{c}\text { Model } 5 \\
\text { RCs }\end{array}$} & \multicolumn{2}{|c|}{ Final model } \\
\hline & & & & & & RCs & $\mathrm{RCs}^{\mathrm{b}}$ \\
\hline \multicolumn{8}{|l|}{ Parenting style and practice } \\
\hline Matermal involvement/affection & & & & & 0.03 & & \\
\hline Maternal restrictive control & & & & & -0.02 & & \\
\hline Lenient obligation rules & & & & & 0.04 & & \\
\hline Strict obligation rules & & & & & 0.00 & & \\
\hline Adjusted $R^{2}$ model & 0.38 & 0.41 & 0.36 & 0.37 & 0.35 & 0.42 & \\
\hline
\end{tabular}

** $p<0.10 * * 0<0.05^{* * *} p<0.01$.

In model 1 only demographic variables were entered. in models $2-5$ blocks of variables were added to demographic variables. The final model includes demographic variables and variables with a $p$-value < 0.10 from models $2-5$.

${ }^{b} \mathrm{RC}_{\mathrm{s}}$ : standardized regression coefficient.

${ }^{c} \mathrm{RC}$ : regression coefficient.

Some limitations of our study should be noted for a correct interpretation of the findings. First, the mean educational level of the parents in our study was relatively high. Since educational level is associated with fruit and vegetable consumption (see e.g., (46)), our findings may not be applicable to other populations. The families that participated were probably relatively health-conscious families since mothers were selected only if they did not smoke. Moreover, they were very motivated because participation implied a relatively high burden for the participants, i.e. filling out rather extensive questionnaires and coming to the study centre for blood sampling in another part of the project. A second point is that mothers completed the FFQ for their children, which may have resulted in wrong estimates of children's fruit and vegetable consumption outside the home. However, based on correlations with biomarkers of fruit and vegetable intake (children's serum carotenoid and vitamin $\mathrm{C}$ concentrations), it has been concluded that parental reports of young children's diets obtained with food frequency methods can be used to rank children according to their fruit and vegetable consumption (47). Finally, we did not have information about attitudes, parenting styles and practices, and fruit and vegetable consumption in fathers, and thus we may have missed some relevant parental influence. For a more complete exploration of parental influences on children's fruit and vegetable intake, future studies should also incorporate measures of paternal influence.

In conclusion, our findings indicate that several family-related factors influence consumption of fruits and vegetables in children. This implies that targeting families is a promising strategy to increase children's fruit and vegetable intake. The fact that fruit and vegetable consumption of mothers and children were strongly related further supports the use of interventions at the family level. However, since the present study does not identify the cause of this association, it is too early to give specific recommendations for interventions. Our findings further suggest that if parents oblige children to eat fruit and vegetables, this may have a positive effect on their children"s fruit consumption. However, the present data do not indicate what would be the best strategy to bring into practice these obligation rules. Furthermore, parents should ensure a sufficient availability of fruit and vegletables at home. An association between children"s fruit intake and maternal employment has to be confirmed in future studies. Because of the selective study population our findings need to be replicated in populations of a different composition before they can be conclusive. 


\section{References}

1. Steinmetz KA and Potter JD (1996): Vegetables, fruit, and cancer prevention: a review. $J$ Am Diet Assoc $96,1027-39$.

2. Ness AR and Powles JW (1997): Fruit and vegetables, and cardiovascular disease: a review. Int $J$ Epidemiol $26,1-13$.

3. WHO/FAO (2003): Jloint WHO/FAO Expert Consultation on Diet, Nutrition and the Prevention of Chronic Diseases. Geneva: WHO/FAO.

4. Agudo A, Slimani $N$, Ocke MC, Nasika A, Miller AB, Kroke A, Bamia C, Karalis D, Vineis P, Pall D, Bueno-de-Mesquita HB, Peeters PH, Engeset D, Hiartaker A, Navarro C, Martinez Garcia C, Wallstrom P, Zhang JX, Welch AA, Spencer E, Stripp $C$, Overvad $K$, Clavel-Chapelon $F$, Casagrande $C$ and Riboli $E$ (2002): Consumption of vegetables, fruit and other plant foods in the European Prospective Investigation into Cancer and Nutrition (EPIC) cohorts from 10 European countries. Public Health Nutr 5 , 1179-96.

5. Li R, Serdula M, Bland S, Mokdad A, Bowman B and Nelson D (2000): Trends in fruit and vegetable consumption among adults in 16 US states: Behavioral Risk Factor Surveillance System, 1990-1996. Am J Public Health 90, 777-81.

6. Krebs-Smith SM, Cook A, Subar AF, Cleveland L. Friday J and Kahle LL (1996): Fruit and vegelable intakes of children and adolescents in the United States. Arch Pediatr Adolesc Med 150, 81-6.

7. Dennison BA, Rockwell HL and Baker SL (1998): Fruit and vegetable intake in young children. J Am Coll Nutr 17, 371-8.

8. Kelder SH, Perry CL, Klepp KI and Lytle LL (1994): Longitudinal tracking of adolescent smoking, physical activity, and food choice behaviors. Am I Public Health 84, 1121-6.

9. Wang $Y$, Bentley ME, Zhai $F$ and Popkin BM (2002): Tracking of Dietary Intake Patterns of Chinese from Childhood to Adolescence over a Six-Year Follow-Up Period. I Nutr 132, 430-8.

10. Baranowski T, Cullen KW and Baranowski J (1999): Psychosocial correllates of dietary intake: advancing dietary intervention. Arnu Rev Nutr 19, 17-40.

11. Wardle J (1995): Parental influences on children's diets. Proc Nutr Soc 54, 747-58.

12. Contento IR and Michela JL (1997). Nutrition and food choice behavior among children and adolescents. in Handbook of pediatric and adolescent health psychology. Boston: Alyn \& Bacon.

13. Koivisto Hursti UK (1999): Factors influencing children's food choice. Ann Med 31 (Suppl 1), 26-32.

14. Nicklas TA, Baranowski T, Baranowski $J C$, Cullen $K$, Rittenberry $L$ and Olvera $N$ (2001): Family and child-care provider influences on preschool children's fruit, juice, and vegetable consumption. Nutr Rev 59, 224-35.

15. Cullen KW, Baranowski T, Owens E, Marsh T, Rittenberry L and de Moor C (2003): Avallability, accessibility, and preferences for fruit, $100 \%$ fruit juice, and vegetables influence children's dietary behavior. Health Educ Behav 30,615-26.

16. Hearn M (1998): Environmental influences on dietary behavior among children: availlability and accessability of fruits and vegetables enable consumption. $J$ Health Educ 29, 26-32.

17. Reynolds KD, Hinton AW, Shewchuk RM and Hickey CA (1999): Socilal cognitive model of fruit and vegetable consumption in elementary school children. J Nutr Educ: $31,23-30$.

18. Kratt $P$, Reynolds $K$ and Shewchuk $R(2000)$ : The role of availability as a moderator of family fruit and vegetable consumption. Health Educ Behav 27, 471-82.

19. Edmonds J, Baranowski T, Baranowski J, Cullen KW and Myres D (2001): Ecological and socioeconomic correlates of fruit, juice, and vegetable consumption among African-American boys. Prev Med 32, 476-81. 
20. Billson $H$, Pryer $\| A$ and Nichols $R(1999)$ : Variation in fruit and vegetable consumption among adults in Britain. An analysis from the dietary and nutritional survey of British adults. Eur J Chin Nutr 53, 946-52.

21. Gillman MW, Rifas-Shiman SL, Frazier AL, Rockett HR, Camargo CA, Jr, Field AE Berkey CS and Colditz GA (2000): Family dinner and diet quality among older children and adolescents. Arch Fam Med 9, 235-40.

22. Stanek K, Abbott D and Cramer S (1990): Diet quality and the eating environment of preschool children. J Am Diet Assoc 90, 1582-4.

23. Feunekes $G$ l, de Graaf $C$ and van Staveren WA (1995): Social facilitation of food intake is mediated by meal duration. Physiol Behav 58, 551-8.

24. Drucker RR, Hammer LD, Agras WS and Bryson S (1999): Can mothers influence their child's eating behavior? I Dev Behav Pediatr 20, 88-92.

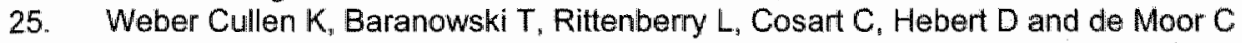
(2001): Child-reported family and peer influences on fruit, juice and vegetable consumption: Reliability and validity of measures. Health Educ Res 16, 187-200.

26. Fisher JO, Mitchell DC, Smiciklas Wright $H$ and Birch $L L(2002)$ : Parental influences on young girls' fruit and vegetable, micronutrient, and fat intakes. J Am Diet Assoc 102, 58-64.

27. Young EM, Fors SW and Hayes DM (2004): Associations between perceived parent behaviors and middle school student fruit and vegetable consumption. J Nutr Educ Behav 36, 2-8.

28. DeBourdeaudhuij I and Van Oost P (2000): Personal and family determinants of dietary behaviour in adolescents and their parents. Psychol Health 15, 751-70.

29. Gibson $\mathrm{EL}$, Wardle $\mathrm{J}$ and Watts $\mathrm{CJ}$ (1998): Fruit and vegetable consumption, nutritional knowledge and beliefs in mothers and children. Appetite 31, 205-28.

30. Darling $N$ and Steinberg L (1993): Parenting style as context: an integrative model. Psychol Bull 113, 487-96.

31. Gelles RJ (1995). Child socialization, in Contemporary families: a sociological view (ed. Gelles RJ). Thousand Oaks: Sagle Publications.

32. Kremers SP, Brug J, de Vries H and Engels RC (2003): Parenting style and adolescent fruilt consumption. Appetite 41,43-50.

33. Simons-Morton BG and Hartos $J(2002)$. Application of the authoritative parenting model to adolescent health behavior. in Emerging theories in health promotion practice and research (eds. DiClemente RJ, Crosby RA \& Kegler MC). San Francisco: JosseyBass.

34. Lytle LA, Varnell S, Murray DM, Story M, Perry C. Bimbaum AS and Kubik MY (2003): Predicting adolescents intake of fruits and vegetables. J Nutr Educ Behav $35,170-5$.

35. Bogers RP, Van Assema P. Kester AD, Westerterp KR and Dagnelie PC (2004): Reproducibility, validity, and responsiveness to change of a short questionnaire for measuring fruit and vegetable intake. Am J Epidemiol 159,900-9.

36. Vermaes IPR, Van As NCM and Gerris JRM (1999). Tussen voeding en opvoeding:: een voorstel voor een meetinstrumentarium van gezins- en opvoedingskenmerken bij ouders en kindern van zeven jaar (in Dutch). Nijmegen: Institute of Family Studies.

37. Hupkens CL, Knibbe RA, Van Otterloo AH and Drop MJ (1998): Class differences in the food rules mothers impose on their children: a cross-national study. Soc Sci Med $47,1331-9$.

38. Hannon PA, Bowen DJ, Moinpour CM and McLerran DF (2003): Correlations in perceived food use between the family food preparer and their spouses and children. Appetite 40,77-83.

39. Cooke LJ, Wardle J, Gibson EL, Sapochnik M, Sheiham A and Lawson M (2004): Demographic, familial and trait predictors of fruit and vegetable consumption by preschool children. Public Health Nutr 7, 295-302. 
40. Vereecken CA, Keukelier $E$ and Maes L (2004): Influence of mother"s educational level on food parenting practices and food habits of young children. Appetite 43, 93-103.

41. Feunekes $\mathrm{Gl}$. Stafleu $\mathrm{A}$, de Graaf $\mathrm{C}$ and van Staveren WA (1997): Family resemblance in fat intake in The Netherlandis. Eur $J$ Clin Nutr $51,793-9$.

42. De Bourdeaudhuij I and Van Oost $P$ (1998). Family members' influence on decision making about food; Differences in perception and relationship with healthy eating. Am J Healh Promot $13 ; 73-81$.

43. DeBourdeaudhuif ( 1997 ): Perceived family members' influence on introducing healthy food into the family. Health Educ Res 12, 77-90.

44. De Bourdeaudhuif 1 (1997): Family food rules and healthy eating in adolescents. I Health Psychol 2, 45-56.

45. Johnson RK, Smiciklas-Wright $H$, Crouter AC and Wilits FK (1992): Maternal employment and the quality of young children's diets: empiricall evidence based on the 1987-1988 Nationwide Food Consumption Survey. Pediatrics 90, 245-9.

46. Laforge RG, Greene GW and Prochaska JO (1994): Psychosocial factors influencing low fruit and vegetable consumption. I Behav Med 17, 361-74.

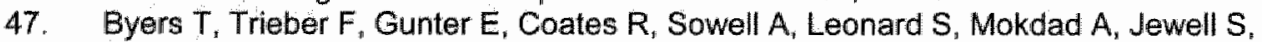
Miller $D$, Serdula $M$ and et al. (1993): The accuracy of parental reports of their children's intake of fruits and vegetables: validation of a food frequency questionnaire with serum levels of carotenoids and vitamins $C, A$, and $E$. Epidemiology 4, 350-5. 


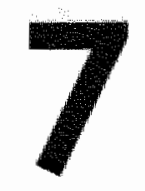

Effect of four weeks of increased fruit and vegetable consumption on plasma folate and homocysteine concentrations

Rik P Bogers

Pieter C Dagnelie

Aalt Bast

Marcella van Leeuwen

Jacob D van Klaveren

Pief A van den Brandt

Submitted for publication 


\section{Abstract}

The effects of an intervention aimed at increasing the consumption of fruits and vegetables on plasma folate and homocysteine concentrations were assessed in a randomised controlled intervention study. In 71 healthy nonsmoking women (mean (SD) age 41 (4) years, body mass index $24.1(3.4) \mathrm{kg} / \mathrm{m}^{2}$ ) folate, homocysteine and vitamin B12 concentrations were determined in plasma, and fruit and vegetable consumption was assessed with a food-frequency questionnaire at baseline and directly following the intervention. Participants in the intervention group $(n=36)$ received weekly packets containing fruits and vegetables free of charge, and were asked to consume a daily amount of at least $200 \mathrm{~g}$ of vegetables and two pieces of fruit (the Dutch recommended intake level) over a period of one month. Control subjects did not receive any intervention. Relative to the control group, reported fruit and vegetable intake in the intervention group increased by $133 \mathrm{~g} / \mathrm{day}$ $(95 \% \mathrm{Cl} 87-179, \mathrm{p}<0.001)$ for fruits and juice and $64 \mathrm{~g} /$ day $(95 \% \mathrm{Cl} 37-91, \mathrm{p}<0.001)$ for vegetables, and estimated folate intake from fruit and vegetables increased by $40 \mu \mathrm{g} / \mathrm{day}$ $(95 \% \mathrm{Cl} 22-58, \mathrm{p}<0.001)$. However, no effect was observed on plasma folate concentrations (intervention effect $0.3 \mathrm{nmol} / \mathrm{L}, 95 \% \mathrm{Cl}-1.8-2.8, \mathrm{p}=0.77$ ) or homocysteine concentrations (intervention effect $0.26 \mu \mathrm{mol} / \mathrm{L}, 95 \% \mathrm{Cl}-0.34-0.87, \mathrm{p}=0.39$ ). It is concluded that four weeks of increased fruit and vegetable consumption to the recommended amounts may not be sufficient to change plasma folate and homocysteine concentrations. 


\section{Introduction}

Fruits and vegetables contain various micronutrients with potentially favourable effects on human health. Among these micronutrients folate is a vitamin which has received considerable interest because of its impact on public health. A high folate intake by women of child-bearing age is associated with a reduced risk of neural tube defects in their new born children (1). Moreover, increasing the intake of folate has the potential of lowering elevated blood concentrations of homocysteine ( $\mathrm{Hicy}$ ) " which is considered to be an independent risk factor for cardiovascular disease (2-4). A meta-analysis of 12 randomised controlled trials showed that daily supplementation with both folic acid (the form of folate found in vitamin supplements and fortified food) in the range of $0.5-5 \mathrm{mg}$, and about $0.5 \mathrm{mg}$ vitamin B12, another determinant of Hcy in blood (5), would be expectied to reduce blood Hcy concentrations in Western populations by about a quarter to a third (6).

Compared to synthetic folic acid, naturally occurring food folate is less effective in reducing blood Hcy concentrations (7). Natural sources of folate include fruits and vegetables (8). Additionally, fortification or enrichment of foods with follate could lead to higher folate intakes. However, this fortification is not allowed in some countries, including the Netherlands. A number of intervention studies have been conducted on the potential of fruits and vegetables $(7,9-11)$ or fruits, vegetables and other folate-rich foods (12-14) to increase folate and decrease Hcy concentrations in blood, with generally favourable results in terms of increasing folate concentrations, but mixed results in terms of lowering Hcy concentrations. The above studies either compared subjects consuming controlled diets high or low in fruits and vegetables $(7,9-11)$, or provided them with a list of foods rich in folate from which they could choose in order to enhance their folate intake (12-14).

The advice to the public in the Netherlands is to consume two pleces of fruit and $200 \mathrm{~g}$ of vegetables per day (15), which is similar to the recommendation to consume at least five. servings of fruits and vegetables per day in other Western countries. Little is known about the effects of consuming the recommended amounts of fruits and vegetables irrespective of their folate content, which is closer to the real-life situation and to current dietary recommendations, which do not specifically recommend the consumption of folate-rich fruits and vegetables. Therefore, the purpose of the present study was to assess the effects of an increased consumption of fruits and vegetables to these recommended amounts on plasma folate and Hcy concentrations in a subset of adult women participating in a randomised controlled intervention study on biomarkers of fruit and vegetable consumption and determinants of consumption in adults and children (16-18).

\section{Methods}

\section{Study design and study population}

Approval for the study was obtained from the medical ethics committee of Maastricht University. Eligible were apparently healthy nonsmoking mothers with primary school age children who agreed not to use vitamin supplements from one month before the first blood collection until the end of the study period. Participants were recruited via invitation letters distributed to households with children aged $7-10$ years by mail and via schools. Recruitment was stopped after more than 200 women had been enrolled.

An initial questionnaire, which was refurned by the participants by mail, was sent out in February 2001, including a short (eight items) food-frequency questionnaire (FFQ) (18). Participants were randomly allocated to the intervention or control group after prestratification 
for fruit and veglable intake (below vs. above median) as determined with this FFQ. A more extended $\mathrm{FFQ}$. which was used to calculate baseline fruit and vegetable and folate intake (16), was sent out to intervention and control participants in March 2001. Participants handed in the FFQ at the study centre and a fasting venous blood sample was taken. Directly following the four-week intervention period, the elaborate FFO was completed once again and another fasting blood sample taken. The present paper is restricted to 71 participants of whom a spare blood sample was available for analysis of folate, Hcy and vitamin B12. These 71 participants did not differ significantly from the rest of the participants in terms of age, body mass index, and fruit and vegetable consumption at baseline and post-intervention (data not shown).

\section{Intervention}

Participants in the intervention group were asked to consume a daily amount of at least $200 \mathrm{~g}$ of vegetables and two pieces of fruit (the Dutch recommended intake level) over a period of one month. Packets containing fruits and vegetables sufficient to meet recommended amounts for each family member for one week were delivered weekly at the participants" homes free of charge, together with a newsletter and recipes. In addition, as a means to encourage ample consumption of fruits and vegetables, participants in the intervention group were asked to monitor the number of servings of fruits and vegetables they consumed each day during the intervention period by scoring boxes on a form. Women in the control group received neither fruit and vegetables, nor further information on fruit and vegetables.

\section{Dietary assessment}

Fruit and vegetable consumption was determined with an FFQ asking detailed information on consumption of specific fruits and vegetabies, with a reference period of one month. The FFQ and the procedure used to calculate fruit and vegetable consumption is described in Bogers et al. (2003) (16). Total fruit and vegetable intake was calculated using summary questions on intake of fruits, cooked vegetables and raw vegetables, and fruit and vegetable juice. Potatoes were excluded because these are considered a staple food in the Netherlands. Folate intake from fruits and vegetables was calculated by multiplying the intake of specific fruits, vegetables, and juices (61 items) with their folate content (19). In the case of combination categories of fruits or vegetables in the $F F Q_{\mu}$ e.g. cauliflower and broccoli, the corresponding folate content was calculated as a weighed mean folate content of all fruits or vegetables in that category. with the weighing factor calculated from the number of users (women, $22-50$ years) of a particular fruit or vegetable observed in the third Dutch National Food Consumption Survey (20).

\section{Plasma folate, vitamin $\mathrm{B} 12$ and Hoy determination}

After an overnight fast, $10 \mathrm{~mL}$ venous blood was collected between 07:00 and 11:00 $\mathrm{h}$ in a K KEDTA-Coated plastic tube (Becton Dickinson Vacutainer Systems, Plymouth, UKK), which was immediately placed on ice in the dark. Subsequently the blood was centrifuged $\left(1000 \times g, 10 \mathrm{~min}, 4^{\circ} \mathrm{C}\right)$ and plasma was transferred into amber Eppendorf vials and stored at $-80^{\circ} \mathrm{C}$ until analysis. Plasma folate, vitamin B12 and total Hoy concentrations were determined with a competitive immunoassay with direct chemiluminescent technology using an Advia Centaur (Bayer Diagnostics) at the certified medical laboratory Dr Stein (Mönchengladbach, Germany). Chemicals were obtained from Bayer Diagnostics, CV for folate were $6.7 \%, 7.5 \%$, and $14.4 \%$ for test samples with concentrations of $28.9,11.2$, and $5.55 \mathrm{nmol} / \mathrm{L}$, respectively. CV for vitamin B12 were $4.5 \%$ at $968 \mathrm{pmol} / \mathrm{L}, 7.1 \%$ at $542 \mathrm{pmol} / \mathrm{L}$, and $6.0 \%$ at $235 \mathrm{pmol} / \mathrm{L}$. The $\mathrm{CV}$ for Hcy was $5.5 \%$ at $8.7 \mu \mathrm{mol} / \mathrm{L}$. 
Statistical analysis

Statistical analyses were performed using the SPSS program (version 10.0; SPSS Inc, Chicago, 1L). Standardised regression coefficients were used as a measure of association between plasma concentrations of Hcy and folate, and intake of fruit. vegetables and folate at baseline. Differences between the control and intervention group at baseline were tested with the Mann-Whitney $U$ test, and changes from baseline to post-intervention within the control group and intervention group were tested with the Wilcoxon signed rank test because most variables were non-normally distributed. Linear regression analysis was used to determine the effect of the intervention on fruit and vegetable intake, folate intake, plasma folate concentrations, and Hcy concentrations, adjusting for baseline values. Since vitamin B12 is a determinant of plasma Hcy concentrations (5), analyses which involved Hcy concentrations were adjusted for plasma witamin $\mathrm{B} 12$ concentrations in cross-sectional analyses, and for changes in vitamin $\mathrm{B} 12$ concentrations in longitudinal analyses. Regression models were checked for normality of residuals, linearity and homogeneity of variance. Outliers " defined as observations with an absolute studentised deleted residual greater than 3.5 were identified as outliers (21), excluded from the anallysis, and models rerun until no outliers were left. To improve the regression modell for plasma folate concentrations, these were transformed using the natural logarithm.

\section{Results}

Plasma samples and FFQs were available for a subset of 36 intervention subjects and 35 controls. The age of the participants was $42 \pm 4$ (mean \pm SD) years in the intervention group and $41 \pm 3$ years in the control group, and mean body mass index was $24.5 \pm 3.8 \mathrm{~kg} / \mathrm{m}^{2}$ in the intervention group and $23.8 \pm 3.0 \mathrm{~kg} / \mathrm{m}^{2}$ in the control group.

At baseline, reported fruit and vegetable consumption was similar in the intervention and control group. The estimated folate intake from fruil and vegetables was $113 \pm 49 \mu \mathrm{g} / \mathrm{day}$ in the intervention group and $115 \pm 48 \mu \mathrm{g} / \mathrm{day}$ in the control group. Plasma folate concentrations were non-significantly higher $(p=0.15)$ and plasma Hcy concentrations lower $(p=0.50)$ in the intervention group. Plasima vitamin $B 1.2$ concentrations in the intervention group were $196 \pm 82 \mathrm{pmol} / \mathrm{L}$ vs. $245 \pm 98 \mathrm{pmol} / \mathrm{L}$ in the control group ( $p=0.016_{\text {" }}$ table 1). As shown in table 2, folate intake calculated from the consumption of fruits and vegetables at baseline was not significantly associated with plasma folate (standardised regression coefficient $\left(R C_{s}\right)=0.21, p=0.08$ ) or Hcy concentrations $\left(R C_{s}=-0.09, p=0.46\right.$ ). Plasma folate was significantly positively related to consumption of total vegetables $\left(R_{\mathrm{s}}=0.34, \mathrm{p}=0.003\right.$ ) and cooked vegetables $\left(\mathrm{RC}_{s}=0.33, \mathrm{p}=0.005\right)$. Plasma Hcy was negatively associated with plasma folate concentrations $\left(R C_{s}=-0.30, p=0.013\right)$ and consumption of raw vegetables $\left(\mathrm{RC}_{\mathrm{s}}=-0.24, \mathrm{p}=0.045\right)$.

During the intervention period the reported fruit and vegetable consumption in the intervention group increased by $214 \pm 155$ g/day $(p<0.000)$ and folate intake by $43 \pm 46$ $\mu \mathrm{g} /$ day $(p<0.000)$ as compared to $7 \pm 98 \mathrm{~g} /$ day $(p=0.26)$ and $2 \pm 32 \mu \mathrm{g} /$ day $(p=0.86)$, respectively, in the control group; the between-group difference (i.e. intervention effect) was statistically significant at $p<0.001$ for both fruit and vegetable consumption and follate intake (Table 1). The observed decreases in plasma folate concentrations of $1.1 \pm 8.5 \mathrm{nmol} / \mathrm{L}$ $(p=0.32)$ in the intervention group and $1.6 \pm 4.9 \mathrm{nmol} / \mathrm{L}(p=0.26)$ in the control group were not significantly different between the two groups (intervention effect $0.3 \mathrm{nmol} / \mathrm{L}, p=0.77$ ). Plasma Hcy concentrations did not change significantly from baseline to post-intervention in either the intervention group $(0.19 \pm 1.58 \mu \mathrm{mol} / L, p=0.42)$ or the controll group $(-0.30 \pm 1.41 \mu \mathrm{mol} / \mathrm{L}$, $p=0.28$; intervention effect $0.26 \mu \mathrm{mol} / \mathrm{L}, \quad p=0.39$ ). Plasma vitamin $B 12$ concentrations 
decreased by $14 \pm 34$ pmol/L in the intervention group $(p=0.013)$ and $17 \pm 43 \mathrm{pmol} L \mathrm{~L}$ in the control group ( $p=0.038$; intervention effect -7 pmol/ $/ \mathrm{L}, \mathrm{p}=0.38$ ).

\section{Table 1}

Effects of a 4-week dietary intervention on fruit, vegetable and folate intake and plasma concentrationis of falate and homocysteine (Hcy) in 71 healthy women

\begin{tabular}{|c|c|c|c|c|}
\hline & Baseline & $\begin{array}{c}\text { Post- } \\
\text { intervention }\end{array}$ & Change & $\begin{array}{l}\text { Intervention effect } \\
(95 \% \mathrm{Cl})^{2}\end{array}$ \\
\hline & Mean (SD) & Mean (SD) & Mean (SD) & \\
\hline \multicolumn{5}{|l|}{ Fruil and vegetable } \\
\hline \multicolumn{5}{|l|}{ consumption $(g / d)^{b}$} \\
\hline Intervention group ( $n=36$ ) & $363(177)$ & $577(153)$ & $214(155)$ & $214(158-270)$ \\
\hline Control group $(n=33)$ & $382(172)$ & $375(168)$ & $7(98)$ & \\
\hline \multicolumn{5}{|l|}{ Frult consumption $(g / d)^{c}$} \\
\hline intervention group $(n=36)$ & $218(148)$ & $357(109)$ & $140(125)$ & $133(87-179)$ \\
\hline Control group $(n=34)$ & $239(139)$ & $235(132)$ & $-4(111)$ & \\
\hline \multicolumn{5}{|l|}{ Vegetable consumption (g/d) } \\
\hline Intervention group ( $n=36$ ) & $145(69)$ & $220(74)$ & $75(69)$ & $64(37-91)$ \\
\hline Control group $(n=35)$ & $144(51)$ & $154(66)$ & $11(48)$ & \\
\hline \multicolumn{5}{|l|}{$\begin{array}{l}\text { Folate intake from fruit and } \\
\text { vegetables }(\mu g / d)\end{array}$} \\
\hline Intervention group $(n=36)$ & $113(49)$ & $156(46)$ & $43(46)$ & $40(22-58)$ \\
\hline Control group $(n=35)$ & $115(48)$ & $118(54)$ & $2(32)$ & \\
\hline \multicolumn{5}{|l|}{ Plasma folate (nmol/lo) } \\
\hline Intervention group $(n=36)$ & $16.9(8.7)$ & $15.7(9.2)$ & $-1.1(8.5)$ & $0.3(-1.8-2.8)$ \\
\hline Control group $(n=35)$ & $14.6(9.3)$ & $13.0(5.9)$ & $-1.6(4.9)$ & \\
\hline \multicolumn{5}{|l|}{ Plasma Hcy $(\mu \mathrm{mol} / \mathrm{L})^{d}$} \\
\hline Intervention group $(n=35)$ & $9.70(2.56)$ & $9.89(2.07)$ & $0.19(1.58)$ & $0.26(-0.34-0.87)^{e}$ \\
\hline Control group $(n=33)$ & $10.60(4.14)$ & $10.30(3.46)$ & $-0.30(1.41)$ & \\
\hline \multicolumn{5}{|l|}{ Plasma vitamin B12 (pmol/L) } \\
\hline Intervention group $(n=36)$ & $196(82)$ & $182(80)$ & $-14(34)$ & $-7(-24-9)$ \\
\hline Control group $(n=35)$ & $245(98)$ & $228(77)$ & $-17(43)$ & \\
\hline
\end{tabular}




\section{Discussion}

The present study assessed the effects of a four-week intervention aimed at increasing the consumption of fruits and vegetables to at least the recommended intake of $200 \mathrm{~g}$ of vegetables and two pieces of fruit per day on plasma folate and Hoy concentrations. The results showed that although fruit and vegetable consumption in the intervention group during the intervention period increased by $214 \mathrm{~g} /$ day relative to the control group this did not result in increased plasma folate concentrations, nor in decreased plasma Hcy concentrations.

The present intervention is realistic in the sense that the extra amounts of fruits and vegetables consumed by participants in the intervention group can also be expected to be achieved by the general population. Moreover, the sorts of fruits and vegetables in the packets provided to the participants during the intervention period were selected to represent a variety of fruits and vegetables, and were not selected on the basis of their folate content. Although the increase in fruit and vegetable consumption measured by the FFQ was subject to measurement error, a real increase in consumption during the intervention period is likely because other biomarkers of fruit and vegetable intake (plasma carotenoids and vitamin $\mathrm{C}$ ) reported in another publication (18) increased from baseline to post-intervention. Further, our data are not biased by supplement use, because this was an exclusion criterion. Fortification of foods with folate is not allowed in the Netherlands.

\section{Table 2}

Relationships between plasma folate and homocysteine concentrations, and dietary intake of fruits, vegetables, and folate from fruits and vegelables in $7 /$ healthy women at baselinea

\begin{tabular}{llc}
\hline & plasma folate & Plasma Hcy \\
\hline Fruit and vegetable consumption & $0.21(p=0.09)$ & $-0.12(p=0.31)^{b}$ \\
Fruit consumption & $0.11(p=0.38)$ & $-0.06(p=0.61)^{b}$ \\
Vegetable consumption & $0.34(p=0.003)$ & $-0.22(p=0.08)^{b}$ \\
Cooked vegetables & $0.33(p=0.005)$ & $-0.09(p=0.45)^{b}$ \\
Raw vegetables & $0.14(p=0.25)$ & $-0.24(p=0.045)^{b}$ \\
Folate intake from fruit and vegetables & $0.21(p=0.08)$ & $-0.09(p=0.46)^{b}$ \\
Plasma folate & - & $-0.30(p=0.013)^{b}$ \\
Plasmai vitamin B12 & $0.12(p=0.32)$ & $-0.06(p=0.59)^{b}$ \\
\hline
\end{tabular}

${ }^{a}$ Numbers are standardized regression coefficients which were obtained using univariate models for plasma folate and models adjusted for plasma vitamin B12 concentrations for plasma Hcy.

- One outtier excluded.

${ }^{c}$ Controlled for plasma fiolate concentrations.

The lack of an intervention effect on plasma folate concentrations conlrasts with severall previous intervention studies, which showed higher blood folate concentrations in subjects consuming diets high in fruits and vegetables or diets high in folate than in subjects. consuming normal diets or diets low in fruits and vegetables or in folate $(7,9-14)$. Several potential explanations can be given for this contrast.

The first explanation is the duration of the intervention period in the present study. Most comparable to our study is a study by Ashfield-Watt et al. (14), in which an additional folate intake of $50 \mu \mathrm{g} /$ day for a period of four months resulted in an increase in plasma folate concentrations of $2.76 \mathrm{nmol} / \mathrm{L}$ in 41 persons consuming folate from natural sources compared to a control group. Since in our study an intervention effect on folate intake of $40 \mu \mathrm{g} / \mathrm{day}$ was estimated, the short intervention period of four weeks is the most likely explanation for a lack. of an effect on plasma folate and Hcy concentrations. The findings therefore suggest that in 
situations in which a rapid increase in plasma folate concentrations is desirable, e.g. during preginancy, only increasing intake of fruit and vegetables without folic acid supplementation may not be sufficient.

Second, the modest increase in folate intake may be an additional explanation. Previous studies incorporated higher contrasts in fruit and vegetable or folate intake (approximately $100-400 \mu$ g/day) between control and intervention groups than did our study $(7,11,12)$, and in some studies the period of enhanced folate intake also was longer than in our study (approximately $400 \mu g / d a y$ higher folate intake in the intervention group for 5 to 12 weeks) $(9,10,13)$. Additional folate intake in the present study may have been limited by either non-compliance or high consumption of fruit and vegetables at baseline. Compliance during the intervention period in our study was not $100 \%$. almost $60 \%$ of the participants in the intervention group reported to have eaten the recommended amount of $200 \mathrm{~g} / \mathrm{day}$ of vegetables, and almost $80 \%$ said to have eaten two pieces of fruit a day during the intervention period. However, when we excluded non-compliers this did not essentially alter our results. Furthermore, baseline fruilt and vegetable intake, excluding juice, was high (i.e. $300 \mathrm{~g} /$ day in the control group and $304 \mathrm{~g} /$ day in the intervention group) compared to the intake of $230 \mathrm{~g} /$ day in women aged $20-49$ years as measured in the third Dutch National Food Consumption Survey (22). In addition, plasma folate concentrations in our study population may have been less responsive to an increased folate intake because the mean plasma folate concentration at baseline in the intervention group was relatively high $(16.9 \pm 8.7 \mathrm{nmol} / \mathrm{L})$ compared to a mean serum follate concentration of $12.2 \pm 5.4 \mathrm{nmol} / \mathrm{L}$ observed in a subsample of women aged $20-49$ years who participated in the second Dutch National Food Consumption Survey (23).

Third, plasma folate concentrations unexpectedly decreased (although not statistically significant) from baseline to post-intervention in both the intervention and the control group. Other factors than dietary folate intake may have caused this decrease. Mckinley et all. (24) have reported seasonal variation in serum folate concentrations independent of dietary folate intake, with highest values observed at the end of winter (February) and lowest values at the end of spring (May). Since the first blood sample in the present study was drawn in spring (March) and the second in April, it is possible that the observed decreasing folate concentrations in the course of the study may be ascribed to seasonal variance. Alternatively, the folate content in fruits and vegetables might have been subject to seasonal variation. However, the nutritional database we used did not provide information on seasonal variation.

Fourth, poor bio-availability of folate may have attenuated the effect of an increased folate intake on pliasma folate concentrations. Although it is clear that the bioavaillability of naturally occurring folate is incomplete $(25)$, and that preparation $(26,27)$ and cooking methods (28) of vegetables affect bio-availability, we cannot be sure how this affected our findings.

Finally, it has to be noted that we only assessed folate intake from fruit and vegetables. Other sources of follate in the Netherlands include potatoes, bread and dairy products (23). Although consumption of potatoes did not change during the intervention period (data not shown), we cannot exclude that the higher intake of fruits and vegetables in the intervention group could have been associated with a decrease in intake of bread and dairy products to compensate for the extra consumption of fruit and vegetables.

The fact that we did not find an intervention effect on plasma Hcy concentrations is not unexpected given the observation that plasma folate concentrations also remained unaffected. Previous results regarding the effect of a high folate intake on blood Hcy concentrations are mixed. Four studies $(7,10-12)$ showed differences in blood concentrations of homocysteine between subjects consuming diets high in fruits and vegetables or dietary (natural occurring) folate vs. subjects consuming their usual diet or diets low in fruits and vegetables or in folate, whereas three siludies $(9,13,14)$ did not.

In accordance with previous studies $(9,10,14)$ we found a negative association between plasma Hcy and folate concentrations at baseline. However, plasma Hcy 
concentrations were not associated with vitamin $B 12$ concentrations. Although previous studies did show a relationship between Hcy and vitamin B12 concentrations, it was generally lower than between Hoy and folate concentrations $(9,10,14)$. The lack of a significant relation between plasma vitamin B12 concentrations and Hcy at baseline in the present study makes it unlikely that the lower baseline B12 levels in the intervention group negatively influenced the effect of the intervention.

In summary, we did not find an effect of a one-month intervention to increase fruit and vegetable consumption on plasma folate or Hcy concentrations in healthy nonsmoking women. The most likely explanation for the lack of an intervention effect is the relatively short intervention period. Other potential explanations include a relatively modest increase in dietary folate intake and a high plasma folate concentration at baseline in the intervention group. Future studies with longer intervention periods among persons having lower blood concentrations of folate may provide more conclusive findings. Further, the bio-availlability of folate from different fruits and vegetables and the effect of cooking deserve closer attention. In conclusion, our findings suggest that four weeks of increased fruit and vegetable consumption to the recommended amounts may not be sufficient to change plasma folate and homocysteine concentrations.

\section{References}

1. Geisel J (2003): Folic acid and neural tube defects in pregnancy: a review. I Perinat Neonatal Nurs 17, 268-79.

2. The homocysteine studies collaboration (2002): Homocysteine and risk of ischemic heart disease and stroke: a meta-analysis. JAMA 288, 2015-22.

3. Klerk M, Verhoef P, Clarke R, Blom HJ, Kok FJ and Schouten EG (2002): MTHFR $677 \mathrm{C}->$ T polymorphism and risk of coronary heart disease: a meta-analysis. JAMA 288, 2023-31.

4. Mangoni AA and Jacksan SH (2002): Homocysteine and cardiovascular disease: current evidence and future prospects. Am J Med 112, 556-65.

5. Pietrzik $K$ and Bronstrup A (1998): Vitamins B12, B6 and folate as determinants of homocysteine concentration in the healthy population. Eur J Pediatr 157 Suppl 2, S135-S138.

6. Homocysteine Lowering Trialists' Collaboration (1998): Lowering blood homocysteine with folic acid basied supplements: meta-analysis of randomised trials. BMJ 346, 8948.

7. Brouwer $\mid A$, van Dusseldorp $M$, West $C E$, Meyboom $S$, Thomas $C M$. Duran $M$, van het Hof KH. Eskes TK. Hautvast JG and Steegers Theunissein RP (1999): Dietary folate from vegetables and citrus fruit decreases plasma homocysteine concentrations in humans in a dietary controlled trial. J Nutr 129, 1135-9.

8. Suitor CW and Bailey LB (2000): Dietary folate equivalents: interpretation and application. I Am Diet Assoc 100, 88-94.

9. Appel LJ, Miller ER, 3rd, Jee SH, Stolzenberg Solomon R, Lin PH, Erlinger T, Nadeau MR and Selhub J (2000): Effect of dietary patterns on serum homocysteine: results of a randomized, controlled feeding study. Circulation 102, 852-7.

10. Silaste ML, Rantala M, Alfthan G, Aro A and Kesaniemi YA (2003): Plasma homocysteine concentration is decreased by dietary intervention. Br J Nutr 89, 295301.

11. Broekmans WM, Klopping Ketelaars $\mid A$, Schuurman $C R$, Verhagen $H_{\text {, van den } B e r g ~} H_{\text {, }}$ Kok FJ and van Poppel G (2000): Fruits and vegetables increase plasma ciarotenoids and vitamins and decrease homocysteine in humans. J Nutr 130, 1578-83. 
12. Venn Bل, Mann J\|l, Williams SM, Riddell LJ, Chisholm A, Harper MJ and Aitken W (2002): Dietary counseling to increase natural folate intake: a randomized, placebocontrolled trial in free-living subjects to assess effects on serum folate and plasma total homocysteine. Am J Clin Nutr 76, 758-65.

13. Riddell Ld, Chisholm A, Williams $S$ and Mann il (2000): Dietary strategies for lowering homocysteine concentrations. Am J Clin Nutr 71, 1448-54.

14. Ashfield Watt PA, Whiting JM, Clark ZE, Moat SJ, Newcombe RG, Burr ML and McDowell IF (2003): A comparison of the effect of advice to eat either '5-a-day' fruit and vegetables or folic acid-fortified foods on plasma folate and homocysteine. Eur $J$ Clin Nutr 57, 316-23.

15. Commissie Richtlinen Goede Voeding (11986): Guidelines for a healthy diet: recommendiations drawn up by the Committee on Guidelines for a Healthy Diet. The Hague: Nutrition Council.

16. Bogers RP, Dagnelie PC, Westerterp KR, Kester ADM, van Klaveren JD, Bast $A$ and van den Brandt PA (2003): Using a correction factor to correct for overreporting in a food-frequency questionnaire does not improve biomarker-assessed validity of estimates for fruil and vegetable consumption. J Nutr 133, 1213-9.

17. Bogers RP, Brug J, van Assema P and Dagnelie PC (2004): Explaining fruit and vegetable consumption: the theory of planned behaviour and misconception of personal intake levels. Appetite 42, 157-66.

18. Bogers RP, Van Assema $P$, Kester AD, Westerterp KR and Dagnelie PC (2004): Reproducibility, validity, and responsiveness to change of a short questionnaire for measuring fruit and vegetable intake. Am J Epidemiol 159, 900-9.

19. Beremster CJM (2001): Dutch food composition table 2001 (on CD-ROM). Zeist: NEVO Foundation.

20. Kistemaker C, Bouman M and Hulshof KFAM (1998): The consumption of separate products by Dutch population groups: Dutch National Food Consumption Survey $1997-$ 1998 (in Dutch). Zeist: TNO Nutrition and Food Research.

21. Weisberg S (1985). Applied linear regression. New York: John Wiley \& Sons.

22. Hulshof KFAM, Kistemaker $C$ and Bouman $M(1998)$ : The consumption of food groups by Dutch population groups: food consumption survey 1997-1998 (in Dutch). Zeist: TNO Nutrition and Food Research.

23. Brussaard JH, Lowik MR, van den Berg H, Brants HA and Goldbohm RA (1997):

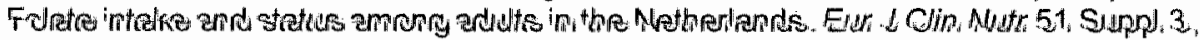
S46-50.

24. McKinley MC, Strain JJ, McPartlin J, Scott JM and McNulty H (2001): Plasima homocysteine is not subject to seasonal variation. Clin Chem 47, 1430-6.

25. Gregory uF, 3rd (2001): Case study: folate bioavailability. INutr 131, 1376S-1382S.

26. van het Hof KH, Tijburg LB, Pietrzik K and Weststrate JA (1999): Influence of feeding different vegetables on plasma levels of carotenoids, folate and vitamin $C$. Effect of distuption of the vegetable matrix. $\mathrm{Br} J$ Nutr $82,203-12$.

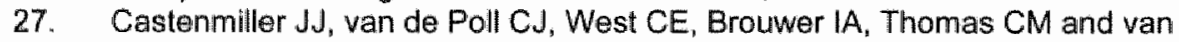
Dusseldorp $M(2000)$ : Bicavailability of folate from processed spinach in humans. Effect of food matrix and interaction with carotenoids. Ann Nutr Metab 44.163-9.

28. McKillop DJ, Pentieva K, Daly D, MCPartlin JM, Hughes J, Strain JJ, Scott JM and McNulty H (2002): The effect of different cooking methods on folate retention in various foods that are amongst the major contributors to folate intake in the UK diet. Br J Nutr $88,681-8$. 


\section{8}

\section{General discussion}



The three main objectives of the studies described in this thesis were:

- to validate two food-frequency questionnaires (FFQ) for measuning fruit and vegetable consumption against plasma carotenoids and vitamin $\mathrm{C}$;

- to identify determinants of fruit and vegetable intake in adults and children;

- to assess the effects of an increased fruit and vegetable consumption on plasma concentrations of carotenoids, vitamin $C_{\text {, folate }}$ and homocysteine.

Six studies were performed in a population of mothers with children. This chapter will

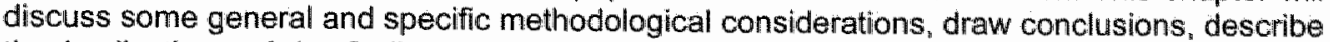
the implications of the findings, and give suggestions for further research. First the main findings of the studies will be briefly summarised.

\section{Main findings}

\section{Measurement of fruit and vegetable consumption}

Two FFQs were validated for their ability to rank individuals according to their consumption of fruits and vegetables. Correlation coefficients between consumption assessed with the extensive FFQ (summary questions) and total carotenoids/vitamin C were $0.30 / 0.25$ for fruit and 0.32/0.34 for vegetables. Correlations between fruit and vegetable consumption assessed with a concise FFQ and plasma carotenoids/vitamin $C$ were $0.39 / 0.37$ for fruits and $0.24 / 0.26$ for vegetables.

Correlations between changes in consumption estimated with the concise FFQ and changes in plasma carotenoids/vitamin $C$ were $0.32 / 0.33$ for fruits and $0.28 / 0.30$ for vegetables. The one-month/one-year reproducibility (Spearman's $r$ ) of total fruit and vegetable consumption assessed with the concise FFQ was $0.80 / 0.79$.

In addition, it was shown that estimates of cooked, raw and total vegetable consumption obtained with summary questions about these categories correlated better with biomarkers than did estimates obtained by summing separate types of vegetables, whereas for fruit no difference between either method was observed. Adjusting the consumption of carrots and total cabbage with correction factors, calculated from summary and sum estimates, resulted in lower correlations with relevant biomarkers, but for broccoli/cauliflower, Brusseis sprouts and citrus fruits, correlations with biomarkers did not change after correction.

\section{Determinants of frut and vegetable consumption}

First it was studied how overestimation of fruit and vegetable consumption by participants compromised the usefulness of the theory of planned behaviour. Forty percent and $68 \%$ of the mothers overestimated their consumption of fruit and vegetables, respectively. It was shown that the model of the theory of planned behaviour explained variation in FFQ-estimated fruit and vegetable intake much better among mothers who had a realistic view of their own fruit and vegetable consumption ('realists', $R^{2}=45 \%$ for fruits and $39 \%$ for vegetables) than among mothers who overestimated their fruit and vegetable intake (coverestimators', $R^{2}=18 \%$ and $5 \%$, respectively). When plasma vitamin $C$ and carotenoid concentrations were used as objective indicators for fruit and vegetable intake, the explanatory value of the model was lower, but again more variance was explained among realists than among overestimators. Perceived behavioural control was most strongly associated with fruit and vegetable consumption, followed by attitude and intention (the latter only for fruit consumption). Subjective norm was not associated with fruit and vegetable intake. 
Changes in fruit consumption of the mothers after one month of increased availability were positively associated with perceived costs and with the perceived health benefits of fruit for their children, and negatively associated with perceived behavioural control $\left(R^{2}\right.$ of model including baseline consumption was $34 \%$. Changes in vegetable consumption were positively related with the intention to eat at least $200 \mathrm{~g}$ of vegetables and the taste preferences of the children ( $R^{2}$ of model including baseline consumption was $48 \%$ ). Changes in vegetable consumption one year after the period of enhanced availability were positively related to perceived behavioural control and perceived health benefits of vegetables for the children, and tended to be negatively related to perceived costs of vegetables $\left(R^{2}\right.$ of model including baseline consumption was $55 \%$ ).

In children, positive associations were observed between fruit consumption and their mothers" fruit consumption, strict obligation rules to eat fruit and vegetables, adherence to a special diet ${ }_{\mathrm{n}}$ percerved home availability of fruit, and their mothers' educational level. Children with employed mothers consumed less fruit than children with non-working mothers $\left(\mathrm{R}^{2}=41 \%\right)$. Children's consumption of vegetables was positively associated with their mother's vegetable consumption and negatively associated with adherence to a special diet $\left(R^{2}=41 \%\right)$. Changes in children's fruit consumption were not related to any of the variables under study. Changes in vegetable consumption were lower in children from families that grew their own produce and higher in families in which the father worked at irregular times $\left(R^{2}\right.$ of model including baseline consumption was $42 \%$ ).

Intervention effects on plasma carotenoids, vitamin C, folate, and hamocysteine

The intervention led to a increases in consumption of 1.1 servings/day ( $147 \mathrm{~g} /$ day) for fruit and 1.3 servings/day $(68 \mathrm{~g} /$ day) for vegetables. This resulted in increases of plasma concentrations of vitamin $\mathrm{C}(+18 \%, 10.05 \mu \mathrm{mol} / \mathrm{L})$ and total carotenoids $(+16 \%, 0.32 \mu \mathrm{mol} / \mathrm{L})$ as well as of specific carotenoids except lycopene $(\beta$-carotene $+12 \%$, $\alpha$-carotene $+17 \%$, lutein $+23 \%$ and $\beta$-cryptoxanthin $+23 \%$ ). However, the intervention did not lead to changes in either plasma folate concentrations (intervention effect $0 \%$ or $0.3 \mathrm{nmol} / \mathrm{L}$ ), or homocysteine concentrations (intervention effect $0 \%$ or $0.26 \mu \mathrm{mol} / \mathrm{L}$ ).

\section{General methodological considerations}

Since the separate studies that are reported in this thesis are the result of a multidisciplinary project, some methodological issues concerning the overall project will be discussed first. These include the type of intervention, representativeness and drop-out of the study participants, and time frame of the study.

in terms of methodology, the study contains some innovative features such as the use of biomarkers in the study of determinants of fruit and vegetable intake, and the longitudinal study on determinants of change in fruit and vegetable intake. In the design of the study, an optimal balance had to be ensured between what was best for the validation studies on one hand and for the study of determinants on the other. In order to validate the concise FFQ for its ability to measure changes in fruit and vegetable intake, it was essential that the intervention resulted in an increased fruit and vegetable consumption. Therefore we chase to provide fruit and vegetables for free during the intervention period. This type of intervention, however, did not allow us to study the effect of a "real-life" intervention on changes in psychosocial determinants of fruit and vegetable consumption.

The selection criteria for the study population also originated from the requirements of the validation study and the study of determinants. For the validation study all participants had to be healthy nonsmokers and had to agree not to use vitamin supplements during the study. To study determinants of fruit and vegetable intake in children, the participants had to be 
mothers with children in a particular age range. The percentage of women who responded to the invitation to participate in the study was very small. The mostly intermediate to high educational level of these women suggests a selective response by relatively highly educated women, who are known to consume more fruit and vegetables (1). Reasons that were often given for non-participation were lack of time or interest. Given that the study involved giving blood and completing rather extensive questionnaires, the women who participated might have been highly interested in the study. They reported (using the extensive FFQ) a mean fruit and vegetable consumption of $307 \mathrm{~g} / \mathrm{day}$, which is high compared to the fruit and vegetable intake of $230 \mathrm{~g} / \mathrm{d}$ ay in women aged $20-49$ years as measured in the third Dutch National Food Consumption Survey (2). The implication of the selective study population is a limited generalizability of the results with respect to both the validity of the FFQs and the determinants of fruit and vegetable intake. Also the intervention effects on plasma micronutrients and homocysteine are likely to be different in different study populations consisting of e.g. men and smokers.

Another consideration concerns drop-out of study participants. Forty-five of the 194 participants dropped out in the course of the study. The ones who dropped out were significantly younger ( 39 years vs. 41 years) and consumed significantly less vegetables ( 2.9 vs. 3.5 servings/day), which may further limit the generalizability of the results to persons consuming a relatively high amount of vegetables.

Finally, not only may the findings be applicable to a limited population, but also to a limited time frame. All measurements were performed in spring to minimise the influence of season on biomarker concentrations and on the reproducibility study of the short FFQ. However, since availability and costs of fruits and vegetables differ between seasons, total fruit and vegetable consumption and the relative contribution of individual sorts will be different in other seasons. In addition, the importance of the various determinants of fruit and vegetable consumption may also vary between seasons. Nevertheless, we believe that the benefits for the validation studies of performing all measurements in the same season outweigh the limitations.

\section{Conclusions, implications and recommendations}

\section{Measurement of fruit and vegetable consumption}

Correlation coefficients between fruit and vegetable consumption and biomarkers were reported as a measure of validity. Based on comparisons with previous findings it is concluded that our two FFQs have a similar level of validity as most FFQs in terms of ranking individuals according to their fruit and vegetable intake. The concise FFQ was also validated for its ability to rank individuals according to changes in fruit and vegetable intake. We are not aware of any previous studies using biomarkers to validate an FFQ for the ability to measure changes in fruit and vegetable consumption, which makes this a novel aspect of our validation study. Since there is no material for comparison, the absolute values of the correlation coefficients lead to the conciusion that the concise $F F Q$ allows ranking of persons according to changes in fruit and vegetable intake. Since the concise FFQ is short, cheap and easy to implement, it can be a valuable dietary assessment instrument in several types of studies, including epidemiological studies, studies on determinants of fruit and vegetable intake, and studies evaluating the effectiveness of fruit and vegetables promotion interventions. Further validation work of the FFQs has to include validation for their ability to measure the absolute magnitude of the average fruit and vegetable consumption in groups and individuals. Future studies also have to provide informaltion on the minimal (though relevant for health) change in fruit and vegetable consumption that can be measured with the concise FFQ. This is an important issue to be addressed, because many interventions that encourage fruit and 
vegetable consumption achieve only modest increases. In order to refine validation studies, it is necessary to continue the search for reliable biomarkers of (absolute) fruit and vegetable intake. Recently, urinary flavonoid excretion has been identified as a marker for total fruit and vegetable consumption (3-5), and conjugates of isothiocyanate in urine have been shown to be related to intake of cruciferous vegetables $(6,7)$. However, correlations between total urinary flavonoid excrelion and fruit and vegetable intake in individuals consuming their usual diet were modest $(r=0.35)$ (3). The lack of an intervention effect on plasma folate concentrations in the present study suggests that folate is not a suitable biomarkers for current fruit and vegetable consumption. In addition to the usual approach of validating one method against a reference method, other types of validation studies might be possible. For example, dietary assessment methods might be validated in controlled feeding studies, in which participants complete an FFQ or other instrument covering the study period after being provided with a known diet, which in that case is the "golld standard'. Although the limitation of this approach would be the unnatural setting, it would certainily shed light on the maximum validity of FFQs that can be achieved, and the effects of -controlled-variations or changes in diet.

The conclusion of the study on the use of summary questions for main categories of fruit and vegetables is that these questions may suffice to rank individuals according to their intake of main fruit and vegetable categories. This implies that short FFQs are as valid as extensive FFQs in determining total fruit and vegetable intake. Previous studies showed that estimates of fruit and vegetable intake increase when the number of questions in an FFQ increase (8), and that a summary question yielded a lower estimate of fruit and vegetable intake (9). However, in contrast to our study the above studies did not validate the various estimates of intake against a reference method, which makes this a novel aspect of the present study. The results also suggests that correction for overreporting of individual vegetable items is not likely to result in a better ranking of individuals according to intake of these items. However, the effects on validity of adjusting estimates of absolute fruit and vegetable intake with a correction factor remain to be studied. A previous study showed that applying a weighting factor decreased estimates of fruit and vegetable consumption and vitamin $A, C, E_{n}$ and folate intake (9). but this study neither compared the results with an independent reference method. Since it has been shown that women with lower educational levels were more likely to show a large discrepancy between estimates of fruit and vegetable intake derived from summary questions and from the sum of individual types of fruits and vegetables (9), our conclusions may apply even more to populations of a lower educational level.

\section{Determinants of fruit and vegetable cansumption}

To begin with, it is concluded that overestimation of personal fruit and vegetable consumption levels compromises the usefulness of the theory of planned behaviour. An important implication for future studies aimed at identifying psychosocial determinants of fruit and vegetable intake is that in order to more fully explain variation in consumption, awareness of personal intake levels should be taken into account, e.g. by stratifying analyses according to awareness. Lack of awareness not only has implications for theory, but could also be an important barrier to increased fruit and vegetable consumption; according to the precaution adoption process model (10) persons who are unaware are unlikely to change their behaviour. Based on the present study no recommendations can be given on how to raise awareness, but previous research has shown that this can be done by using interactive computer-tailored nutrition education programmes $(11,12)$. However, awareness of insufficient fruit and vegetable consumption is a prerequisite for behaviour changle but will not induce increased fruit and vegetable intake by itself.

A number of factors associated with (change in) fruit and vegetable consumption were identified, of which the most important was perceived behavioural control. Povey \& Conner 
(13) found evidence that the perceived behavioural control construct from the theory of planned behaviour consists of two distinct components: selfefficacy beliefs which reflect the extent to which performance of the behaviour is easy or difficult for the individual, and perceived control over the behaviour, which reflects the extent to which the individual perceives the performance of the behaviour within his or her control. Therefore interventions may be successful if they tackle self-efficacy beliefs and perceived control. This may be achieved by suggesting strategies to overcome the difficulties that persons have in certain situations. Brug et al. (14) showed that these difficulties include eating fruit and vegetables when alone or with lack of time, at weekends, in winter when thene is less choice, and when preparation is difficult. Similar beliefs (or barriers) were also mentioned by other authors $(15,16)$.

An important role of price and (home) availability of fruit and vegetables is suggested by the findings that the perceived price of fruits and vegetables was a determinant of change in consumption, that children's fruit consumption was associated with perceived home availability of fruit, and the marked effect on consumption of increased availability during the intervention period. It has already been shown that reducing the price of (healthy) foods increases their consumption (17). Another study showed that compared to homes with low fruit and vegetable availability, homes with a higher availability had a richer and generally stronger set of motivating factors for parent and child fruit and vegetable consumption (18). Price and availability are environmental factors and as such may moderate the role of other (personal) determinants. Future research will have to elucidate this moderating role, e.g. by studying personal determinants in settings with high and low availability and price. More generally speaking, the role of personal determinants under different environmental conditions and the interaction between personal and environmental factors deserve further attention. Further, it is recommended that current initiatives to increase consumption of fruit and vegetables by increasing availability, e.g. at school, be continued.

Taste has been shown to be an important determinant of fruit and vegetable consumption $(14,19-22)$. An exploratory correlation analysis (not reported in this thesis) confirmed this well-known association of taste with fruit and vegletable intake in mothers and children. In addition, changes in mothers' vegetable consumption were related to their children"s taste preference for vegetables. Thus, it is important to make the taste of vegetables more attractive to aduits and children. Although the present study did not identify strategies to achieve this, introducing adults to tasty recipes (as is already done) seems a feasible option. In children, previous research has shown that repeated tasting of a certain vegetable enhances the acceptance of that vegetable (23).

The strong observed association between fruit and vegetable consumption in mothers and their children suggests that family-based interventions might be successful in increasing children's fruit and vegetable intake. However, since the present study does not indicate the cause of this association, no recommendations can be given for specific intervention: strategies. Several potential explanations are possible, but in order to gain more insight into how children"s food patterns are formed, longitudinal studies in families of a long duration are needed. Such studies may also provide more conclusive answers to the effect of strictness in food rules on children's fruit and vegetable consumption, because to date there is conflicting evidence surrounding this topic (24-27).

Although several determinants of fruit and vegetable intake were identified, a considerable part of variation in consumption remained unexplained. Apart from overestimation of personal fruit and vegetable intake, a cause could be a low validity of the methods used to assess psychosocial constructs. However, to minimise error in the measurement of these constructs, they were operationalised according to previous directions (28). There may also be additional factors associated with a (low) fruit and vegetable intake that were not studied, e.g. an increasing frequency of eating in restaurants as has been shown in the U.S. $(29,30)$. Finally, items in the questionnaires on determinants concerned fruit and vegetables in general. Due to the wide variety in fruit and vegetable types, responses on 
the items in the questionnaire may apply to some types of fruit and vegetables but not to others. Therefore, more variation in intake of fruit and vegetables may be explained in studies that differentiate between various types of fruits and vegetables.

\section{Intervention effects on plasma carotenoids, vitamin C, folate, and homocysteine}

The observed intervention effects on plasma carotenoid and vitamin $\mathrm{C}$ concentrations confirm the findings of previous research showing that increased fruit and vegetable intake leads to higher concentrations of carotenoids and vitamin $C$ in blood (31-37). Thus the usefulness of these vitamins as biomarkers of fruit and vegetable intake is confirmed. The most probable explanation for the lack of an intervention effect on plasma folate in the present study is the short duration (four weeks) of the intervention period, but the relatively modest increase in follate intake may also be an explanation. Future research studying the effects of a similar intervention of a longer duration is needed to be conclusive about the feasibility of increasing fruit and vegetable consumption as a means of increasing plasma folate and decreasing homocysteine concentrations. However, based on our findings it may be concluded that in situations in which a rapid increase in blood folate concentrations is desirable, e.g. during pregnancy, taking folic acid supplements may be a better option than increasing the intake of fruit and vegetables.

\section{General conclusion}

The present study contributes to the existing knowledge in various ways. First, an extensive and a concise FFQ were validated. It was concluded that these FFQs allow the ranking of individuals according to their consumption of fruit and vegetables. The concise FFQ also allows ranking of persons according to changes in consumption. The FFQs can be valuable dietary assessment instruments in several types of studies, including epidemiological studies, studies on determinants of fruit and vegetable intake, and studies evaluating the effectiveness of fruit and vegetables promotion interventions. Further, knowledge about the use of summary questions and correction factors was obtained, which can be useful in the design and analysis of FFQs. Several determinants of fruit and vegetable intake were identified. This knowledge can be used to develop and refine interventions aimed at increasing intake of fruit and vegetables. A marked effect of overestimation of personal intake levels of fruit and vegetables on the explanatory value of the theory of planned behaviour was shown. An important implication is that future studies on determinants of fruit and vegetable consumption should take awareness into account. Finally, the effects of increased fruit and vegetable consumption on plasma concentrations of carotenoids and vitamin $\mathrm{C}$ confirmed their usefulness as biomarkers of fruit and vegetable intake. Since no intervention effect on plasma folate and homocysteine concentrations was observed, it does not seem feasible to consume more fruit and vegetables as a means of achieving rapid increases in plasma folate. A limitation of the study was a selective study population. Therefore caution should be taken in extrapolating the results to other populations. While this limitation is acknowledged, the study provided valuable and some novel results on various aspects of fruit and vegetable consumption. 


\section{References}

1. Iralia Estevez JD, Groth M, Johansson L, Oltersdorf $U_{1}$. Prattala $R$ and Martinez Gonzallez MA (2000): A systematic review of socio-economic differences in food habits in Europe: consumption of fruit and vegetables. Eur J Clin Nutr 54, 706-14.

2. Hulshof KFAM Kistemaker $C$ and Bouman M (1998): The consumption of food groups by Dutch population groups: food consumption survey 1997-1998 (in Dutch). Zeist: TNO Nutrition and Food Research.

3. Nielsen SE, Freese $R$, Kleemola $P$ and Mutanen $M(2002)$ : Flavonoids in human urine as biomarkers for intake of fruits and vegetables. 11, 459-66.

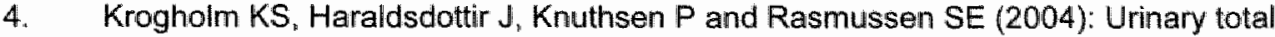
flavonoild excretion but not 4-pyridoxic acid or potassium can be used as a biomarker for the intake of fruits and vegetables. J Nutr 134, 445-51.

5. Brevik A, Rasmussen SE, Drevon CA and Andersen LF (2004): Urinary Excretion of Flavonoids Reflects Even Small Changes in the Dietary Intake of Fruits and Vegetables. Cancer Epidemiol Biomarkers Prev 13, 843-9.

6. Fowke JH, Hebert JR and Fahey JW (2002): Urinary excretion of dithiocarbamates and self-reported Cruciferous vegetable intake: application of the "method of triads" to a food-specific biomarker. Public Health Nutr 5, 791-9.

7. Vermeulen M, van Rooijen HJ and Vaes WH (2003): Analysis of isothiocyanate mercapturic acids in urine: a biomarker for cruciferous vegetable intake. J Agric Food Chem 51, 3554-9.

8. Krebs Smith SM, Heimendinger J, Subar AF, Patterson BH and Pivonka E (1995): Using food frequency questionnaires to estimate fruit and vegetable intake: association between the number of questions and total intakes. I Nutr Educ 27, 80-85.

9. Calvert C, Cade J, Barrett JH and Woodhouse A (1997): Using cross-check questions to address the problem of mis-reporting of specific food groups on Food Frequency Questionnaires. UKWCS Steering Group. United Kingdom Women"s Cohort Study Steering Group. Eur J Clin Nutr 51, 708-12.

10. Weinstein ND (1988): The precaution adoption process. Health Psychol 7, 355-386.

11. Oenema A and Brug J (2003); Feedback strategies to raise awareness of personal dietary intake: results of a randomized controlled trial. 36, 429-39.

12. Oenema A, Tan F and Brug JShort-term efficacy of a web-based computer-tailored nutrition intervention; main effects and mediators. accepted for publication.

13. Povey $R$, Conner $M$, Sparks $P$, James $R$ and Shepherd $R(2000)$ : Application of the Theory of Planned Behaviour to two dietary behaviours: Roles of perceived control and self-efficacy. Br J Health Psychol 5, 121-39.

14. Brug J, Lechner L and De Vries H (1995): Psychosocial determinants of fruit and vegetable consumption. Appetite 25, 285-96.

15. Oygard $L$ and Rise $J(1996)$ : Predicting the intention to eat healthier foods among young adults. Health Educ Res 11, 453-61.

16. Hagdrup NA, Simoes $E_{J}$ and Brownson $R C$ (1998): Fruit and vegetable consumption in Missouri: Knowledge, barriers and benefits. Am J Health Behav 22, 90-100.

17. French SA (2003): Pricing effects on food choices. J Nutr 133, 841S-843S.

18. Kratt $P$, Reynolds $K$ and Shewchuk $R(2000)$ : The role of availability as a moderator of familly fruit and vegetable consumption. Health Educ Behav 27, 471-82.

19. Glanz K, Basil M, Maibach E, Goldberg J and Snyder D (1998): Why Americans eat what they do: taste, nutrition, cost convenience, and weight control concerns as influences on food consumption. I Am Diet Assoc 98, 1118-26. 
20. Krebs Smith SM. Heimendingler J, Patterson BH, Subar AF, Kessler R and Pivonka E (1995): Psychosocial factors associated with fruit and vegetable consumption. Am J Health Promot 10, 98-104.

21. Satia $J_{A}$, Kristal AR, Patterson RE, Neuhouser ML and Trudeau E (2002):

Psychosocial factors and dietary habits associated with vegetable consumption. Nutrition 18, 247-54.

22. Van Duyn MA, Kristal AR, Dodd $K$, Campbell MK, Subar AF, Stables $G$, Nebeling $L$ and Glanz K (2001): Association of awareness, intrapersonal and interpersonal factors, and stage of dietary change with fruit and vegetable consumption: a national survey. Am al Health Promot 16, 69-78.

23. Wardle J, Cooke LJ, Gibson L, Sapochnik M, Sheiham A and Lawson M (2003): Increasing children's acceptance of vegetables; a randomized trial of parent-led exposure. Appetite 40, 155-62.

24. Fisher JO, Mitchell DC, Smiciklas Wright $\mathrm{H}$ and Birch LL (2002): Parental influences on young girls" fruit and vegetable, micronutrient, and fat intakes. J Am Diet Assoc 102, $58-64$.

25. Weber Cullen $K$, Baranowski $T$, Rittenberry $L$, Cosart $C$, Hebert D and de Moor $C$ (2001): Child-reported family and peer influences on fruit, juice and vegetable consumption: Reliability and validity of measures. Health Educ Res 16, 187-200.

26. Young EM, Fors SW and Hayes DM (2004): Associations between perceived parent behaviors and middle school student fruit and vegetable consumption. J Nutr Educ Behav $36,2 \sim 8$.

27. De Bourdeaudhuij 1 (1997): Family food rules and healthy eating in adolescents. $J$ Health Psychol 2, 45-56.

28. Conner $M$ and Sparks $P(1996)$. The theory of planned behaviour and health behaviours. in Predicting health behaviour: Research and practice with social cognition models (eds. Conner M \& Norman P). Buckingham: Open University Press.

29. Cullen KW, Baranowski T, Rittenberry L and Olvera N (2000): Social-environmental influences on children's diets: results from focus groups with African-, Euro- and Mexican-American children and their parents. 15, 581-90.

30. Nielsen SJ, Siega-Riz AM and Popkin BM (2002): Trends in energy intake in U.S. between 1977 and 1996: similar shifts seen across age groups. Obes Res 10, 370-8.

31. John JH, Ziebland $S$, Yudkin P, Roe LS and Neil HA (2002): Effects of fruit and veglettable consumption on plasma antioxidant concentrations and blood pressure: a randomised controlled trial. Lancet $359,1969-74$.

32. Zino S, Skeaff M, Williams S and Mann J (1997): Randomised controlled trial of effect of fruit and vegetable consumption on plasma concentrations of lipids and antioxidants. BMJ 344, 1787-91.

33. Le Marchand L, Hankin JH, Carter FS, Essling $C$, Luffey D, Franke AA, Wilkens LR, Cooney RV and Kollonel LN (1994): A pilot study on the use of plasma carotenoids and ascorbic acid as markers of compliance to a high fruit and vegetable dietary intervention. Cancer Epidemiol Biomarkers Prev 3, 245-54.

34. McEligot AJ, Rock CL, Flatt SW, Newman V, Faerber S and Pierce JP (1999): Plasma carotenoids are biomarkers of long-term high vegetable intake in women with breast cancer. J Nutr 129, 2258-63.

35. Maskarinec $G$, Chan CLY, Meng LX, Franke AA and Cooney RV (1999): Exploring the feasibility and effects of a high-fruit and -vegetable diet in healthy women. Cancer Epidemiol Biomarkers Prev 8, 919-24.

36. Broekmans WM, Klopping Ketelaars IA, Schuurman $C R$, Verhagen $H$, van den Berg $H_{\text {, }}$ Kok FJ and van Poppel $G(2000)$. Fruits and vegetables increase plasma carotenoids and vitamins and decrease homocysteine in humans. J Nutr 130, 1578-83. 
37. Record IR, Dreasti IE and Mclnerney JK (2001): Changes in plasma antioxidant status following consumption of diets high or low in fruit and vegetables or following dietary supplementation with an antioxidant mixture. $\mathrm{Br} J$ Nutr $85,459-64$. 
Summary 
Mean consumption of fruit and vegetables in many countries is below the amounts recommended by public health authorities. To increase the consumption of fruit and vegetables, interventions based on knowledge about determinants of consumption are needed. The research project described in this thesis aimed to identify determinants of fruit and vegetable consumption in mothers and children. Studies on this topic were preceded by validation studies of two food-frequency questionnaires (FFQs) designed to measure fruit and vegetable consumption. Finally, the effects of an increased fruit and vegetable consumption on plasma concentrations of carotenoids, vitamin $C$, folate and homocysteine were determined.

The separate studies were integrated in a larger project performed in 165 mothers with children aged 7-10 years. The mothers completed written questionnaires on fruit and vegetable consumption and potential determinaints " and provided a blood sample at three points of time: at baseline, one month later and one year after the baseline measurement. Following the baseline measurement the group was split by randomization into a control group and an experimental group. In the experimental group, fruit and vegetables for the whole family were supplied free of charge during one month.

\section{Measurement of fruit and vegetable consumption}

The first objective of the project was to validate two FFQs for their ability to rank individuals according to their consumption of fruit and vegetables: an elaborate FFQ for measuring intake of specific fruits and vegetables (chapter 2) and a concise eight-item FFQ designed to measure total fruit and vegetable consumption (chapter 3 ). Validation was done using plasma concentrations of carotenoids and vitamin $\mathrm{C}$ as biomarkers. Correlation coefficients between consumption assessed with the FFQs and biomarkers were moderate but in line with the strength of associations generally found in previous studies. Correlations between changes in consumption estimated with the concise FFQ and changes in biomarkers were also moderate. The one-month/one-year reproducibility (Spearman's $r$ ) of total fruit and vegetable consumption assessed with the concise $F F Q$ was $0.80 / 0.79$. It was concluded that the two FFQs allow ranking of individuals according to their fruit and vegetable intake, and that the concise FFQ can additionally be used for the purpose of ranking according to changes in fruit and vegetable consumption.

One of the issues related to dietary assessment concerns overreporting of fruit and vegetable consumption, especially if a questionnaire contains a large number of items. Therefore it is common practice to use in FFQs, in addition to questions on consumption of specific fruits and vegetables, summary questions about main groups of fruits and vegetables and correction factors to adjust intake estimates of individual fruits and vegetables. Chapter 2 describes a methodological study on the validity of this approach, again with biomarkers as a reference method. Correlations with biomarkers were higher when vegetable consumption was assessed with summary questions than with a number of items, but for fruits no differences were observed. in some cases, application of a correction factor resulted in lower correlations with biomarkers, but in other cases this approach did not alter correlations. It was concluded that summary questions may suffice to rank individuals according to their intake of miain fruit and vegetable categories, and that correction for overreporting of individual fruit and vegetable items is not advisable when ranking individuals according to intake of these items.

\section{Determinants of fruit and vegetable consumption}

Determinents of fruit and vegetable intake were studied in mothers and children. From literature it is known that awareness of personal behaviour is an important determinant of behaviour: the amount of fruits and vegetables people think they eat is in many cases not in agreement with their actual consumption. However, to what extent this misconception affects the usefulness of a model often used to study determinants, the theory of planned behaviour, was hitherto unknown. In chapter 4 it is shown that the model explained variation in FFQ- 
estimated fruil and vegetable intake much better among mothers having a realistic view of their own fruit and vegetable consumption $\left(R^{2}=45 \%\right.$ for fruits and $39 \%$ for vegetables) than among mothers who overestimated their fruit and vegetable intake $\left(R^{2}=18 \%\right.$ and $5 \%$, respectively). These results were confirmed when biomarkers were used as an objective measure of intake, although the explanatory value of the model was much lower using biomarkers. The same study showed that perceived behavioural control was the main psychosocial determinant of fruit and vegetable consumption, followed by attitude and intention (the latter only for fruit consumption). Subjective norms were not associated with fruit and vegetable intake. It was concluded that awareness of personal behaviour should be taken into account when applying the theory of planned behaviour to explain fruit and vegetable consumption. A further implication is that lack of awareness of personal fruit and vegetable consumption may also be an important barrier to increase fruit and vegetable consumption.

The question of what psychosocial factors predict changes in fruit and vegetable intake is studied in chapter 5 . Baseline psychosocial factors were used to predict changes in fruit and vegetable consumption in the experimental group. Changes in fruit consumption of the mothers during the period of enhanced availlability were positively associated with perceived costs and with the perceived health benefits of fruit for their children, and negatively associated with perceived behavioural control. Changes in vegetable consumption were positively related with the intention to eat at least $200 \mathrm{~g}$ of vegetables and with taste preferences of the children. Changes in vegetable consumption one year after the period of enhanced availability were positively related to perceived behavioural control and perceived health benefits of vegetables for the children, and tended to be negatively related to perceived costs of vegetables. It was concluded that fruit and vegetable consumption may be encouraged by influencing the above variables.

Family-related determinants of children's fruit and vegetable consumption are reported in chapter 6. Children's fruit consumption was positively related with their mothers' fruit consumption, with strict obligation rules in the home environment to eat fruit and vegetables, with adherence to a special diet, with perceived home availability of fruit, and with their mothers' educational level. Children with employed mothers consumed less fruit than children with non-working mothers. Children's consumption of vegetables was positively related with their mothers' vegetable consumption, and negatively related with adherence to a special diet. Changes in children's fruit consumption in the experimental group were not related to any of the variables under study. Changes in vegetable consumption were lower in children from families that grew their own produce and higher in families in which the father worked at irregular times. These findings indicate that several family-related factors influence children's fruit and vegetable consumption.

\section{Intervention effects on plasma caratenoids, vitamin C, folate, and homocysteine}

The effects of an increased fruit and vegetable consumption on plasma concentrations of carotenoids, vitamin $C$, folate and homocysteine are reported in chapter 7 . The one-month intervention period led to increases in consumption of 1.1 servings/day (147 g/day) for fruit and 1.3 servings/day $(68 \mathrm{~g} /$ day) for vegetables. This resulted in increases of plasma concentrations of vitamin $C(+18 \%, 10.05 \mu \mathrm{mol} / \mathrm{L})$ and total carotenoids $(+16 \%, 0.32 \mu \mathrm{mol} / \mathrm{L})$, as well as of specific carotenoids $(\alpha$-carotene $+12 \%, \beta$-carotene $+17 \%$, lutein $+23 \%$ and $\beta$ cryptoxanthin $+23 \%$ ) except lycopene. However, the intervention did not lead to changes in either plasma folate or homocysteine concentrations, most likely due to the relatively short duration of the intervention. These findings confirm the usefulness of carotenoids and vitamin $\mathrm{C}$ as biomarkers of fruit and vegetable intake. With respect to folate, it may be concluded that in situations in which a rapid increase in blood folate concentrations is desirable e.g. during pregnancy, supplementation with folic acid may be a better option than increasing the intake of fruit and vegetables. 
Implications of the findings and recommendations for scientific research and practice with respect to measurement, determinants and effects of fruit and vegetable consumption are discussed in chapter 8 . This chapter also addresses methodological considerations which should be taken into account when interpreting the results of this project. 
Samenvatting 
De gemiddelde consumptie van groente en fruit is in veel landen lager dan de hoeveelheden die door gezondheidsinstanties worden aanbevolen. Om de groente- en fruitconsumptie te verhogen zijn interventies nodig die gebaseerd zijn op kennis over determinanten wan groente-en fruitconsumptie. Het in dit proefschrift beschreven onderzoek had als coel determinanten van groente- en fruitconsumptie bij moeders en kinderen te vinden. Daarnaast ziln twee voedselfrequentievragenlijsten (FFQ) om consumptie van groente en fruit te bepalen gevalideerd. Tot slot zijn de effecten bepaald van een verhoogde groente- en fruitconsumptie op concentraties carotenoilden, vitamine $C$, folaat en homocysteine in plasma.

De verschillende deelonderzoeken waren gecombineerd in éen project dat werd uiltgevoerd bij 165 moeders met kinderen in de leeftijd van $7 \mathrm{t} / \mathrm{m} 10$ jaar. De moeders vulden schriftelijke vragenlijsten in over groente- en fruitconsumptie en mogelijke determinanten en lieten bloed bij hen afnemen op drie momenten: aan het begin van het onderzoek, een maand daarna en een Jaar na aanvang van hel onderzoek. $\mathrm{Na}$ de beginmeting werden de deenemers willekeurig verdeeld over een controlegroep en een interventiegroep. Deelnemers uit de interventiegroep kregen gedurende éen maand gratis groente en fruit voor het hele gezin.

\section{Bepaling van groente-en fruitconsumptie}

De eerste doelstelling van het project was om twee FFQs te valideren op de mogelijkheid om mensen te rangschikken naar hun consumptie van groente en fruit. De twee vragenlijsten waren een uitgebreide FFQ om consumptie van specifieke soorten groente en fruit mee te bepalen (hoofdstuk 2) en een korte FFQ van acht items om totale groente- en fruitconsumptie mee te bepalen (hoofdstuk 3). Validering werd gedaan met concentraties carotenoidien en vitamine $\mathrm{C}$ in plasma als biomerkers. De correlatiecoëfficiënten tussen groente- en fruitconsumptie bepaald met de FFQs en de biomerkers waren niet al te hoog. maar vergelijkbaar met wat over het algemeen in voorgaand onderzoek is gevonden. Correlaties tussen veranderingen in consumptie bepaald met de korte FFQ en veranderingen in de biomerkers waren in dezelfde orde van grootte. De reproduceerbaarheid (Spearmans $r$ ) van totale groente- en fruitconsumptie bepaald met de korte FFQ was 0,80 na een maand en 0,79 na een jaar. De conclusie was dat met de twee FFQs mensen gerangschikt kunnen worden naar hun consumptie van groente en fruit, en dat de korte $F F Q$ ook gebruikt kan worden om mensen te rangschikken naar veranderingen in groente- en fruitconsumptie.

Een van de dingen waarmee rekening moet worden gehouden bij het bepalen van de voedselinname is overrapportage van groente- en fruitconsumptie, voorall als een vragenlijst een groot aantal items bevat. Daarom worden in FFQs naast vragen over specifieke groenteen fruitsoorten valak samenvattende vragen gebruikt over de consumptie van hoofdgroepen groente en fruit, en worden correctiefactoren berekend om de consumptie van specifieke soorten te corrigeren. Hoofdstuk 2 beschrijft een methodologische studie naar de validiteit van deze aanpak waarbij biomerkers als referentiemethode worden gebruikt. De correlaties tussen groenteconsumptie en biomerkers waren hoger als de groenteconsumptie werd bepaald met enkele samenvattende vragen dan als deze met een groot aantal items werd bepaald, terwijl er voor fruit geen verschillen waren. In sommige gevallen leidde hel gebruik van een correctiefactor tot lagere correlaties met biomerkers, maar in andere gevallen veranderden de correlaties niet na correctie. Er werd geconcludeerd dat samenvattende vragen voldoende lijken te zijn om mensen te rangschikken naar consumptie van hoofdgroepen groente en fruit en dat het corrigeren voor overrapportage van specifieke groente- en fruitsoorten niet aan te raden is wanneer mensen gerangschikt moeten worden naar inname van deze soorten. 
Determinanten van groente- en fruitconsumptie werden bestudeerd bij moeders en kinderen. Uit de literatuur is bekend dat een belangrijke determinant van gedrag het zich bewust zijn van persoonlijk gedrag is: de hoeveelheid groente en fruit die mensen denken te eten is vaak niet in overeenstemming met hun werkelijke consumptie. Het was tot nu toe echter niet bekend in welke mate deze misconceptie de toepasbaarheid beinvloedt van de theorie van gepland gedrag, een model dat vaak wordt gebruikt om gedragsdeterminanten te bestuderem. In hoofdstuk 4 wordt aangetoond dat het model de variatie in met een $F F Q$ bepaalde groente- en fruitconsumptie veel beter verklaart bij moeders die hun groente-en fruitconsumptie realistisch inschatten $\left(\mathbb{R}^{2}=45 \%\right.$ voor fruit en $39 \%$ voor groente $)$ dan bij moeders die hun groente- en fruitconsumptie overschatten $\left(R^{2}=18 \%\right.$ voor fruit en $5 \%$ voor groente). Deze resultaten werden bevestigd met biomerkers als een objectieve maat voor consumptie, hoewel de verklarende waarde van hel model veel lager was voor biomerkers. Dezelfde studie laat zien dat de mate waarin men meent zijn gedrag te beheersien de belangrijkste psychosociale determinant van groente- en fruitconsumptie was, gevolgd door attitudie en intentie (de laatste alleen voor fruitconsumptie). Subjectieve normen waren niet geassocieerd met groente- en fruitconsumptie. Er is geconcludeerd dat er rekening gehouden moet worden met bewustzijn van persoonlijk gedrag als de theorie van gepland gedrag wordt gebruikt om groente- en fruitconsumptie te verklaren. Een andere implicatie is dat gebrek aan bewustziin van eigen groente- en fruitconsumptie een belangrijke belemmering kan zijn voor de verhoging van groente- en fruitconsumptie.

In hoofo'stuk 5 wordt de vraag bestudeerd welke psychosociale factoren veranderingen in groente- en fruitconsumptie voorspellen. Psychosociale factoren die bij aanvang van het onderzoek werden gemeten. werden gebruikt om veranderingen in groente- en fruitconsumptie te voorspellen in de groep die gratis groente en fruit $\mathrm{kreeg}$. Veranderingen in fruitconsumptie van de moeders tijdens de periode van verhoogde beschikbaarheid waren positief geassocieerd met ervaren kosten en met de ervaren gezondheidswoordelen van fruitt voor hun kinderen, en negatief geassocieerd met de mate waarin men meent zijn gedrag te beheersen. Veranderingen in groenteconsumptie waren positief gerelateerd met de intentie om ten minste $200 \mathrm{~g}$ groente te eten en met smaakwoorkeuren van de kinderen. Veranderingen in groenteconsumptie een jaar na de periode van verhoogde beschikbaarheid waren positief gerelateerd aan de mate waarin men meent zijn gedrag te beheersen en ervaren gezondheidsvoordelen van groente voor de kinderen, en er was een aanwijzing dat de veranderingen negatief gerelateerd waren met de ervaren kosten van groente. Er is geconcludeerd dat consumptie van groente en fruit mogelijk gestimuleerd kan worden door de bovengenoemde factoren te beïnvloeden.

Gezinsgerelateerde determinanten van groente- en fruitconsumptie bij kinderen worden gerapporteerd in hoofdstuk 6. De fruitconsumptie van kinderen was positief gerelateerd met de fruitconsumptie van hun moeders, met strikte regeis binnen het gezin om groente en fruit te eten, met het in acht nemen van speciale leefregels met betrekking tot voeding, met de ervaren beschikbaarheid in huis van fruit en met het opleidingsniveau van de moeder. Kinderen met werkende moeders aten minder fruit dan kinderen met niel-werkende moeders. De graenteconsumptie van kinderen was positief gerelateerd met de groenteconsumptie van hun moeder en negatief gerelateerd met het volgen van leefregels met betrekking tot voeding. Veranderingen in fruitconsumptie van kinderen uit de experimentele groep waren met geen wan de bestudeerde variabelen geassocieerd. Veranderingen in groenteconsumptie waren lager bij kinderen uit gezinnen die een groentetuin hadden en hoger bij kinderen uit gezimnen waarwan de vader op onregelmatige tijclen werkte. Deze bevindingen wijzen erop dat een aantal gezinsgerelateerde factoren de groente- en fruitconsumptie van kinderen beïnvloeden. 
Interventie-effecten op carotenoïden, vitamine C, folacit en homocysteïne in plasma

De effecten van een verhoogde groente- en fruitconsumptie op concentraties carotenoilden, vitamine $C$. folaat en homocysteïne in plasma worden gerapporteerd in hoofdstuk 7 . De interventie van een maand leidde tot verhogingen in consumptie van 1,1 porties per dag ( $147 \mathrm{~g} / \mathrm{dag})$ voor fruit en 1,3 porties per dag $(68 \mathrm{~g} / \mathrm{dag})$ voor groente. Dit resulteerde in verhoogde plasmaconcentraties vitamine $C(+18 \%, 10,05 \mu \mathrm{mol} / \mathrm{L})$ en totaal carotenoilden $(+16 \%, 0,32 \mu \mathrm{mol} / \mathrm{L}$ ), evenals specifieke carotenoïden ( $\alpha$-caroteen $+12 \%$, $\beta$ caroteen $+17 \%$, luteíne $+23 \%$ en $\beta$-cryptoxanthine $+23 \%$ ) behalve lycopeen. De interventie leidde echter niet tot veranderingen in plasmaconcentraties folaat of homocysteine, waarschijnlijk door de relatief korte duur van de interventie. Deze bevindingen bevestigen dat carotenoilden en vitamine $C$ geschikt zijn als biomerkers voor groente- en fruitconsumptie. Wat betreft folaat lijkt in situaties waarin een snelle verhoging van folaatconcentraties in bloed wenselijk is, b.v. tijdens de zwangerschap "suppletie met foliumzuur een betere optie dan het eten van meer groente en fruit.

Implicaties van de bevindingen en aanbevelingen voor wetenschappelijk onderzoek en de praktijk met betrekking tot bepaling, determinanten en interventie-effecten van groente-en fruitconsumptie worden besproken in hoofdstuk 8 . In dit hoofdstuk worden ook methodologische overwegingen besproken waarmee rekening moet worden gehouden bij de interpretatie van de resultaten van dit project. 
Dankwoord en Curriculum Vitae 

De meeste mensen komen bij het lezen van een proefschrift niet veel verder den de samenvalting en het dankwoord, terwijl de tijd die hieraan besteed wordt slechts een duizendste deel is van de totale tijd dat een promotieonderzoek duurt. Gelukkig is er een aantal mensen die meer gelezen hebben en direct of indirect hebben bijgedragen aan de totstandkoming van 'het boekje'. Hen wil ik hieronder allereerst bedanken.

Pieter, als dagelijkse begeleider heb jij het meest met me gewerkt lk stelde het erg op prijs dat we wekelijks een bespreking hadden. Je hebt me veel geleerd over het schrijven van publicaties en het doen van onderzoek. Patricia, aan jou was de lastige tak een epidemioloog wegwijs te maken in de GVO. Mijn interesse in dit voor mij aanvankelijk nieuwe valkgebled is in de loop der tijd steeds groter geworden, wat mede jouw verdienste is geweest. Klaas, je had vanuit je eigen vakgebied een visie op het project en kon daardoor waardevolle opmerkingen plaatsen. Plet, we hebben elkaar vooral in de eindfase gesproken. $\| \mathrm{k}$ vind dat je goed op de hoogte was van mijn werk en daar goed commentaar op gaf. Aunold. als statistiekgoeroe binnen hel project heb je me onder andere geleerd dat er meer manieren zijn om data te analyseren, wat de statistiek ook een creatieve component geeft. Daarnaast heb je een goed gevoel voor humor! Hans, je bent een tijdlang als invaller voor Patricia opgetreden en in een belangrijke fase van het project een goede bijdrage geleverd. Ik vond het zeer prettig wan je deskundigheid te kunnen leren en met je samen te werken. Aalt, bedlankt voor de gelegenheild die je me thebt geboden om te werken in het lab van Toxicologie. Jan, dank voor je hulp bij het artikel over glezinsinvloeden en de interessante discussies die we daarover hadden. De leden van de beoordelingscommissie wil ik bedanken voor hun bereidheid mijn proefschrift kritisch te lezen.

Voedingsvragenlijsten stonden centraal in het onderzoek. Daarom will ik ook de mensen bedanken die me van advies voorzien hebben op het gebied van vragenlijsten en validering: Marga Ocké, Jeanne de Vries, Wija van Staveren en Jacob van Klaveren. Jacab, bedankt dat we de VEG-vragenlijst konden gebruiken. Gregor Franssen en Joldy Coenen: bedankt voor de hulp bij het lay-outen en inlezen wan de vragenlijsten.

Naar de prikassistentes en anderen die me geholpen hebben tijdens de periodes van bloedafnames gaat veel dank uit. Ook groothandel Brands die de groente- en fruitpakketten bij de deelnemers afleverde speelde een belangrijke rol. Tijdens hel labwerk bij Humane Biologie ben ik goed geholpen door Joan en Wendy. Joan, ik vond het gezellig op je lab en de carotenoidenanalyses waren een welkome afwisseling op het vele computerwerk. Marc Fischer wil ik bedanken voor de hulp bij de analyses op het lab van Toxicologie. De vele bloedmonsters die ik op het eind had moesten ergens worden opgeslagen en gelukikig was daar de Biobank: Hasibe, Corine, Poldi en Foekje bedankt!

Ik had het geluk om een aantal keer bijgestaan te worden door stagiaires. Linda en Willemieke, jullie kwamen in de drukste periode van het onderzoek. Ik heb jullie soms tot wanhoop gedreven met stapels brieven die verstuurd moesten worden. Jullie praktische en organisatorische vaardigheden waren van grote waarde! Dorien, bedankt voor het voorwerk dat je gedaan hebt voor het artikel over misconcepties. Marcella, de hplc werkte niet mee... ik zie ons nog eindeloos staren naar pieken die niet kwamen. Gelukkig hield je de moed erin on heb je goed werk afgeleverd.

Ook belangrijk om even bij still te staan is dat er zonder deelnemers geen onderzoek was geweest. Speciale dank gaat dus uit naar de moeders die de moeite hebben genomen om (soms tegen weinig vergoeding) de lange vragenlijsten in te vullen en bloed te laten prikken.

De tijd op de capaciteitsgroep Epidemiologie was aangenaam dankzij de collega's daar. Alle aio's will ik bedanken voor de gezelligheid, o.a. tijdens de aio-etentjes. Margreet, ik heb genoten van je verhalen over al je belevenissen; ik zou er een proefschrift mee kunnen vullen... Bedankt ook voor alle steun en interesse voor mijn werk en mij persoonlijk. Anita, bedankt voor de gezelligheid tijdens de eerste maanden. Luc, een kort gesprek bij de koffie leidde tot een mooie samenwerking en ik hoop de komende jaren nog veel onderwerpen met 
je 'door te lichten'. Nathalie, bedankt voor de hulp bij het lay-outen van het proefschrift. De mensen van het "voedingsoverleg" van GVO wil ik bedanken voor de interessante discussies en bereidheid mee te denken met mijn onderzoek. Mijn huidige collega's op het RIVM dank ik voor de prettige werkomgeving. Sylvia en Marie-.Josee, met jullie als kamergenoten jou voel ik me toch nog een beetje in het zuiden des lands!

Gie en Boukje, veel dank voor jullie inzet als paranimfen! Een promotie kost veel tijd maar gelukkig konden jullie me helpen met de voorbereidingen. Gie, ik vond het leuk dat we tijdens onze alo-periode samen een artikel geschreven hebben. Boukje, heb je Paradiso al geboekt voor ons gitaaroptreden?

Tot slot gaat er veel dank uit naar vrienden en vriendinnen die mijn leven buiten het werk hebben veraangenaamd. Zonder iedereen apart te noemen wil ik jullie bedanken voor de vele gezellige uren die we hebben doorgebracht, de getoonde interesse en ook de steun in moeillike tijden. Renate, we hebben de afgelopen jaren zoveel meegemaakt. Je hebt letterlijk en figuurlijk mijn horizon verbreed en me veel geleerd. Het proefschrift was belangrijk maar jij was nummer eén. Rob, Anita en Enide, jullie zag ik soms wat meer, soms wat minder tijdens mijn verblijf in het "buitenland'. Maar ik weet dat waar ik ook ben, ik altijd op jullie terug kan vallen en dat is van grote waarde. Bedankt! 
Roderik Pieter Bogers was born on 28 December 4974 in Leiderdorp, The Netherlands. He completed secondary school at College Hageveld in Heemstede in 1993 , after which he did a one-year course at the Vrije Hogeschool in Driebergen. In 1994 he started his studies in Human Nutrition at Wageningen University. As part of the training he fulfilled several internships, two of which were performed at the department of Human Nutrition and Epidemiology of Wageningen University and one at the department of Toxicalogy of the same university. He also spent a training period at the department of Preventive Medicine and Public Health of the University of Mälaga, Spain. He graduated in 1999.

From 2000 until 2004 Rik Bogers worked as a PhD student at the departments of Epidemiology, Health Promotion \& Education and Human Biology of the University of Maastricht. He conducted research on several aspects of fruit and vegetable consumption; this research is presented in this thesis. He presented parts of the research findings at several national and international meetings and conferences. Since September 2004 he works as a research scientist at the Centre of Prevention and Health Services Research of the Dutch National Institute for Public Health and the Environment. 